\title{
Returning to the roots: resolution, reproducibility, and robusticity in the phylogenetic inference of Dissorophidae (Amphibia: Temnospondyli)
}

\author{
Bryan M Gee ${ }^{\text {Corresp. } 1}$ \\ ${ }^{1}$ Burke Museum and Department of Biology, University of Washington, Seattle, WA, United States \\ Corresponding Author: Bryan M Gee \\ Email address: bmgee@uw.edu
}

The phylogenetic relationships of most Paleozoic tetrapod clades remain poorly resolved, which is variably attributed to a lack of study, the limitations of inference from phenotypic data, and constant revision of best practices. While refinement of phylogenetic methods continues to be important, any phylogenetic analysis is inherently constrained by the underlying dataset that it analyzes. Therefore, it becomes equally important to assess the accuracy of these datasets, especially when a select few are repeatedly propagated. While repeat analyses of these datasets may appear to constitute a working consensus, they are not in fact independent, and it becomes especially important to evaluate the accuracy of these datasets in order to assess whether a seeming consensus is robust. Here I address the phylogeny of the Dissorophidae, a speciose clade of Paleozoic temnospondyls. This group is an ideal case study among temnospondyls for exploring phylogenetic methods and datasets because it has been extensively studied (eight phylogenetic studies to date) but with most (six studies) using a single matrix that has been propagated with very little modification. In spite of the conserved nature of the matrix, dissorophid studies have produced anything but a conserved topology. Therefore, I analyzed an independently designed matrix, which recovered less resolution and some disparate nodes compared to previous studies. In order to reconcile these differences, I carefully examined previous matrices and analyses. While some differences are a matter of personal preference (e.g., analytical software), others relate to discrepancies with respect to what are currently considered as best practices. The most concerning discovery was the identification of pervasive dubious scorings that extend back to the origins of the widely propagated matrix. These include scores for skeletal features that are entirely unknown in a given taxon (e.g., postcrania in Cacops woehri) and characters for which there appear to be unstated working assumptions to scoring that are incompatible with the character definitions (e.g., scoring of taxa with incomplete skulls for characters based on skull length). Correction of these scores and other pervasive errors recovered a distinctly less Peer) reviewing PDF | (2021:02:58550:3:0:NEW 7 Oct 2021) 
resolved topology than previous studies, more in agreement with my own matrix. This suggests that previous analyses may have been compromised, and that the only real consensus of dissorophid phylogeny is the lack of one. 
1 Returning to the roots: resolution, reproducibility, and 2 robusticity in the phylogenetic inference of Dissorophidae 3 (Amphibia: Temnospondyli)

10 Corresponding author:

11 Bryan Gee

12 UW Biology, Box 351800, Seattle, WA, 98195-1800, USA

13 Email address: bmgee@uw.edu 
15

16

17

\section{Abstract}

The phylogenetic relationships of most Paleozoic tetrapod clades remain poorly resolved, which is variably attributed to a lack of study, the limitations of inference from phenotypic data, and constant revision of best practices. While refinement of phylogenetic methods continues to be important, any phylogenetic analysis is inherently constrained by the underlying dataset that it analyzes. Therefore, it becomes equally important to assess the accuracy of these datasets, especially when a select few are repeatedly propagated. While repeat analyses of these datasets may appear to constitute a working consensus, they are not in fact independent, and it becomes especially important to evaluate the accuracy of these datasets in order to assess whether a seeming consensus is robust. Here I address the phylogeny of the Dissorophidae, a speciose clade of Paleozoic temnospondyls. This group is an ideal case study among temnospondyls for exploring phylogenetic methods and datasets because it has been extensively studied (eight phylogenetic studies to date) but with most (six studies) using a single matrix that has been propagated with very little modification. In spite of the conserved nature of the matrix, dissorophid studies have produced anything but a conserved topology. Therefore, I analyzed an independently designed matrix, which recovered less resolution and some disparate nodes compared to previous studies. In order to reconcile these differences, I carefully examined previous matrices and analyses. While some differences are a matter of personal preference (e.g., analytical software), others relate to discrepancies with respect to what are currently considered as best practices. The most concerning discovery was the identification of pervasive dubious scorings that extend back to the origins of the widely propagated matrix. These include scores for skeletal features that are entirely unknown in a given taxon (e.g., postcrania in Cacops woehri) and characters for which there appear to be unstated working assumptions to scoring that are incompatible with the character definitions (e.g., scoring of taxa with incomplete skulls for characters based on skull length). Correction of these scores and other pervasive errors recovered a distinctly less resolved topology than previous studies, more in agreement with my own matrix. This suggests that previous analyses may have been compromised, and that the only real consensus of dissorophid phylogeny is the lack of one.

\section{Introduction}

Inferring phylogenetic relationships remains one of the most timeless pursuits within paleontology. The persistence of such studies owes to: (1) the great importance of phylogeny as the macroevolutionary framework within which all other studies are situated; and (2) the probable lability of any given topology when it relies entirely on morphological data and the discretization of continuous traits. While there is broad interest in exploring clade-independent practices that are applicable to a broad range of studies (e.g., comparison of likelihood and parsimony methods, approaches to missing data and polymorphisms), it is equally important to critically examine empirical datasets in order to assess their robusticity and reproducibility and to seek to improve them whenever possible.

One longstanding practice is the propagation of an existing matrix with modifications, at minimum by adding taxa of interest, and possibly more substantially by changing scores and character sampling. In this, there is an implicit goal of developing a semblance of a consensus matrix that the majority of workers have worked with (not necessarily within the confines of a single collaboration) and therein agree (or assume) is well-designed to test the relationships of a given in-group. However, in propagating a matrix, each derivate is inherently a pseudoreplicate 
60 (non-independent), especially when changes are minimal beyond taxon addition. While

61 propagation creates consistency between analyses, it also constrains the possible outcomes unless

62 substantial changes are made. If a consensus emerges from such a matrix, it must be assessed

63 whether this is a truly defensible consensus. The easiest way to test this is with a novel

64 (independent) matrix, assuming that the set of characters and their scoring do not substantially

65 overlap with (converge on) those of previous matrices. Conversely, if no consensus emerges

66 from repeated propagation of a largely unchanged matrix, this is perhaps even more troubling, as

67

68 it indicates that most topologies are labile and thus should not be relied upon heavily for qualitative discussion or for integration into other studies.

This study focuses on the phylogenetic relationships of Dissorophidae, a clade of dissorophoid temnospondyls (Fig. 1), as a case study in phylogenetic analyses of temnospondyls. Temnospondyli, often referred to as 'amphibians' (nonamniote tetrapods in a broad historical sense and as the putative amphibian stem-group in more recent works), is best known for the clade's longstanding role in the unresolved debate over lissamphibian origins. This ongoing debate has drawn extensive attention in recent decades (e.g., Laurin \& Reisz, 1997; Anderson, 2001; McGowan, 2002; Ruta, Coates \& Quicke, 2003; Vallin \& Laurin, 2004; Lee \& Anderson, 2006; Carroll, 2007; Ruta \& Coates, 2007; Anderson et al., 2008a; Pyron, 2011; Sigurdsen \& Green, 2011; Pardo, Small \& Huttenlocker, 2017; Marjanović \& Laurin, 2019; Daza et al., 2020; Schoch, Werneburg \& Voigt, 2020). Workers interested in this topic have largely focused on Amphibamiformes, another dissorophoid clade, as the likely candidate within Temnospondyli. However, outside of this context, the phylogeny of most temnospondyl clades has received scant attention. Nonetheless, the intrarelationships of temnospondyls are of inherent import for this debate, especially with the recent proposal of a diphyletic origin of Lissamphibia from within Temnospondyli (Pardo, Small \& Huttenlocker, 2017). Furthermore, with the increasing tractability of so-called "big data" studies with wide taxonomic breadth that are rooted in phylogenetic backbones, the phylogenetic relationships of these clades have acquired new import beyond the narrow scope of taxonomic specialists. Temnospondyls are both an excellent case study and an area in need of redress because they are not regarded as 'charismatic taxa' and thus suffer from a paucity of workers. As a result, certain workers or working groups may inadvertently exert disproportionate influence on the study of a given clade, which, in phylogenetics, manifests as one worker's matrix rapidly becoming the only utilized matrix.

Dissorophids, a clade of dissorophoids only peripherally related to the lissamphibian origins debate, are an ideal case study within Temnospondyli. Firstly, the clade is very speciose, with over 20 nominal species. The anatomical foundation is well-established for most of these taxa, with nearly 20 studies published in the $21^{\text {st }}$ century alone. As a result, there is a more substantive history of phylogenetic inquiry into dissorophids than for less speciose Paleozoic clades, such as eryopids or zatracheids. To date, there have been eight studies that addressed the phylogeny of Dissorophidae (Fröbisch \& Reisz, 2012; Schoch, 2012; Holmes, Berman \& Anderson, 2013; Maddin et al., 2013; Schoch \& Sues, 2013; Liu, 2018; Dilkes, 2020; Gee et al., 2021). However, nearly all of them derive from the same source matrix (Schoch, 2012; Fig. 2)

100 and are nearly identical in scoring, taxon sampling, and character sampling. Surprisingly, there is 101 widespread disparity between their recovered topologies (Figs. 3-4). As remarked upon by 102 Dilkes (2020:26), "results of recent attempts to unravel the phylogeny of dissorophids, even though they are using modified and hopefully updated versions of the same matrix, have consistently shown a lack of agreement on a broader pattern of dissorophid relationships with poor resolution and low support for most nodes that are present in a strict consensus tree." The 
106 situation of dissorophids can be characterized as a largely consistent matrix producing largely

107 inconsistent results. Finally, the study of dissorophids is relevant for other studies. Dissorophids

108 are a common outgroup for amphibamiform studies, whether in comparative anatomical

109 descriptions or in quantitative studies (e.g., Pérez-Ben, Schoch \& Báez, 2018; Atkins, Reisz \&

110 Maddin, 2019). Additionally, as ubiquitous components of Early Permian terrestrial ecosystems,

111 dissorophids (and their sister group, Trematopidae), are frequently sampled in broader studies of

112 Paleozoic tetrapods at large (e.g., Brocklehurst et al., 2018; Dunne et al., 2018; Pardo et al.,

113 2019).

114 I previously addressed the phylogeny of Trematopidae, the sister group to Dissorophidae

115 (collectively Olsoniformes; Anderson et al., 2008b), which is less studied and for which there

116 also remains no consensus (Gee, 2020b; Fig. 5). A key aspect of my previous study was

117 demonstrating how taxon sampling (and more specifically, selective exclusion) can drastically

118 improve or alter topological resolution. Previous olsoniform studies have either focused on

119 dissorophids or trematopids - there has never been a matrix that evenly samples these clades as a

120 collective in-group. The closest approximation is Atkins, Reisz \& Maddin (2019), a derivate of

121 Schoch (2018a) that samples six of the 10 trematopids (deficient in Carboniferous taxa as with

122 other studies) and 11 dissorophids. Schoch's (2018a) dissorophoid matrix is in turn derived from

123 Schoch's (2012) dissorophid matrix, though with a different taxon sample than that of Atkins,

124 Reisz \& Maddin.

125

126

127

In this study, I expand the taxon and character sampling of my previous trematopidcentric matrix to encompass dissorophids, thereby forming such a matrix. I opted to use my matrix as the foundation, rather than the long-propagated dissorophid matrix of Schoch (2012) or

128

129

130

131

132

133

134

135

136

137

138

139

140

141

142

143

144 more modified derivates like that of Schoch (2018a). This decision was motivated by a desire to approach these questions from as independent of a perspective as possible and in light of the markedly disparate topologies of different derivates of Schoch's matrix despite the matrix's conserved nature. While it broadly samples Olsoniformes, this study is targeted primarily towards dissorophids simply because I have recently focused on trematopids. There are three primary objectives: (1) to test whether this independent matrix can produce either better resolution or stronger nodal support compared to previous studies and in turn to interpret that resolution; (2) to assess factors that might contribute to potentially spurious resolution in analyses that recover a high degree of resolution or that confound recovery of resolution in analyses that recover a low degree of resolution; and (3) to summarize the present state of Dissorophidae and to identify key areas in need of redress in order to work towards a consensus.

\section{Materials \& Methods}

Taxon sampling. I sampled the vast majority of olsoniforms, with all ten of the undisputed trematopid species carried over from my previous analysis (Gee, 2020b). Acheloma dunni is regarded as a junior synonym of Acheloma cumminsi, and their scores are thus merged here. Phonerpeton whitei is excluded on the basis of a suspect differentiation from Phonerpeton pricei, which stems from the absence of detailed description or illustration. I expanded the sample to include most dissorophids, the recently described olsoniform Palodromeus bairdi (Schoch, Hook \& Henrici, 2020), and the putative 'basal' dissorophoid Perryella olsoni (Table 1).

In my previous study, I scored practically every published and figured trematopid

151 specimen. I opted for a more selective approach in adding dissorophids, and the trematopid specimen-level OTUs are not carried over. The main reason is that many dissorophid specimens 
152 consist only of neural spines and osteoderms (e.g., DeMar, 1966b; May et al., 2011; Gee, Bevitt

$153 \&$ Reisz, 2019) and can only be scored for a handful of characters $(<10 \%)$. Dissorophid taxa that

154 are excluded in their entirety are: Aspidosaurus glascocki, "Aspidosaurus" apicalis,

155 "Aspidosaurus" crucifer, "Aspidosaurus" peltatus, and Astreptorhachis ohioensis. Very

156 fragmentary cranial remains or those without sutures were excluded unless they were the

157 holotype of a valid taxon (e.g., Broiliellus arroyoensis), as similar specimens were frequently

158 problematic in my trematopid analysis. This exclusion includes the holotypes of "Fayella

159 chickashaensis" and "Trematopsis seltini," both too poorly preserved to be scored, and two

160 junior synonyms of D. multicinctus, "Otocoelus mimeticus" and "Otocoelus testudineus," both

161 characterized only by relatively brief and dated descriptions (Cope, 1896a, 1896b). The only

162 holotype of a junior synonym that is sampled here is "Longiscitula houghae" $(=D$. multicinctus)

163 because its cranial sutures are well-described and figured (DeMar, 1966a; Milner, 2003).

164 Additionally, testing interspecific ontogenetic disparity in dissorophids was not a focus of this

165 study (addressed in the Discussion), and therein assessing whether the matrix could detect

166 intraspecific ontogenetic variation as a proof of concept was not as essential. Almost two-thirds

167 of dissorophids are represented only by the holotype in any event. I did run one analysis to assess

168 this, and thus Anakamacops petrolicus, Cacops morrisi, Cacops woehri, and Conjunctio

169 multidens are scored at the specimen level.

$170 \quad$ Schoch \& Milner (2014) listed several taxa as possible early-diverging dissorophoids: Macrerpeton huxleyi from the Late Carboniferous of Ohio; Parioxys ferricolus and Parioxys bolli from the Early Permian of Texas; Perryella olsoni from the Early Permian of Oklahoma; and Stegops newberryi from the Late Carboniferous of Ohio. Parioxys ferricolus and $S$. newberryi are in need of redescription. Parioxys bolli (Carroll, 1964b) is included to test the performance of an exclusively postcranial skeleton (the holotype and only known specimen). Perryella olsoni is included, but its position should only be interpreted in light of assumed dissorophoid affinities. Ruta \& Bolt (2006) considered it to be a dvinosaur and recovered it as such in a broad analysis of Paleozoic temnospondyls, while Schoch (2018a) recovered it as the sister taxon to Dissorophoidea but in a dissorophoid-focused analysis with only one dvinosaur taxon. Schoch \& Milner (2021) recently recovered M. huxleyi as the sister-group of all other dissorophoids (what they term a "stem dissorophoid") diverging before $P$. olsoni, so the former is not sampled here. 'Broiliellus hektotopos' from the Early Permian of Ohio was described as a dissorophid (Berman \& Berman, 1975), but it has never been included in an analysis and is probably an amphibamiform (May et al., 2011), following Romer's (1952) initial interpretation of the holotype as a "branchiosaur." I included the holotype to test this in a phylogenetic framework.

The non-olsoniform outgroups were carried over from Gee (2020b): the amphibamiforms Doleserpeton annectens, Eoscopus lockardi, Pasawioops mayi, and Tersomius texensis, and the micromelerpetid Micromelerpeton credneri. The same non-dissorophids were included (Dendrysekos helogenes, Eryops megacephalus) but with Chenoprosopus milleri (Langston, 1953) replacing Chenoprosopus lewisi to better sample palatal characters. I replaced my previous functional outgroup, the anthracosaur Proterogyrinus scheelei, with the colosteid Greererpeton burkemorani (Smithson, 1982; Godrey, 1989a, 1989b; Bolt \& Lombard, 2001) because the latter's preservation allows it to be confidently scored for more characters without relying on reconstructions (e.g., skull length-based characters), but scores for $P$. scheelei were still updated. 
197 Character sampling. The character matrix was derived from that used in my trematopid 198 analysis (Gee, 2020b), and characters are listed in Appendix 1. Additional characters were added 199 to differentiate between dissorophids. I removed five characters (Appendix 2) and split one 200 character (lateral exposure of the palatine; LEP) into two characters. There are a total of 109

201

202

203

204

205

206

207

208

209

210

211

212

213

214

215

216

217

218

219

220

221

222

223

224

225

226

227

228

229

230

231

232

233

234

235

236

237

238

239

240

241

242 characters; multi-state characters that can be hypothesized to be ordered in an evolutionary sense were ordered here. The decision to order certain characters follows other workers (e.g., Marjanović \& Laurin, 2019), including other dissorophid studies (e.g., Dilkes, 2020), and is motivated by two factors: (1) that leaving characters unordered is neither neutral nor a lack of assumption, as unordered characters imply that transitions between all states are equally likely (e.g., Slowinski, 1993; Wiens, 2001); and (2) that various studies have shown that ordering characters tends to improve the ability to recover genuine clades and to increase topological resolution (e.g., Fröbisch \& Schoch, 2009; Grand et al., 2013; Rineau et al., 2015; Simões et al., 2017; Rineau, Zaragüeta i Bagils \& Laurin, 2018). Of the 18 multistate characters, 15 were ordered $(2,4,11,18,20,28,31,38,51,68,70,84,99,104,107)$; characters 19, 88, and 98 are left unordered. Characters were equally weighted.

Character scoring. Scores were carried over at the species level from Gee (2020b) unless noted in Appendix 2. Scoring was based strictly on the literature, and reconstructions were not utilized. Scoring of species-level operational taxonomic units (OTU) accounted for any polymorphisms that are not clearly attributable to ontogeny. Anatomical differences correlated with very slight size differences were treated more skeptically than those correlated with large size gaps in determining whether to code a condition as polymorphic or only for the inferred 'adult' condition. Comments on scoring approaches to specific characters and the treatment of taxa for which a character can only be scored from an immature specimen are provided in Appendix S2 of Gee (2020a) and in Appendix 3 here. The matrix was compiled in Mesquite version 3.6b917 (Maddison \& Maddison, 2020) and is provided as a NEXUS file in Appendix 4.

I want to make particular mention of Kamacops acervalis here because it is difficult to reconcile its historical scoring with existing descriptions, figures of which are either reconstructions in palatal and lateral view or close-up illustrations of the occiput and braincase (Gubin, 1980; Schoch, 1999). The detailed discussion is relegated to Appendix 3, but I emphasize a few key points here because this taxon in particular (or rather, uncertainty over the taxon) influenced the design of the analyses that I conducted here.

The only published photograph of any specimen is a snout (Schoch \& Milner, 2014:fig. $37 \mathrm{E}$ ), which does not show any clear sutures. This taxon has also been reconstructed as a silhouette in dorsal view but without sutures by Schoch (2012:fig. 6), in contrast to most other dissorophids. Therefore, it is strange that there are cranial characters scored for this taxon (e.g., prefrontal-postfrontal suture). Additionally, none of the specimens of Kamacops acervalis is even half-complete, and without photographs, it is unclear how much skeletal overlap exists between specimens, therein questioning the fidelity of the reconstructions. This is particularly important because the reconstruction is the only means of scoring characters involving skull length, including two of the three characters that differentiate $K$. acervalis from Cacops. At present, many of the historic scores cannot be reconciled with the literature. Schoch indicated that he personally examined material of this taxon, so it is possible that he identified new features, but the data to support the scoring of many characters are not established in the literature. Therefore, I constructed two different species-level OTUs for this taxon. The first is termed the 'conservative' OTU and scores only based on the explicit descriptions and specimen 
243 illustrations (but not reconstructions) of Gubin (1980) and Schoch (1999). The second is termed

244 the 'reconstructed' OTU and augments the previous one with data from reconstructions; this led

245 to the scoring of an additional 20 characters. In neither OTU are skull roof sutures scored except

246 in the occipital region, so both OTUs are underscored compared to previous studies.

247

248

249

250

251

252

253

254

255

256

257

258

259

260

261

262

263

264

265

266

267

268

269

270

271

272

273

274

275

276

277

278

279

280

281

282

283

284

285

286

287

288

Phylogenetic analysis. I elected to perform only maximum parsimony analyses of the data matrix; the topologies recovered by a simple non-clock Bayesian analysis in my previous study (Gee, 2020b) did not differ substantially from those recovered by the parsimony analyses. Most discrepancies were related to additional resolution recovered in the Bayesian analysis only on account of the overestimation of support of posterior probabilities compared to bootstrap value (e.g., Alfaro, Zoller \& Lutzoni, 2003; Cummings et al., 2003; Douady et al., 2003; Erixon et al., 2003; Simmons, Pickett \& Mia, 2004; Zander, 2004).

The analyses were primarily performed in TNT v1.5 (Goloboff \& Catalano, 2016). For analyses with more than 30 taxa, I used a heuristic search ("traditional search" in TNT) with the following parameters: 10,000 random addition sequence replicates, holding 10 trees at each step, and tree-bisection-and-reconnection (TBR). All sets of MPTs were then used as the starting trees for a second round of branch swapping to obtain the final set of MPTs. For analyses with 30 or fewer taxa, a branch-and-bound ("implicit enumeration" in TNT) search was used. Default settings of TNT (e.g., rule 1 for branch collapsing: min. length $=0$ ) were otherwise maintained. I performed 10,000 bootstrap replicates with a heuristic search to assess absolute nodal support for all analyses. Given the intensive computation time of branch-and-bound searches, I elected to use heuristic searches to calculate Bremer decay indices after confirming that a heuristic search recovered the same set of MPTs as the branch-and-bound search. TNT was selected for its ability to rapidly process large datasets, which was a concern for analyses with species-level OTUs that have high proportions of missing data (as with some of the dissorophids here); no search (or resampling) exceeded nine hours. I used PAUP* 4.0a169 (Swofford, 2021) for several analyses that mirrored previous analyses conducted in PAUP*. The more taxonomically restricted TNT analyses can be run within PAUP* (no search exceeded 36 hours), although these analyses were consistently more costly, and bootstrapping could exceed 48 hours. One noteworthy difference is that to the best of my knowledge (based on the associated publications and other online resources), TNT cannot handle partial uncertainty (or at least the syntax used for this in NEXUS files is incompatible). These scores were thus changed to polymorphisms encompassing the possible character states in TNT analyses (e.g., a partial uncertainty score of ' $\left\{\begin{array}{l}0 \\ 1\end{array}\right\}$ ' was scored as '[ $\left[\begin{array}{l}0 \\ 1\end{array}\right]$ ' in TNT; this is how Mesquite treats partial uncertainty when exporting a NEXUS file to TNT). These are computationally the same but with an additional step added to the tree for each polymorphism compared to a partial uncertainty. All analyses were performed on a personal computer (MacBook Pro, 2015 model, 16 GB of RAM, macOSMojave 10.14.5).

As with my previous study, I performed a large number of analyses (Table 2). Almost all of the trematopid analyses were determined a priori, but because the focus of this study was different, most of these analyses were only determined after examining previous results. The first four analyses broadly sample Olsoniformes and have an eye towards testing topology using standard historical methods (e.g., sampling all taxa, removal of wildcards), whereas the last five analyses relate more to assessing possible sources of disparity between previous studies.

1. Analysis 1A (all olsoniforms): all presently valid species that I scored are sampled here at the species level. Taxa: 47. 
294

295

296

297

298

299

300

301

302

303

304

305

306

307

308

309

310

311

312

313

314

315

316

317

318

319

320

321

322

323

324

325

326

327

328

329

330

331

332

333

334

2. Analysis 1B (wildcard removal): an Adams consensus was used to identify wildcard taxa in the previous analysis (method for identifying wildcards is listed in the Results). The analysis was subsequently rerun without these wildcards. Taxa: 30 / 33 (number differs due to different wildcard identification).

3. Analysis 2 (best representatives): this analysis follows historic approaches by excluding poorly known taxa, which are arbitrarily defined as having either an overall low percentage of scoreable features or a low percentage specifically for cranial characters. The sampling thus omits any taxon for which cranial sutures are unknown: Aspidosaurus chiton, Broiliellus arroyoensis, Iratusaurus vorax, Parioxys bolli, and Zygosaurus lucius. Cranial material of Aspidosaurus novomexicanus, Brevidorsum profundum, Diploseira angusta, Kamacops acervalis, and Nooxobeia gracilis is relatively fragmentary, and these taxa are also excluded. Of the exclusions, $B$. profundum, $K$. acervalis, and Z. lucius were usually sampled in previous studies. All non-dissorophids are sufficiently characterized to be retained. Taxa: 37.

4. Analysis 3 (dissorophid-focused): this analysis samples almost every nominal dissorophid but with a trimmed subset of trematopids, as would commonly be done for dissorophid-focused analyses (e.g., Schoch, 2012, and derivates thereof). I excluded Actiobates peabodyi, Mordex calliprepes, and Rotaryus gothae as taxa probably represented only by markedly immature specimens (these are the smallest trematopids). 'Broiliellus' hektotopos and Parioxys bolli were excluded since they were recovered well outside Dissorophidae in previous analyses. Taxa: 42.

I ran one analysis with specimen-level dissorophid OTUs to assess whether the matrix can resolve intraspecific ontogeny in dissorophids.

5. Analysis 4 (cacopine specimen-level OTU): this analysis focuses on Anakamacops petrolicus, the three species of Cacops, and Conjunctio multidens, for which at least two specimens can be scored. Based on my trematopid analyses, poorly preserved or highly fragmentary specimens were clear confounds. Therefore, I omitted highly fragmentary referred material (like the two partial snouts referred to Ca. woehri by Gee, Bevitt \& Reisz, 2019; ROMVP 80800, ROMVP 80801) and material without sutures (like the holotype and paratype of Ca. aspidephorus; FMNH UC 647, FMNH UC 649). Iratusaurus vorax and Zygosaurus lucius are entirely excluded on the same grounds. Species-level dissorophid OTUs are restricted to Broiliellus brevis, Dissorophus multicinctus and Kamacops acervalis. Non-olsoniforms include Chenoprosopus milleri, Dendrysekos helogenes, Doleserpeton annectens, Eoscopus lockardi, and Eryops megacephalus, and the outgroup, Greererpeton burkemorani. OTUs: 32 .

The third set of analyses relate to taxon sampling. As with my previous study, I ran so-called "mirror analyses" in which I took the taxon sample of a previous study and the character sample and scoring of my own study.

6. Analysis 5 (taxon mirror of Dilkes, 2020): this analysis mirrored the taxon sample of Dilkes (2020). Because not all equivalent taxa are found in my matrix, I replaced Sclerocephalus haeuseri with Eryops megacephalus and Platyrhinops lyelli with 
Eoscopus lockardi. Dendrysekos helogenes was utilized as the outgroup. I used the 'reconstructed' OTU of Kamacops acervalis to approximate the historic scoring of this taxon. Although I intended to mirror all of Dilkes' parameters in PAUP*, a preliminary run with a branch-and-bound search produced no progress after 24 hours. This is not surprising as 29 taxa are already above the typical threshold for running this search. Therefore, I ran a heuristic search with 10,000 random addition sequence replicates, holding 10 trees per step; all other settings, including the bootstrapping, were mirrored where possible. I then removed the four wildcard taxa that Dilkes identified and reran the analysis; this trimmed sample was recognized to be tractable with a branch-and-bound search. Taxa: 29 (25 without wildcards).

7. Analysis 6 (taxon mirror of Gee, 2020b): this analysis mirrored the taxon sample of Gee (2020b). Acheloma and Phonerpeton are treated as discussed above. I used Proterogyrinus scheelei as the outgroup (as with the original study) and excluded Greererpeton burkemorani. In order to account for the adjusted scoring of $A$. cumminsi and the exclusion of $P h$. whitei, I reanalyzed my original matrix with the revised treatments of these taxa but with the original scoring otherwise intact. Since only one OTU was changed, the revised string for Acheloma cumminsi (inclusive of data from Acheloma dunni) is provided in Appendix 2 rather than in a separate NEXUS file. Taxa: 23.

The next analysis resulted from a close examination of previous scores of the Schoch (2012) matrix and its derivates in which I identified a large number of cells that either were scored for features that are definitively unknown (e.g., postcrania of Cacops woehri) or that were unscored but that are definitely known (e.g., palatal features of Fedexia striegeli). Most of the cells that were spuriously scored are scored identically to other members of a presumed close relative by Schoch (e.g., questionable scores of Cacops aspidephorus were scored identical to those of Cacops morrisi), although some were introduced by Holmes, Berman \& Anderson (2013; e.g., all questionable scores of $C$. woehri were scored identical to at least one other species of Cacops). This observation suggests that some scores have been "assumed," but not actually observed, based on inferred relatedness, a troubling prospect.

8. Analysis 7 (updated version of Dilkes, 2020): this analysis is a direct reanalysis of Dilkes' matrix with updated scores that focused on cells where the scoring or lack thereof seems unequivocally erroneous. The primary objective therein is to strictly examine the influence of dubious scorings on the matrix. I did not adjust scores unless there was strong evidence against the current score, so subjective decisions (e.g., is an atlas-axis sufficient postcranial representation to determine the absence of osteoderms in Fedexia striegeli) were not changed. I only rescored cells for polymorphisms when this condition was not clearly linked to size variation and was unequivocally non-taphonomic. One note is that the Acheloma of this matrix is specifically "Acheloma dunni"; I only updated scores based on material referred to this junior synonym (Maddin, Reisz \& Anderson, 2010; Polley \& Reisz, 2011). This differs from my own matrix in which Acheloma cumminsi is scored from both originally referred material and that of "A. dunni," a junior synonym (Gee, 2020b). Changes were not made to taxon sampling, character sampling, or character construction (including ordering), even though certain characters of Dilkes' matrix 
(e.g., palpebral ossifications) are intentionally excluded in my own matrix. These approaches minimize personal scoring philosophy and should provide an acceptable derivate of this matrix should other workers continue to use it. Any restored scores will have to be justified with appropriate data. All scoring changes are listed and justified in Appendix 5, and the revised matrix is provided as Appendix 6. The analysis was rerun in PAUP* following Dilkes' parameters. Note that I first analyzed Dilkes' original matrix in PAUP* as well to ensure that my program settings recovered the same results.

Finally, when considering explanations for disparity in the degree of resolution and the placement of wildcard taxa, I observed that different programs have been used to examine the Schoch (2012) matrix and its derivates. Schoch (2012), Holmes, Berman \& Anderson (2013), Maddin et al., (2013), and Dilkes (2020) used PAUP*, whereas Schoch \& Sues (2013) and Liu (2018) used TNT. The analyses using TNT have recovered more resolution in the strict consensus and without any wildcards. It is known that these programs' algorithms and default settings differ, but studies rarely compare the results obtained by analyzing the same matrix. Therefore, I performed two analyses that analyze the same matrix with each program; I term these "parallel analyses." These analyses are not intended to test whether one program's settings and results can be reproduced in the other but rather to test whether default parameters and algorithmic differences (usually default settings are employed by other workers) produce different results.

9. Analysis 8 (parallel of trematopid mirror): this analysis parallels Analysis 6 (trematopid-focused sample, analyzed using TNT) in PAUP*; this analysis was chosen because it achieved a measurable degree of resolution in TNT and has a low taxon sample that would make it tractable for a branch-and-bound search in PAUP*.

10. Analysis 9 (parallel of Dilkes, 2020): this analysis parallels the original results of Dilkes (2020) and the updated version of that matrix that I analyzed in Analysis 7 , both using TNT (Dilkes ran his analysis in PAUP*). Dilkes ran three analyses with a branch-and-bound search: a full taxon sample, a full taxon sample with osteoderm characters removed, and a reduced taxon sample without wildcards but with the full character sample. I paralleled the two with the full character sample. The iterations comparing different programs' analysis of Dilkes' original matrix are termed Analysis 9A, and the iterations comparing the TNT analysis of the original and updated versions of Dilkes' matrix are termed Analysis 9B.

Two nomenclatural notes. The dissorophid subfamily defined by all taxa more closely related to Cacops aspidephorus than to Dissorophus multicinctus has a complex history. Cacops was historically referred to Aspidosaurinae (e.g., Williston, 1914; DeMar, 1966b; Milner, 2003; Witzmann \& Soler-Gijón, 2010). However, Daly (1994) considered the poorly known Aspidosaurus to be a dissorophine, making Aspidosaurinae a junior synonym of Dissorophinae and necessitating a new name for historical aspidosaurines that could not be placed in Dissorophinae (like Cacops); to this end, she coined the name 'Cacopinae.' However, Daly did not substantiate her classification, so Cacopinae was unused until the study of Schoch \& Rubidge (2005), who used it as a terminal OTU (of Cacops aspidephorus + Kamacops acervalis); note that this study did not include Aspidosaurus. The use of Cacopinae was then followed by nearly 
427 all subsequent workers (except Witzmann \& Soler-Gijón, 2010) but with the original source only 428 noted by Berman et al. (2010). The name was then changed to Eucacopinae by Schoch \& Sues

429

430

431

432

433

434

435

436

437

438

439

440

441

442

443

444

445

446

447

448

449

450

451

452

453

454

455

456

457

458

459

460

461

462

463

464

465

466

467

468

469

470

471

472 (2013), who noted that Cacopinae, the proper derivation from Cacops, was preoccupied for a group of microhylid frogs named for "Cacopus" (=Uperodon) per Noble (1931); Cacopinae sensu Noble became a junior synonym of Microhylinae. The erection of Eucacopinae was considered to be the appropriate solution by Schoch and Sues. However, as has been brought to my attention by David Marjanović, there are two fundamental flaws with this nomenclatural act. The first is that per Article 11.7.1.1 of the International Code of Zoological Nomenclature (ICZN, 1999), family names 'must be [...] formed from the stem of an available generic name,' but there is no genus bearing the name 'Eucacops' or something similar. Furthermore, Noble's (1931) derivation of 'Cacopinae' from 'Cacopus' only includes part of the stem (which is 'Cacopod,' not 'Cacop'), and, per the same article, is unavailable. Therefore, Cacopinae Daly, 1994, is both the valid derivation from Cacops and not preoccupied, so it need not be replaced. Schoch (2018a), Atkins, Reisz \& Maddin (2019), Anderson, Scott \& Reisz (2020), and Schoch $\&$ Milner (2021) recently employed Cacopinae, without comment, which I follow here.

Cacopinae may yet prove to be a junior synonym of Aspidosaurinae, but this is not supported by the following results of this study.

Also as pointed out to me by David Marjanović, Platyhystrix is feminine (following the gender of 'hystrix'), and therefore, when Ctenosaurus rugosus Case, 1910, was transferred to Platyhystrix Williston, 1911, nomenclatural standards dictated that it be changed to Platyhystrix rugosa (per Article 34.2 of the ICZN), even though this was not actually put into practice until this study, over a century later. This change is implemented throughout this manuscript.

Institutional abbreviations. AMNH FARB, American Museum of Natural History, Fossil Amphibians, Reptiles, and Birds, New York, NY; BMRP, Burpee Museum of Natural History, Rockford, IL; CM, Carnegie Museum, Pittsburgh, PA; FMNH, Field Museum of Natural History, Chicago, IL; ICGAS, Institute of Geology, Chinese Academy of Geological Sciences, Beijing, China; IVPP, Institute of Vertebrate Paleontology and Paleoanthropology, Chinese Academy of Sciences, Beijing, China; MCZ, Museum of Comparative Zoology, Cambridge, MA; OMNH, Sam Noble Oklahoma Museum of Natural History, Norman, OK; ROMVP, Royal Ontario Museum, Vertebrate Paleontology, Toronto, Canada; UCMP, University of California Museum of Paleontology, Berkeley, CA; UMMP, University of Michigan Museum of Paleontology, Ann Arbor, MI.

\section{Results}

My reporting practices are outlined here to reduce redundancy. Figured topologies are either strict consensus trees or Adams consensus trees (only Analysis 1A). The associated MPTs of each analysis are included as .tre files in Appendix 7. All bootstrap values are reported, so any node without a listed bootstrap value was not recovered in more than $1 \%$ of the bootstrap replicates (for TNT analyses) or more than 5\% of the replicates (for PAUP*). Note that bootstrap frequencies reported for TNT analyses are absolute frequencies, not frequency differences (GC), which are the program's default. Because bootstrap support below 50\% and Bremer support below 3 is not considered strong, any values below these thresholds are colored in grey, whereas any values at or above these thresholds are colored in black.

The node-based definition of Dissorophoidea (the least inclusive grouping with Dissorophus multicinctus and Micromelerpeton credneri) and the stem-based definitions for 
473 Trematopidae (most inclusive clade containing Acheloma cumminsi but not D. multicinctus),

474 Dissorophidae (specifiers of Trematopidae inverted), Cacopinae (most inclusive clade containing

475 Cacops aspidephorus but not D. multicinctus), and Dissorophinae (specifiers of Cacopinae

476 inverted) are used here following Schoch \& Milner (2014). Therefore, all of these clades are

477 "recovered" in any analysis in which the specifiers are sampled, but they may include only that

478 specifier (e.g., only A. cumminsi for Trematopidae). Some specifiers for the node-based

479 definitions of Xerodromes, Amphibamiformes, and Olsoniformes are not sampled in this

480 analysis (Amphibamus grandiceps and Apateon pedestris), but these names are used in the same

481 sense as other workers (the sister group of Micromelerpetidae, the clade of all small-bodied

482 xerodromes, and the sister group of Amphibamiformes, respectively). The looser definitions of

483 these clades in this context means that they are not always recovered and must include at least

484 two taxa that form a clade. Nominal placement of taxa, specifically for dissorophids, is also from

485 Schoch \& Milner (2014). These definitions are color-coded in the figures to visually facilitate the

486 comparison of topologies and placement of taxa.

487

488

489

Analysis 1A (all olsoniforms). The iteration with the 'conservative' OTU of Kamacops

490

491

492

493

494

495

496

497

498

499

500

501

502

503 acervalis recovered 93,116 MPTs with a length of 401 steps $(\mathrm{CI}=0.314 ; \mathrm{RI}=0.592)$. The strict consensus is predictably unresolved beyond a node for Temnospondyli and the default node excluding the operational outgroup (Greererpeton burkemorani). The iteration with the 'reconstructed' OTU of $K$. acervalis recovered 21,646 MPTs with the same length of 401 steps and an identical strict consensus topology. Because of the total lack of resolution, these topologies are not presented here.

Adams consensus trees were computed for both iterations in order to identify wildcard taxa (Fig. 6). The topologies are largely consistent with the main differences lying in the composition of Cacopinae. All nominal trematopids form a clade, but all nominal dissorophids do not. Parioxys bolli is recovered entirely outside of Dissorophoidea in a polytomy at the base of Temnospondyli; Iratusaurus vorax and Reiszerpeton renascentis are recovered in a polytomy outside of Olsoniformes with Palodromeus bairdi; and Platyhystrix rugosa is recovered in a polytomy with Trematopidae and Dissorophidae (as defined above). "Broiliellus" hektotopos is recovered in a polytomy with individual branches for all four amphibamiforms and a branch for all nominal dissorophids other than Par. bolli at the base of Xerodromes.

Wildcard identification was restricted to nominal olsoniforms. The highly incomplete Parioxys bolli was removed because it falls well outside of Olsoniformes in the Adams consensus. Palodromeus bairdi was also removed given its position outside of Olsoniformes. Iratusaurus vorax ${ }_{2}$ Platyhystrix rugosa, and Reiszerpeton renascentis were removed given their position outside of Dissorophidae. Within Dissorophidae, I removed any nominal dissorophid that was part of a polytomy at the base of the clade; this led to the removal of Aspidosaurus chiton, Aspidosaurus novomexicanus, Brevidorsum profundum, and Nooxobeia gracilis, all of which are poorly known taxa. In the iteration with the 'conservative' OTU of Kamacops acervalis, this taxon was also recovered in this basal polytomy and was removed. Similar to Dilkes (2020), I then removed any taxon recovered in a polytomy with Cacopinae and Dissorophinae, leading to the removal of Aspidosaurus binasser and Scapanops neglectus in both iterations, as well as Anakamacops petrolicus and Zygosaurus lucius in the iteration with the 'conservative' OTU of $K$. acervalis. One notable retention in both iterations is Conjunctio

517 multidens, a wildcard as identified by Dilkes (2020). The two iterations differ in dissorophid

518 composition by three taxa. For Trematopidae, I removed any taxon that was part of a basal 
519 polytomy; the pair of Actiobates peabodyi + Mattauschia laticeps and Mordex calliprepes met 520 this criterion in both iterations. These are the more fragmentary trematopids and have rarely been 521 sampled in previous analyses.

522

523

524

525

526

527

528

529

530

531

532

533

534

535

536

537

Following the wildcard identifications, taxa were then removed from the original sets of MPTs, and the strict consensus was recalculated. When newly identical MPTs were subsequently removed, there was a substantial reduction in the number of unique MPTs. There are 122 remaining MPTs for the iteration with the 'conservative' OTU of Kamacops acervalis and 346 remaining MPTs for the iteration with the 'reconstructed' OTU. The strict consensus of the retained taxa of both iterations (Fig. 7) largely follows that observed in the Adams consensus (Fig. 6), though with a loss of resolution in Trematopidae and Dissorophinae. Micromelerpeton credneri and Perryella olsoni now form a polytomy with amphibamiforms and "Broiliellus" hektotopos instead of forming an earlier diverging branch (i.e. Xerodromes is not recovered). In the iteration with the 'reconstructed' OTU, Anakamacops petrolicus, K. acervalis, and Zygosaurus lucius form branches of a cacopine polytomy with Cacops.

Analysis 1B (wildcard removal). The iteration derived from the previous analysis with the 'conservative' OTU of Kamacops acervalis (which excluded this OTU) recovered 64 MPTs with a length of 329 steps $(\mathrm{CI}=0.380$; $\mathrm{RI}=0.610$; Fig. $8 \mathrm{~A})$. The omission of wildcards produced a weakly resolved topology that recovered all nominal dissorophids and all nominal trematopids in their respective clades but not Olsoniformes. Trematopidae is largely unresolved, with Acheloma cumminsi + Phonerpeton pricei as the only recovered relationship. Conjunctio multidens and all three species of Cacops are recovered as cacopines, with Cacops aspidephorus and Cacops morrisi as sister taxa, Cacops woehri as the sister taxon to this pair, and Co. multidens as the sister taxon to Cacops. All four species of Broiliellus, Diploseira angusta, and Dissorophus multicinctus are recovered as dissorophines in an unresolved polytomy. All amphibamiforms (including "Broiliellus" hektotopos) are single branches in a polytomy with Dissorophidae and Trematopidae. Bremer support is usually below 3 , and bootstrapping was usually below or just slightly above $50 \%$.

The iteration derived from the analysis with the 'reconstructed' OTU of Kamacops acervalis (which included this OTU) recovered 72 MPTs with a length of 338 steps $(\mathrm{CI}=0.370$; $\mathrm{RI}=0.617$; Fig. 8B). The strict consensus topology is nearly identical to that of the previous iteration with respect to mutually overlapping taxa. Anakamacops petrolicus, Kamacops acervalis, and Zygosaurus lucius do not form a clade (as they did in Liu, 2018) but instead form single branches of a polytomy with the clade of Cacops. Conjunctio multidens is still recovered as the earliest-diverging cacopine. Bremer and bootstrap support are consistently low. One node dropped below the threshold of strong support for Bremer decay index ( $\mathrm{Ca}$. aspidephorus $+\mathrm{Ca}$. morrisi), and three nodes dropped below the threshold for bootstrapping (the two nodes of Cacops and Dissorophidae).

Analysis 2 (Best representatives). The analysis recovered 785 MPTs with a length of 382 steps $(\mathrm{CI}=0.327$; $\mathrm{RI}=0.582$; Fig. 9). The strict consensus is largely unresolved. Dissorophoidea is recovered (inclusive of Perryella olsoni), but the only in-group clades are a clade of the three species of Cacops + Anakamacops petrolicus (Cacopinae) and the pairing of Acheloma cumminsi + Phonerpeton pricei (Trematopidae). Both Dissorophidae and Dissorophinae therefore include only Dissorophus multicinctus. Bremer and bootstrap support are low except for Trematopidae. 
565 Analysis 3. The iteration with the 'conservative' OTU of Kamacops acervalis recovered 420

566 MPTs with a length of 375 steps $(\mathrm{CI}=0.333$; $\mathrm{RI}=0.589$; Fig. 10). The strict consensus is largely

567 unresolved and does not recover Amphibamiformes or Olsoniformes. Perryella olsoni is the

568 sister taxon to Xerodromes. All nominal trematopids form a clade. Dissorophidae and

569 Dissorophinae include only Dissorophus multicinctus, and Cacopinae includes only Cacops

570 aspidephorus. All other dissorophids, amphibamiforms, and Palodromeus bairdi are single

571 branches of a xerodrome polytomy with one branch for Trematopidae. Within Trematopidae,

572 Mattauschia laticeps diverges at the base, followed by successively diverging branches of: (1)

573 Anconastes vesperus + Tambachia trogallas; (2) Ecolsonia cutlerensis; and (3) Fedexia striegeli,

574 the last of which is the sister taxon to Acheloma cumminsi + Phonerpeton pricei. Both Bremer

575 and bootstrap support are universally low.

576

577

578

The iteration with the 'reconstructed' OTU of Kamacops acervalis recovered 23 MPTs with the same length of 375 steps. The strict consensus topology is more resolved with respect to nominal dissorophids, with all taxa except Reiszerpeton renascentis recovered as a clade.

579 Platyhystrix rugosa is recovered as the earliest diverging dissorophid. All species of Broiliellus and Diploseira angusta are now recovered as dissorophines; Cacopinae remains restricted to Cacops aspidephorus. Bremer support did not change from the previous iteration, and bootstrap support changed only by $1-2 \%$ for nodes shared between iterations. Support for newly recovered nodes is extremely low, and most were not even recovered in the bootstrap tree $(<1 \%$ occurrence).

Analysis 4. The iteration with the 'conservative' OTU of Kamacops acervalis recovered 220 MPTs with a length of 280 steps $(\mathrm{CI}=0.436$; $\mathrm{RI}=0.649$; Fig. 11). The strict consensus is poorly resolved. A noteworthy result is the recovery of the holotype of Conjunctio multidens (FMNH UC 673) at the base of Dissorophidae, whereas the two referred specimens (CM 91215, UCMP 40103) are recovered as sister taxa at the base of Cacopinae. The separation of the holotype from UCMP 40103 (historically the "Rio Arriba Taxon") is the same as that of Schoch (2012). All other cacopines form a single polytomy with the exception of the pair of two specimens of Cacops woehri, the holotype (OMNH 73216) and a larger referred specimen (BMRP 2007.3.5). Bremer and bootstrap support are low for dissorophid nodes.

The iteration with the 'reconstructed' OTU of Kamacops acervalis recovered 40 MPTs with a length of 281 steps $(\mathrm{CI}=0.434$; $\mathrm{RI}=0.647)$. The strict consensus remains unchanged and is thus not depicted separately here. Bremer and bootstrap support are essentially unchanged.

Analysis 5 (taxon mirror of Dilkes, 2020). This analysis recovered 750 MPTs with a length of 348 steps $(\mathrm{CI}=0.494 ; \mathrm{RI}=0.579$; Fig. 12A). The strict consensus topology is discordant with

601

602 that of Dilkes. Amphibamiformes and Olsoniformes are not recovered, and Dissorophidae and Dissorophinae only include Dissorophus multicinctus. Most nominal dissorophids are single branches in a polytomy with non-dissorophids. Cacopinae includes the three species of Cacops, Anakamacops petrolicus, Kamacops acervalis, and Zygosaurus lucius; within this, Cacops is monophyletic, and the other three taxa are single branches of a polytomy. All nominal trematopids form a clade, with one resolved in-group: Fedexia striegeli as the sister taxon to Acheloma cumminsi + Phonerpeton pricei. The other three taxa form a polytomy at the base. Bootstrap and Bremer support were usually below meaningful thresholds except for Trematopidae. The Adams consensus (not presented here) identifies Aspidosaurus binasser, Platyhystrix rugosa, Reiszerpeton renascentis, and Scapanops neglectus as wildcards following 
611 the same approach as in Analysis 1, but does not identify Brevidorsum profundum or Conjunctio 612 multidens as wildcards (both were wildcards in Dilkes' analysis).

613 Recently, Silva \& Wilkinson (2021) proposed a method of representing consensus 614 topologies when there are multiple islands recovered by a heuristic search by computing a 615 consensus topology for each island. This can be useful when the strict consensus of all MPTs is 616 relatively unresolved, although it relies on the analytical program not only identifying the 617 number of islands but also the constituent MPTs. To the best of my knowledge, TNT does not do 618 so; Silva \& Wilkinson used PAUP*, as in this analysis. The above analysis recovered three 619 distinct islands, with 564 MPTs, 108 MPTs, and 78 MPTs (Fig. 13). When the strict consensus of each island is computed, the resolution is improved from the total consensus. The largest island (Fig. 13A) newly recovers Olsoniformes, a more inclusive Dissorophidae of all nominal taxa except Reiszerpeton renascentis, and a more inclusive Dissorophinae (Broiliellus, Diploseira angusta, Dissorophus multicinctus). Reiszerpeton renascentis is instead recovered as the sister taxon to Olsoniformes. For this island, only Brevidorsum profundum and Platyhystrix rugosa are identified as wildcards among Dissorophidae. The second largest island (Fig. 13B) newly recovers Trematopidae inclusive of $R$. renascentis and a relatively inclusive Dissorophidae (to the exclusion of $R$. renascentis, B. profundum, and Platyhystrix rugosa). Cacopinae now includes Conjunctio multidens, which is recovered at the base of the clade. Broiliellus brevis and Broiliellus texensis are recovered as sister taxa within Dissorophinae. For this island, no dissorophids (or olsoniforms) would be identified as wildcards. The smallest island (Fig. 13C) differs more starkly from the other two islands' consensus topologies.

Reiszerpeton renascentis forms a polytomy with Dissorophidae and Trematopidae, and $C$. multidens and P. rugosa are recovered as sister taxa within Dissorophinae. Trematopidae is fully resolved here, with Anconastes vesperus + Tambachia trogallas as the sister group to Ecolsonia cutlerensis. For this island, Aspidosaurus binasser, R. renascentis, and Scapanops neglectus would be identified as wildcards.

The iteration with Dilkes' wildcards removed recovered 296 MPTs with a length of 318 steps $(\mathrm{CI}=0.522$; $\mathrm{RI}=0.597$; Fig. 12B $)$. All MPTs belong to the same island. The strict consensus topology is more congruent with that of Dilkes, although still with less resolution. Xerodromes, Olsoniformes, Trematopidae, and Dissorophidae are all recovered. The composition of Cacopinae and Dissorophinae is the same as that of Dilkes' analysis. Platyhystrix rugosa and Aspidosaurus binasser are recovered as the earliest diverging dissorophids. Polytomies are found at the base of Trematopidae and Cacopinae, and Dissorophinae is a single polytomy. Nodal support remained low.

Analysis 6. The rerun of my original trematopid matrix with the newly combined Acheloma cumminsi OTU and the exclusion of Phonerpeton whitei recovered 27 MPTs with a length of 209 steps $(\mathrm{CI}=0.445 ; \mathrm{RI}=0.615$; Fig. 14A). For comparison, the original analysis recovered 105 MPTs with a length of 210 steps $(\mathrm{CI}=0.443, \mathrm{RI}=0.640)$. The strict consensus topology is nearly unchanged; Olsoniformes and Amphibamiformes are recovered, but Xerodromes is not. Dissorophidae and Trematopidae include all of their respective nominal taxa. Within Trematopidae, the only resolved relationships are the pairing of A. cumminsi + P. pricei and Rotaryus gothae as the sister group to this pair. The newfound resolution of $R$. gothae from the previously large polytomy is an intuitive result given the taxon sample modifications that were made to long-snouted taxa. Nodal support is weak except for some non-trematopid nodes. 
656

657

658

659

660

661

662

663

664

665

666

667

668

669

670

671

672

673

674

675

676

677

678

679

680

681

682

683

684

685

686

687

688

689

690

691

692

693

694

695

696

697

698

699

700

701
The mirror analysis with the same taxon treatment and the revised matrix's character sampling recovered 19 MPTs with a length of 282 steps $(\mathrm{CI}=0.429$; $\mathrm{RI}=0.567 ; \mathrm{Fig} .14 \mathrm{~B})$. The strict consensus is slightly more resolved, but with the major caveat that Trematopidae only includes Acheloma cumminsi and Phonerpeton pricei. Anconastes vesperus + Tambachia trogallas is also recovered and forms one branch of a polytomy with the relatively exclusive Trematopidae, all other nominal trematopids, and Dissorophidae. Examination of the MPTs reveals that all nominal trematopids form a clade in all but one MPT in which Dissorophidae nests within Trematopidae as the sister group to Ecolsonia cutlerensis to form a late-diverging clade. Nodal support has improved, including a change in Bremer support for Olsoniformes and Trematopidae (from 2 to 3 ) that reaches the threshold for meaningful support.

Analysis 7. Analysis of the updated Dilkes' matrix recovered substantially more MPTs than the original analysis. With all 29 taxa, the analysis recovered 3,408 MPTs with a length of 169 steps $(\mathrm{CI}=0.527$; RI $=0.733$; Fig. 15B $)$, compared to $513 \mathrm{MPTs}$ with a length of 163 steps $(\mathrm{CI}=$ $0.5460 ; \mathrm{RI}=0.7574$; Fig. $15 \mathrm{~A}$ ). Recovering Dilkes' original topology requires an additional 34 steps in the revised version of the matrix. All MPTs belong to the same island (both in Dilkes' original analysis and in the new one). Resolution is relatively low, although not too dissimilar from Dilkes' topology in this regard. Dissorophinae is restricted to Dissorophus multicinctus, and Cacopinae is restricted to the three species of Cacops. Cacops aspidephorus and Cacops morrisi are sister taxa to the exclusion of Cacops woehri, in contrast to the historic polytomy of these taxa, which form the entirety of Cacopinae here. All other dissorophids with the exception of Platyhystrix rugosa (the earliest diverging dissorophid) form a single polytomy. Bremer and bootstrap support have generally slightly declined for nodes shared between the original and the reanalysis, and Bremer support is below the threshold of meaningful support for almost all nodes. The resultant Adams consensus would identify a slightly different set of wildcards (Aspidosaurus binasser and Diploseira angusta and not Scapanops neglectus) than in Dilkes' analysis, but I reran the search after removing the same four taxa that he identified as wildcards (Brevidorsum profundum, Conjunctio multidens, Reiszerpeton renascentis, Scapanops neglectus).

With removal of Dilkes' wildcards, the analysis recovered 20 MPTs with a length of 151 steps $(\mathrm{CI}=0.556 ; \mathrm{RI}=0.750 ;$ Fig. $15 \mathrm{D})$, in contrast to the original $27 \mathrm{MPTs}$ with a length of 143 steps $(\mathrm{CI}=0.5874 ; \mathrm{RI}=0.7839$; Fig. $15 \mathrm{C})$. Dilkes' original topology requires an additional 6 steps in the revised version of the matrix. The MPTs are evenly divided between two islands, but the strict consensus topologies of each are nearly identical, differing only in the relationships of dissorophines (Fig. 16). The strict consensus is more resolved than the previous iteration but less resolved than Dilkes' topology. The relationships of Cacops are as with the previous iteration, but Anakamacops petrolicus, Kamacops acervalis, and Zygosaurus lucius are also recovered as cacopines. A more inclusive Dissorophinae is also recovered, with Broiliellus olsoni recovered as the earliest diverging taxon, followed by $B$. reiszi and then a polytomy of all other nominal dissorophines, which differs from the original analysis (Fig. 15C). This polytomy is the only source of differences between islands; in one, Dissorophus multicinctus and Diploseira angusta are sister taxa, and Broiliellus brevis and Broiliellus texensis are sister taxa (Fig. 16A). In the other island, Dis. multicinctus and B. texensis are sister taxa, and Dip. angusta and B. brevis are sister taxa (Fig. 16B). None of these configurations of Dissorophinae have been previously recovered. Acheloma cumminsi and Phonerpeton pricei are recovered in a polytomy with Anconastes vesperus + Tambachia trogallas. Fedexia striegeli and Ecolsonia cutlerensis are

Peer) reviewing PDF | (2021:02:58550:3:0:NEW 7 Oct 2021) 
702 successive branches at the base of Trematopidae. Bremer and bootstrap support have again

703 declined slightly for nodes shared with Dilkes' analysis.

704

705

Analysis 8. The parallel analysis of the trematopid-focused sample in PAUP* recovered 23

706

707 MPTs with a length of 326 steps $(\mathrm{CI}=0.506$; $\mathrm{RI}=0.567$; Fig. 17A), compared to the 19 MPTs with a length of 282 steps $(\mathrm{CI}=0.429$; $\mathrm{RI}=0.564$; Fig. 17B) that I recovered in Analysis 6

708

709 (reproduced from Fig. 14B). The strict consensus topology is identical, but it is notable that there are three islands (of sizes 14, 8, and $1 \mathrm{MPTs}$ ), which differ in the relationships of olsoniforms (Fig. 18). As with the TNT results in Analysis 6, only one MPT does not recover all nominal trematopids within a clade, and that MPT instead recovers the nominal trematopids as a grade from Eoscopus lockardi to the nominal dissorophids (Fig. 18C). Based on the definition of Dissorophidae utilized here, several nominal trematopids are technically dissorophids (Actiobates peabodyi, Anconastes vesperus, Ecolsonia cutlerensis, Mordex calliprepes, Rotaryus gothae, and Tambachia trogallas). Similarly, the definition of Olsoniformes utilized here would

716 result in a recovery of Mattauschia laticeps outside of Olsoniformes. The observation of multiple islands in the PAUP* analysis suggests that the MPTs of the TNT analysis might also be distributed across multiple islands. Nodal support is the same with respect to Bremer decay indices but is consistently higher in the PAUP* analysis, with differences ranging from $7 \%$ (Cacops morrisi + Cacops woehri) to 27\% (Olsoniformes). Two nodes would be considered well-supported by bootstrap values in the PAUP* analysis but not in the TNT analysis: Dissorophoidea and Olsoniformes. I note that the PAUP* branch-and-bound search took a particularly long time (33.5 hours) despite the eventual low number of MPTs and indicates the upper threshold of reasonable computation time for this matrix (23 taxa, 109 characters). Over half of the search process occurred after all MPTs had been recovered. A heuristic search with 10,000 random addition sequence replicates, holding 10 trees per step, recovered the same set of MPTs in just over a minute.

728

729

Analysis 9. The parallel analysis of Dilkes' (2020) original matrix with all 29 taxa and in TNT recovered 23 MPTs with a length of 157 steps $(\mathrm{CI}=0.529 ; \mathrm{RI}=0.757$; Fig. 19B), in contrast to the original study using PAUP* (513 MPTs of length 163 steps; CI = 0.5460; RI =0.7574; Fig. 19A). The strict consensus is identical to that of Dilkes', as is the Bremer support, but bootstrap support is distinctly lower for all nodes, similar to the previous analysis. Here, the differences between the two analyses range from 3\% (Anconastes vesperus + Tambachia trogallas) to 34\% (Kamacops acervalis + Zygosaurus lucius). Five nodes dropped below the $50 \%$ threshold in the TNT analysis. The Adams consensus (not depicted) would identify the same four wildcard taxa as Dilkes' original analysis (Brevidorsum profundum, Conjunctio multidens, Reiszerpeton renascentis, Scapanops neglectus).

The TNT analysis of the matrix without Dilkes' wildcards recovered a single MPT with a length of 142 steps $(\mathrm{CI}=0.585$; $\mathrm{RI}=0.780$; Fig. 19D), in contrast to Dilkes' analysis in PAUP* (27 MPTs with a length of 143 steps; $\mathrm{CI}=0.5874$; $\mathrm{RI}=0.7838$; Fig. 19C). The differences relate only to resolution of polytomies recovered by Dilkes; there are no shifts in the general position of taxa. The same pattern of Bremer and bootstrap support was identified, with the latter ranging between 4\% (Anconastes vesperus + Tambachia trogallas) and 20\% (all three species of Cacops; Dissorophinae; Cacopinae + Dissorophinae). However, zero nodes dropped below the 50\% threshold in the TNT analysis. 
781

782

783

784

785

786

787

788

789

790

791

792

The TNT analysis of my updated version of Dilkes' matrix with all taxa sampled recovered 284 MPTs with a length of 161 steps $(\mathrm{CI}=0.509$; $\mathrm{RI}=0.734$; Fig. 20A). Resolution has decreased across the tree with a large basal polytomy in Dissorophidae. Cacopinae consists only of the three species of Cacops. Platyhystrix rugosa is still recovered as the earliestdiverging dissorophid. Trematopidae has also lost resolution; only Anconastes vesperus + Tambachia trogallas is recovered. Bremer and bootstrap values tend to be lower for overlapping nodes. The Adams consensus (not depicted) does not identify the same four wildcards as Dilkes (2020). Of those four, only Reiszerpeton renascentis is still recovered in a wildcard position, in addition to Aspidosaurus binasser and Diploseira angusta, which were not wildcards in Dilkes' original analysis.

The TNT analysis of the same matrix without Dilkes' wildcards recovered 12 MPTs with a length of 148 steps $(\mathrm{CI}=0.554$; $\mathrm{RI}=0.778$; Fig. $20 \mathrm{C})$. The tree is more resolved than in the previous iteration, with two cacopine clades: (1) all three species of Cacops; and (2) Anakamacops petrolicus + Kamacops acervalis + Zygosaurus lucius. This is the only analysis to recover all three taxa within Kamacopini (the clade defined as all taxa closer to K. acervalis than to Cacops aspidephorus; Liu, 2018). The arrangement of Dissorophinae, with Broiliellus olsoni as the earliest diverging taxon, followed by Broiliellus reiszi, differs from both the previous iteration with all taxa sampled and from previous studies. Within Trematopidae, Fedexia striegeli and Ecolsonia cutlerensis are now recovered as successively diverging taxa at the base of the clade rather than as exclusive sister taxa. Acheloma cumminsi and Phonerpeton pricei are also not recovered as exclusive sister taxa and instead form a polytomy with the pair of Anconastes vesperus + Tambachia trogallas. Bremer and bootstrap values are again lower compared to the original matrix analyzed in TNT.

\section{Discussion}

The original goal of this study was to expand my previous trematopid matrix to encompass dissorophids as a means of independently testing the relationships of dissorophids and olsoniforms more broadly. This study "accomplished" that goal, but as may be apparent from a first-hand examination of the results and as I hope to make a case for, the results of both this study and those of previous studies should be treated cautiously. This discussion is therefore divided into three main sections: (1) a brief discussion of the first-hand results of the analyses performed here; (2) a broader discussion of topological disparity, identifiable sources of this disparity, and a critical examination of previous methodologies; and (3) a summary of the state of affairs in dissorophoid phylogenetics and taxonomy with some highlighted areas for future study.

Tallying topologies. This section summarizes the key findings from the various analyses that were performed in this study as they relate to the recovered topologies. It comes as little surprise that across my nine analyses, there is little consensus; indeed, some analyses recover little resolution at all. Larger taxon samples produced less resolution and rarely recovered all nominal dissorophids or all nominal trematopids in a clade (e.g., Analyses 1A, 2; Figs. 6, 9). Parioxys bolli is unsurprisingly not recovered as a dissorophid, let alone as a dissorophoid (Fig. 6). The skew towards cranial characters in this matrix, a characteristic of other matrices as well, reflects the precedent of using cranial remains to differentiate taxa. Even with the expanded postcranial character sampling of this study's matrix, most characters cannot be scored for this taxon. "Broiliellus" hektotopos is also not recovered as an olsoniform, let alone as a dissorophid (Figs. 
793

794

795

796

797

798

799

800

801

802

803

804

805

806

807

808

809

810

811

812

813

814

815

816

817

818

819

820

821

822

823

824

825

826

827

828

829

830

831

832

833

834

835

836

837

838
6-9). Amphibamiformes is never recovered when this taxon is sampled, and it always forms a polytomy with other amphibamiforms. The lack of a monophyletic Amphibamiformes in most analyses likely reflects the character sampling being derived from olsoniform matrices and thus undersampling characters that capture amphibamiform synapomorphies.

A more surprising result is the position of Reiszerpeton renascentis as an unplaced olsoniform or outside of a clade of all other dissorophids in some analyses (Analyses 3, 5; Figs. $6,10 \mathrm{~B}, 13$ ), as it was always recovered as a dissorophid in previous studies (Figs. 3-4). One possibility is that this small specimen was very immature and therefore shares certain qualitative features with amphibamiforms; its original identification as a specimen of Tersomius texensis speaks to this (Maddin et al., 2013). With that said, it never clusters with amphibamiforms. There may be enough features shared with most/all dissorophids or olsoniforms (e.g., a septomaxilla at the mid-length of the naris; postorbital lacking a markedly offset posterior terminus) to maintain its olsoniform affinities. The apparent absence of a ventral process of the prefrontal (Maddin et al., 2013:454) may also contribute to its stemward slippage; this process (the VPP) is found in all other dissorophoids sampled here.

A different hypothesis is that full sampling of trematopids, including the rarely sampled Carboniferous taxa like Mordex calliprepes, draws the taxon down. Many of these Carboniferous taxa have a relatively higher number of plesiomorphies than the more commonly sampled taxa. This hypothesis is supported by some MPTs of Analysis 5 in which Reiszerpeton renascentis is recovered as an early diverging trematopid (Fig. 13B). However, it never clusters with trematopids in analyses of the original or revised matrix of Dilkes (2020), which use the same taxon sample (Analyses 7, 9; Figs. 15-16, 19-20). These discrepancies indicate that character sampling and construction are more likely an explanator since scoring approaches between my matrix and my revised version of Dilkes' were the same (e.g., the taxon cannot be scored for characters invoking skull length). The most likely scenario in my opinion is that the missing data for $R$. renascentis are responsible for its peculiar position. The holotype is only a partial skull, incomplete posteriorly, and definitively lacks apomorphic ornamentation found in cacopines and dissorophines. Therefore, its combination of known scores may approximate the "ancestral" olsoniform condition, even though there is no evidence of either trematopid apomorphies or conditions contrary to the diagnosis of Dissorophidae.

This conjecture could also apply to Brevidorsum profundum and Platyhystrix rugosa. Brevidorsum profundum is represented only by a fragmentary partial skull (without apomorphic ornamentation) and a few postcranial fragments (without osteoderms). Hook (1989) even suggested that it might be a small trematopid related to what was eventually placed in Phonerpeton. However, B. profundum is either recovered with other dissorophids to the exclusion of Reiszerpeton renascentis (e.g., Analysis 3; Fig. 10B) or in a polytomy of all dissorophids including $R$. renascentis and perhaps other taxa (e.g., Fig. 10A). A few features in which $B$. profundum is similar to most other olsoniforms and differs from $R$. renascentis (e.g., tabular-squamosal contact; semilunar curvature) are evidently sufficient to avoid the same degree of stemward slippage.

Platyhystrix rugosa is represented only by a badly crushed skull and isolated postcrania (Berman, Reisz \& Eberth, 1981). It was identified as a wildcard taxon in Analysis 1A (Fig. 6) and was not always recovered as a dissorophid (e.g., Analyses 3, 7, 9, some MPTs of Analysis 5; Fig. 13B), like Brevidorsum profundum. It too never exhibits the same slippage as Reiszerpeton renascentis and is often recovered as the earliest-diverging dissorophid (e.g., Analysis 5; Figs. $10 \mathrm{~B}, 12 \mathrm{~B}, 13 \mathrm{~B}, 15,19-20)$. One consideration worth future consideration is whether this

Peer] reviewing PDF | (2021:02:58550:3:0:NEW 7 Oct 2021) 
839 position is still artificial, even if its position within Dissorophidae is secure. The only semi840 complete skull of $P$. rugosa is badly crushed. While mostly complete longitudinally, the naris is

841

842

843

844

845

846

847

848

849

850

851

852

853

854

855

856

857

858

859

860

861

862

863

864

865

866

867

868

869

870

871

872

873

874

875

876

877

878

879

880

881

882

883

884 not sufficiently preserved to be certain of its shape or the relationship of the elements that normally frame it (e.g., lacrimal; Berman, Reisz \& Fracasso, 1981). Additionally, P. rugosa has historically been scored as lacking osteoderms, contrary to all other nominal dissorophids; the condition of its spines is therefore regarded as ornamentation of the spines, rather than a separate dermal ossification. Notably, however, Witzmann \& Soler-Gijón (2010), the only published histological study of these spines, termed them as osteoderms. Dilkes' (2020) analysis of his matrix with and without osteoderm characters did result in a slight change in topology, so the identity of the spinal ornamentation has clear phylogenetic implications as well. Without these characters, $P$. rugosa formed a polytomy with Aspidosaurus binasser and a branch for all other dissorophids, rather than diverging before $A$. binasser (Dilkes, 2020). It is possible that the combination of absent osteoderms and missing data may produce an artificially early-diverging position, as the taxon is difficult to differentiate from trematopids in scoring (e.g., the nares cannot be characterized) and it lacks certain dissorophid apomorphies (e.g., osteoderms). The Early Permian age of the material from which most scores are derived is incongruent with its present early-diverging position.

There is usually poor resolution within Trematopidae except in analyses with restricted taxon samples (Fig. 5). In this study, nominal trematopids are recovered as a clade in most analyses except Analyses 1A and 2, which recovered almost no resolution anywhere (Fig. 9). A restricted subset of seven trematopids in Analysis 3 did form a clade in spite of relatively little resolution elsewhere (Fig. 10). The more interesting result is that a trematopid-focused sample did not recover all nominal trematopids in a clade (Analyses 6 and 8; Figs. 14, 17). This pattern persisted even when examining individual tree islands of Analysis 8 (Fig. 18), although as noted in the Results, 18 of the 19 MPTs of Analysis 6 did recover all nominal trematopids in a clade. One explanation may be that two characters were removed to avoid redundancy / parsimonyuninformative characters (narial elongation, lacrimal-naris; Appendix 2). Trematopids were all scored the same for both characters, and this redundancy may have overweighted certain apomorphies (the lacrimal always enters an elongate naris in this clade). Another is that the net addition of characters (+24 compared to Gee, 2020b), many of which are postcranial characters for which most olsoniforms cannot be scored, creates sufficient uncertainty to preclude recovery of all nominal taxa in a clade. The commonly recovered in-group nodes are Acheloma cumminsi + Phonerpeton pricei, a longstanding relationship between two Permian taxa from Texas (Figs. 7-12, 14, 17, 19), and Anconastes vesperus + Tambachia trogallas, a more perplexing relationship (Late Carboniferous of New Mexico and Early Permian of Germany; Figs. 10, 12B, 14B, 15, 17, 19-20) but one that has been recovered in most previous studies (Fig. 2).

The resolution of Dissorophidae is quite variable, especially with respect to historical wildcard taxa or historically unsampled taxa. All nominal dissorophids form a clade only in restricted taxon samples that omit wildcards like Reiszerpeton renascentis (e.g., Analyses 1B, 2, 5; Figs. 7-8, 12B) or that have a more limited outgroup sample (e.g., Analyses 7, 9; Figs. 15, 1920). Where resolution is appreciable, Platyhystrix rugosa and Aspidosaurus binasser usually form successively diverging branches at the base as they do in practically all other dissorophid analyses (Figs. 3-4; see Figures 12B, 15D, 19B, 19D, 20C, for topologies of this study).

Dissorophinae is an "all or nothing" of sorts; either it is restricted to Dissorophus multicinctus (Figs. 9, 10A, 12A, 15B, 19B, 20A) or it includes this taxon, all valid species of Broiliellus, and Diploseira angusta (Figs. 7, 8, 10B, 12B, 15D, 19D, 20B). The more inclusive

Peer) reviewing PDF | (2021:02:58550:3:0:NEW 7 Oct 2021) 
885 composition follows the historical characterization of Dissorophinae. This includes $B$.

886 arroyoensis, which has never been previously sampled because the cranial sutures are entirely 887 unknown. It is united with other nominal dissorophines here by its apomorphic ornamentation 888 and demonstrates that taxa without sutures or with a high proportion of missing data are not 889 assured to be wildcards (e.g., Kearney, 2002; Kearney \& Clark, 2003; Wiens, 2003a, 2003b, 890 2005, 2006; Wilkinson, 2003; Prevosti \& Chemisquy, 2010; Wiens \& Morrill, 2011; Guillerme 891 \& Cooper, 2016). Taxon removal exerts the strongest apparent influence on Dissorophinae; 892 analyses with progressive taxon removal often produced a more inclusive clade (e.g., Analyses 5,

893

894

895

896

897

898

899

900

901

902

903

904

905

906

907

908

909

910

911

912

913

914

915

916

917

918

919

920

921

922

923

924

925

926

927

928

929

930 7; Fig. 12, 15). The interrelationships of dissorophines remain poorly resolved however. Cacopinae is similar to Dissorophinae in either being monotaxic (Cacops aspidephorus) or in comprising a consistent, more exclusive clade. The more exclusive version of Cacopinae almost always includes all three species of Cacops (Figs. 15B, 20A); only in Analysis 3 is Cacops aspidephorus recovered as the sole cacopine (Fig. 10). Some analyses also recovered Anakamacops petrolicus, Kamacops acervalis, and Zygosaurus lucius as cacopines (Figs. 7B, 8B, 12, 15D, 19D, 20C). Conjunctio multidens was also sometimes recovered as a cacopine (Figs. 7, 8, 13B), a result sometimes previously found (Figs. 3-4). Cacops was usually monophyletic (but see Analyses 1A and 2; Figs. 7B, 9), with C. aspidephorus and Cacops morrisi as sister taxa and Cacops woehri as the sister taxon to this pair.

Liu (2018) recovered the Middle Permian dissorophids Anakamacops petrolicus, Kamacops acervalis, and Zygosaurus lucius as a clade, which he termed Kamacopini and which was defined as the most inclusive clade that includes $K$. acervalis but not Cacops woehri. Subsequent studies have either recovered Kamacopini to the exclusion of $A$. petrolicus (Dilkes, 2020) or as a monotaxic clade with the nominal taxa as part of a larger polytomy (Gee et al., 2021; Figs. 7-8, 10, 12, 15). Analysis 9A, with Dilkes' wildcards excluded, is the only one to recover the same Kamacopini as Liu (Fig. 19). This likely results from the very poor characterization of $Z$. lucius, which does not differ from $K$. acervalis in scoring except for the distribution of missing data. Anakamacops petrolicus conversely differs from Z. lucius for one character and from $K$. acervalis by two or three depending on which OTU of the K. acervalis is used. Iratusaurus vorax and Nooxobeia gracilis, the other Middle Permian dissorophids, are too fragmentary and lacking in apomorphies to assess whether they are kamacopins (Gubin, 1980; Gee, Scott \& Reisz, 2018; Fig. 6).

Collectively, the results reflect a few influential factors. The first is taxon sampling; it is not surprising that including many poorly known taxa (Analyses 1A, 2,3) led to very poor resolution (Figs. 6, 9-10). This pattern was also apparent in my trematopid study in which restricting the taxon sample to mirror that of previous studies led to the recovery of substantially more resolution than when all taxa were sampled (Gee, 2020b). Nonetheless, taxa like Broiliellus arroyoensis demonstrate that taxon sampling criteria must be nuanced and not rely on blanket characterizations such as "no cranial sutures known," as a handful of qualitative features may still be highly informative. However, the presence of tubercular ornamentation in Iratusaurus vorax and Nooxobeia gracilis, a cacopine apomorphy, was insufficient to draw them into Cacopinae in any analysis. The absence of this ornamentation in Cacops woehri, which still clusters with the other species of Cacops, could be a confound. However, I. vorax and N. gracilis are also some of the most fragmentary taxa (scored for $<20 \%$ of characters; Table 1 ). The status of osteoderms also predictably exerts influence (as shown also by Dilkes, 2020); as discussed above, nominal dissorophids that are sometimes recovered outside of Dissorophidae or at the base are often those for which the postcranial skeleton is not sufficient to score the 
931 presence/absence (e.g., Reiszerpeton renascentis) or where osteoderms are scored as being

932 absent (e.g., Platyhystrix rugosa).

933 To summate, in spite of a few broadly conserved aspects (e.g., composition of

934 Dissorophinae), there remain many outstanding questions and uncertainties, even if the

935 discussion is restricted to relatively resolved, restricted-taxon-sample analyses (Figs. 12-20).

936 Therefore, there is very little consensus in dissorophid intrarelationships, and as Dilkes (2020)

937 remarked, it is not merely surprising but rather concerning that there is so much disparity

938 between previous studies that used a nearly identical character matrix. This questions whether

939 any study, including this one, has produced a reasonably robust topology that is acceptable for

940 use in other studies or for qualitative discussion of olsoniform evolution. The following sections

941 present a more detailed discussion of my findings regarding potential methodological

942 explanators for the persistent disparity, some of which are rather concerning and some of which

943 may invalidate previous analyses.

944

945

946

The search for a consensus. Almost every living worker who has specialized in terrestrial dissorophoids in the last four decades (J. Anderson; D. Berman; D. Dilkes; N. Fröbisch; B. Gee;

947

948

949 R. Holmes; A. Huttenlocker; H. Maddin; A.R. Milner; J. Pardo; R. Reisz; R. Schoch) has participated in dissorophid phylogenetic analysis, with only two (Fröbisch, Schoch) involved in more than one analysis. However, almost every previous matrix other than the modified one used in this study is a direct derivate from Schoch (2012), and almost every one of these derivates is over 95\% similar in character sampling, taxon sampling, and scoring to the original (Figs. 3-4).

952

953

954

955

956

957 Two of the three first-order derivates only added or subtracted taxa (Maddin et al., 2013; Schoch $\&$ Sues, 2013). The majority of cumulative changes present up through the derivate by Dilkes is the result of Dilkes adding seven new characters (cumulative changes summarized in Appendix 8). Gee et al.'s (2021) matrix is the most recent derivate to be published, although it is not a direct derivate, as it combined Holmes, Berman \& Anderson's (2013) derivate with the amphibamiform-focused matrix of Maddin et al. (2013); accounting for elimination of

958 redundancies, only 33 characters are carried over from the former. Fröbisch \& Reisz (2012) used

959

960 a slightly modified version of Polley \& Reisz's (2011) trematopid matrix, although it only sampled five dissorophids. However, because all 53 characters of Polley \& Reisz were 961 incorporated into Schoch (2012), Fröbisch \& Reisz's matrix is in fact very similar in character 962 sampling, even if it is not derived from Schoch's. Schoch did not expressly state whether he

963

964

965

966

967

968

969

970

971 rescored characters but the absence of any polymorphisms in his matrix in comparison to nine in Polley \& Reisz's matrix suggests as much. The Gee (2020b) trematopid matrix and the derivate used here are also in part derived from Polley \& Reisz, so the general character sampling thus converges on the sampling of Schoch (2012). However, character construction differs for many (Appendix 1), and scoring was expressly novel for all characters. There are also notable departures from the sampling of previous analyses to avoid redundant or dependent characters (Appendices 1-2).

In detailing this history, I want to emphasize that I am not advocating against the standard practice of propagating an existing matrix; there are many advantages to doing so. However, 972 implicit in the propagation of a consensus matrix is the assumption that the underlying

973 framework is largely sound. While there may be minor differences in scoring philosophy, such as

974

975 whether reconstructions can be used, the matrix should obviously be as error-free as possible while maximizing the available data. If it is not, then widespread adoption of this matrix will

976 result in widespread propagation of errors. There are therefore also inherent disadvantages to 
977 propagating matrices when their quality is suspect. This underscores the emphasis on quality of

978 the matrix, rather than quantity of characters, duration or frequency of usage, or other

979 quantitative metrics, that have been raised by numerous recent studies (e.g., Brazeau, 2011;

980 Simões et al., 2017; Laurin \& Piñeiro, 2018). However, wide discrepancies in practice clearly

981 persist within the field. As reflected in Analysis 7 (Fig. 15, Appendices 5-6), I have concerns

982 about the accuracy of the widely propagated Schoch matrix. These findings therefore cast doubt

983 on previous studies that used this matrix, which I outline in greater detail below.

984

985

986

987

988

989

990

991

992

993

994

995

996

997

998

999

1000

1001

1002

1003

1004

1005

1006

1007

1008

1009

1010

1011

1012

1013

1014

1015

1016

1017

1018

1019

1020

1021

Scoring issues. Examination of previous matrices for possible explanators of topological disparity led me to conduct a thorough survey of Dilkes' version of the Schoch (2012) matrix (as the most recent direct derivate). I identified a large number of scores for features that are simply unknown in the given taxon (73 in total; Appendix 5). I also identified a smaller number of unscored cells that can definitively be scored from the literature (35 total) and scores that were scored for the wrong character state ( 35 total). I want to emphasize that the changes that I made are corrections to unequivocal errors in the sense that standard practices do not permit scoring of features that are unknown. I also accounted for the datedness of some literature with respect to previously unscored cells that were newly scored. While some typographical errors are to be expected in any matrix, the number of changed scores (143) and the pattern of these scores either suggest an intentionally non-standard coding philosophy that permits scoring of unknown features or an unusually large number of typographical errors. Most of these errors stem from either the original matrix or the first direct derivative (Holmes, Berman \& Anderson, 2013), so they have been propagated through several analyses. Below I outline a few examples in detail. Cacops provides the clearest example. For Cacops woehri, I identified 14 errors; in a matrix of 70-77 characters, this is a substantial amount (note that the particular scores of this taxon that have been propagated were introduced by Holmes, Berman \& Anderson, 2013). Ten of these relate to features that are simply not preserved (exoccipital, stapes, quadrate, postcrania). Having worked extensively on Richards Spur, from which C. woehri is known, I am not aware of any unpublished material of $C$. woehri that can reconcile these errors (but see Gee, Bevitt \& Reisz, 2019:fig. 9.7-9.14 for an isolated jaw articulation that was assigned to Dissorophidae cf. C. woehri). At least the postcranial scores could not have been taken from the original scoring by Fröbisch \& Reisz (2012) because that matrix has zero postcranial characters. One of the 14 errors is a score for the wrong state (tubercular ornamentation present); $C$. woehri lacks the tubercular ornamentation found in other species of Cacops (Fröbisch \& Reisz, 2012; Fröbisch, Brar \& Reisz, 2015; Gee, Bevitt \& Reisz, 2019). Notably, of the 14 erroneous scores, 13 were scored identically to both of the other species of Cacops; the last score was only the same as Cacops morrisi (Cacops aspidephorus was unscored). In fact, there were no characters for which the three species differed other than in the distribution of missing data. This false homogeneity certainly accounts for the unresolved relationships of the three species in all previous analyses (Figs. 3-4), despite the many features that separate them taxonomically (Fröbisch \& Reisz, 2012; Gee \& Reisz, 2018a) and the recent questioning of whether C. woehri is even properly placed in the genus (Anderson, Scott \& Reisz, 2020). The most reasonable conclusion is that scores for $C$. woehri were "assumed" on the basis of the phenetic placement of the taxon within Cacops. This approach is problematic since a phylogenetic analysis should inform taxonomy, rather than vice versa. The notable cranial differences of $C$. woehri from the other two species suggest that it may have also differed in other skeletal attributes that are not presently known for it. 
1022

1023

1024

1025

1026

1027

1028

1029

1030

1031

1032

1033

1034

1035

1036

1037

1038

1039

1040

1041

1042

1043

1044

1045

1046

1047

1048

1049

1050

1051

1052

1053

1054

1055

1056

1057

1058

1059

1060

1061

1062

1063

1064

1065

1066

1067
Cacops aspidephorus also corroborates the hypothesis that scores have been "assumed." The taxon is famously known for the total absence of any knowledge of the cranial sutures (inclusive of the palate and braincase) due to poor preservation. Only in the past year has this gap been addressed (Anderson, Scott \& Reisz, 2020). However, in Schoch's (2012) original matrix, there were no fewer than 15 scores for which the sutures would have to be known in order to score the taxon. These scores were then propagated without modification by all derivates. Schoch did not personally examine the material of this taxon (as indicated in his table 1), and it is telling that while he reconstructed the cranial anatomy of almost every dissorophid with their respective known sutures, that of C. aspidephorus is only a silhouette (see figures 6 and 7 therein). While Anderson, Scott \& Reisz's (2020) description corroborated many of these scorings, at least five original scores were shown to be errors (e.g., parasphenoid dentition, exoccipital-postparietal contact). One originally unscored character (postorbital-supratemporal) should have been scoreable if other cranial suture characters could have been scored. These erroneous scores are identical to those of $C$. morrisi and would have to have been "assumed" from this taxon (Cacops woehri was not sampled in the original matrix). This is further corroborated by the observation that Cacops morrisi does not show a pattern of erroneous scores, probably because it was the exemplar from which scores for the two other species were "assumed"; only one score is clearly erroneous: the iliac blade. No pelvis is known for the taxon, but this could have been "assumed" either based on the fact that this feature is an olsoniform apomorphy or based on Williston's description of C. aspidephorus.

As discussed in the Methods and Appendix 3, the previous scoring for Kamacops acervalis cannot be fully corroborated by the literature. This taxon's cranial sutures have never been described or figured, but it is scored for many characters that require these sutures to be known and is specifically scored almost identically to the three species of Cacops. The only reconstruction of the skull roof of $K$. acervalis in dorsal view (Schoch, 2012:fig. 6) lacks sutures, like Cacops aspidephorus. If sutural characters could be scored for these taxa, it is unclear why they were not reconstructed with them. The scoring of my matrix is based on my assumption that the sutures are not actually known since data to support their characterization have never been published. Broiliellus, with four commonly sampled species, does not clearly show evidence of widespread "assumed" scores. Broiliellus arroyoensis, for which sutures are also unknown, has never been previously sampled or reconstructed, and it is almost never discussed in the literature. Broiliellus olsoni does have a few erroneous scores for elements that are not preserved, but no pattern is apparent for other species. Broiliellus brevis and Broiliellus texensis are difficult to assess from the literature given its datedness (Williston, 1914; Carroll, 1964a; DeMar, 1966b). These descriptions are not well-suited for scoring due to their brevity and limited figures. Schoch indicated that he personally examined material of both taxa, and therefore, it is possible that he was able to score features from personal examination that are not mentioned in the literature, contrary to C. aspidephorus.

Some of the errors that I identified are related to how characters are defined, something that Dilkes (2020:20-22) discussed at length. For example, the position of the jaw articulation is referenced by the position relative to the exoccipital facets. However, the character has been scored for taxa in which the jaw articulation or the exoccipitals are unknown (e.g., Cacops woehri, Scapanops neglectus, Tambachia trogallas). It was probably assumed that the occiput was vertical (like in most temnospondyls), from which it can be assumed that the occipital margin of the postparietals is an acceptable proxy for the exoccipitals' posterior extent. If this series of working assumption was indeed used, the character should have been redefined (as I did 
1068 here; Appendix 1). Otherwise, it could lead to inconsistent scoring where one worker operates 1069 with this unstated assumption and thus scores the character, but another worker operates strictly 1070 based on the character as defined and thus leaves it unscored. The other set of characters for 1071 which this applies are those related to the relative length or height of different regions of the 1072 skull (e.g., suborbital bar height, distance between the squamosal embayment and orbit). These are all defined by relation to the midline skull length, yet a number of taxa whose skulls are incomplete posteriorly were scored for these characters (e.g., Broiliellus olsoni, Reiszerpeton renascentis). These characters could be redefined based on a proxy to facilitate scoring of incomplete specimens (something that Liu, 2018, attempted, but that Dilkes, 2020, reversed). As defined, these characters cannot be scored from such specimens.

Certain characters also seem more susceptible to either "assumed" scoring, or in some instances, a peculiar lack of scoring. The best example of the latter is how exoccipital-tabular contact (only found in Sclerocephalus in the matrix) is often scored, but exoccipital-postparietal contact is not. This is in spite of frequent explicit description and figuring of the exoccipitalpostparietal contact and the lack of an exoccipital-tabular contact. Some scores here also appear to have been "assumed" based on a taxon's broader affinity (e.g., to Dissorophidae). For example, a prefrontal-postfrontal contact is not found in any dissorophid and only in the earliestappearing trematopids (not sampled in Schoch's matrix or any derivate). Anconastes vesperus is scored as lacking this contact, yet no specimen preserves the medial margins of the orbit (Berman, Reisz \& Eberth, 1987). The dorsal quadrate process (a xerodrome feature as scored) is another example; several taxa without complete (or any) quadrates are scored as having this feature (e.g., Cacops woehri).

It is worth pointing out that many of the original erroneous scores, whether a typographic error, an assumption, or an inference, were not necessarily inaccurate. It is reasonable to predict, for example, that Cacops morrisi would have an expanded iliac blade, an olsoniform synapomorphy that is positively identified in Cacops aspidephorus (Williston, 1910). However, this feature has yet to be positively identified in Cacops morrisi and should not be scored as such. It is simply unknown. The correction of five previously inferred scores of C. aspidephorus following the study of Anderson, Scott \& Reisz (2020) underscores the point that even scores that are inferred through close phenetic relatedness may prove to be wrong when data are produced to assess them. A phylogenetic analysis is a test of hypotheses that goes beyond the historical phenetic frameworks that were not only subject to, but predicated on, each worker's personal conceptions of relatedness. While a phylogenetic analysis may be a test of inferences, it is not a test that can be based on inferences - it is a test only properly based on strict observations (i.e. data). I am under no illusions that phylogenetic analyses are unbiased or completely objective - taxon sampling and character construction are just two ways in which workers' biases can be imposed upon the analysis. But there is an implicit aim for minimizing biases when conducting these analyses, and scores that are simply inferred based on phenetic taxonomic placement or previous phylogenetic placement are the opposite.

Correcting for these inferences or assumptions, as I have done, has predictably reduced resolution and nodal support (Figs. 15, 20). While loss of resolution and nodal support is an unfavorable outcome, an analysis based only on what is properly observable is the only truly defensible topology. Relationships recovered from inferred "observations" are spurious. A lack of resolution does not necessarily indicate that the matrix is compromised or poorly constructed, and workers should not tinker with the matrix in a way that produces resolution at the cost of data integrity. The ultimate goal is to recover correct clades while avoiding incorrect ones 
1114 (Rineau, Zaragüeta i Bagils \& Laurin, 2018), not to maximize resolution at the expense of

1115 accuracy. The sampled characters could capture all of the historical characters that were

1116 incorporated into phenetic taxonomy yet be insufficient to recover statistical support for

1117 relationships. Such a possibility is inherently tied to the data available for each taxon and thereby

1118 to the incomplete fossil record.

1119

1120 Slippery slope. The concerns I outlined in the matrix of Schoch (2012) and its derivates are not

1121 exclusive to this "family" of matrices. The 70 characters from Schoch's (2012) matrix were

1122 carried over to Schoch's (2018a) matrix, which broadly samples dissorophoids (Fig. 2).

1123 Presumably, the scores for the 10 taxa that are sampled in both matrices were also propagated;

1124 this appears to be the case based on a random assessment of cells that I corrected (i.e. the same

1125 erroneous scores are found in both matrices). The taxon sample of Schoch's (2018a) matrix was

1126 skewed towards amphibamiforms (only eight olsoniforms are sampled), but this matrix has been

1127 expanded in four studies (Atkins, Reisz \& Maddin, 2019; Gee \& Reisz, 2019; Schoch, Henrici \&

1128 Hook, 2020; Schoch \& Milner, 2021), three of which added olsoniforms. The same matrix with a

1129 different taxon sample was also used by Schoch \& Witzmann (2018) in their study of the

1130 micromelerpetid Limnogyrinus; this study preceded the online publication of Schoch (2018a) by

1131 a few weeks.

1132 The densest taxon sampling of any previous study with respect to olsoniforms is that of

1133 Atkins, Reisz \& Maddin (17 OTUs), but as far as I can discern, the scores for the first 70

1134 characters for almost all newly added olsoniforms (Anconastes, Aspidosaurus, Brevidorsum,

1135 Kamacops, Platyhystrix, and the "Rio Arriba" and "Admiral" taxa) are taken directly from

1136 Schoch (2012). This would explain why the referred specimen of Conjunctio multidens is still

1137 treated as the "Rio Arriba Taxon," separate from the holotype, and why Scapanops neglectus is

1138 still termed the "Admiral Taxon"; both terms went into disuse following Schoch \& Sues (2013).

1139 Therefore, the same erroneous scores present in Schoch (2012) would also be present in Atkins,

1140 Reisz \& Maddin's matrix, which I cursorily confirmed based on a random examination of

1141 equivalent cells that I had corrected in Dilkes' (2020) matrix. Workers seeking to expand any

1142 version of Schoch's (2018a) matrix should carefully examine the matrix to assess the fidelity of

1143 scores in order to avoid the same issue of propagation of dubious scores. I want to emphasize

1144 that my discussion of previous matrices' scores is not meant as overt criticism of other workers

1145 for the sake of being critical (it was not even part of my original study design), nor is it under

1146 any assumption that I or any other worker produce entirely infallible work. It is instead meant to

1147 highlight that historic practices have produced a topology that is not reproducible under best

1148 practices (e.g., scoring only based on observed features), with the topology resulting from

1149 correction of errors being noticeably different (Figs. 15, 20).

1150

1151

1152

1153

1154

The treatment of polymorphisms. The treatment of polymorphisms has been a contentious topic in phylogenetics for some time (e.g., Wiens, 1999; Watanabe, 2015). Polymorphisms are generally rare in temnospondyl matrices. It was not until Liu (2018) that polymorphisms were

1155

1156

1157

1158

1159 introduced into a dissorophid matrix, and it was only for Conjunctio multidens. Dilkes (2020) subsequently introduced one polymorphic scoring for Dissorophus multicinctus. While some of this owes to the singleton representation of many taxa, there are also examples of incontrovertible biological variation within a single individual (e.g., postorbital-supratemporal contact in Phonerpeton pricei; Dilkes, 1990) that were not scored. This specific example is odd because Schoch (2012) explicitly called out this polymorphism (p. 128 therein) yet did not score 
1160 it as such. A second example is his mention of the polymorphic state of the intertemporal in

1161 Sclerocephalus, another sampled taxon for which this polymorphism is unscored (p. 128 as

1162 well). In contrast to this propagated matrix, polymorphisms are widespread in my matrix; at the

1163 species level, there are 48 polymorphisms. Such disparity is not related to my increased sampling

1164 of postcranial characters; only two polymorphisms are for such characters.

1165

1166

It has historically been assumed that polymorphic characters are less reliable for

1167 inference (e.g., Wiens, 1995). Indeed, comparisons of matrices with polymorphisms with the same matrices without polymorphisms recover distinctly different topologies (e.g., Trinajstic \& Dennis-Bryan, 2009; Watanabe, 2015; Garbin, Ascarrunz \& Joyce, 2018). Nonetheless, not representing intraspecific variation in some form is an oversimplification of the data, and proper

1171 representation is essential, even if it comes at the expense of topological resolution. Furthermore,

1172 analysis of both simulated and empirical datasets has demonstrated that failing to score polymorphisms may in fact decrease accuracy (e.g., Wiens \& Servedio, 1997, 1998; Wiens, 1998; Trinajstic \& Dennis-Bryan, 2009). Therefore, there is no strong a priori standing for intentionally omitting polymorphisms. Numerous strategies for approaching polymorphisms have been discussed (e.g., Kornet \& Turner, 1999; Wiens, 1999), but many are not well-suited for paleontological datasets. For example, scoring based on the frequency with which a certain state appears will require an appreciable sample size that is rarely met for extinct tetrapods. I believe that no olsoniform is known from such a sample size. The use of an alternative character state for polymorphisms (e.g., 'scaled,' 'unscaled,' and 'unordered' scoring; Campbell \& Frost,

1181 1993; Mabee \& Humphries, 1993; Wiens, 1995, 1999) is one option that does not rely on a large

1182 sample. However, no previous olsoniform study has utilized this approach (the use of 'a' for polymorphisms by Polley \& Reisz, 2011, seems to be only for visual alignment of the typeset matrix's columns). This approach has also drawn criticism (e.g., see discussion by Kornet \& Turner, 1999) because this polymorphic character state is not mutually exclusive with other states, as is the convention for character construction (e.g., Sereno, 2007). There is no consensus among any subset of workers as to the treatment of polymorphisms, but it should be emphasized that whatever approach is being employed should be explicitly stated, and ignoring polymorphisms, as seems evident from many previous studies, should be discouraged.

Conjunctio multidens merits discussion because it is scored for the most polymorphisms in derivates of the Schoch (2012) matrix. The holotype and the referred specimen long referred to as the Rio Arriba Taxon (UCMP 40103) were historically separate OTUs. They are superficially somewhat different (e.g., Schoch \& Sues, 2013:fig. 2), which may reflect that the holotype is nearly twice as large. Schoch \& Sues (2013) did not report their new composite OTU of these two specimens, so the composite OTU currently in use is that of Liu (2018). There are five polymorphisms for $C$. multidens: interorbital width (23); tabular process (46); preorbitalpostorbital ratio (52); tabular horn (64); and pointed snout (67). Two of these characters $(23,52)$ are related to skull proportions, which conceivably could be ontogeny-related. Another two (46, 64) relate to the same part of the tabular, and the first of these has been explicitly stated to be ontogeny-related in some dissorophids like Cacops (e.g., Reisz, Anderson \& Schoch, 2009). Any workers continuing to use this matrix should consider rescoring these with an eye towards ontogeny, as I did here, since polymorphisms are not scored for taxa represented by a much narrower size range of specimens that capture anatomical variation (e.g., the tabular horn of Cacops morrisi).

The last character (pointed snout) appears to be a typographic error introduced by 
1206 shaped) snout is only found in Broiliellus, Dissorophus, and Scapanops (“Admiral Taxon"); he 1207 scored it as absent in the holotype and the referred specimen of Conjunctio multidens. However, 1208 it is scored as present in the holotype of C. multidens by Holmes, Berman \& Anderson (2013). 1209 This was only identified by examining their matrix; they did not list it in the text despite listing 1210 other scoring changes, further evidence that it is a typographic error. The final line of evidence is 1211 that the "Admiral Taxon" was scored as lacking a pointed snout in this derivate, contrary to

1212 Schoch. The holotypes of $C$. multidens and Scapanops neglectus were scored as successive lines 1213 and could have been misread (Schoch's matrix was available only as scoring strings in a typeset 1214 figure). I hypothesized that this error could account for the shift of $C$. multidens from the base of 1215 Cacopinae in Schoch \& Sues (2013), who presumably scored the composite as lacking this 1216 feature (as in Schoch, 2018a), to the base of Dissorophinae in Liu (2018), who scored $C$.

1217 multidens as polymorphic. Since this was a simple test, I corrected the scoring of $C$. multidens 1218 from '0\&1' to ' 0 ' and that of Scapanops neglectus from ' 0 ' to ' 1 ' and reanalyzed Liu's matrix. 1219 The MPT length increased by one step, but the same number of MPTs were recovered (six), and the strict consensus topology remained unchanged, indicating that this one propagated error is not the sole explanator of Liu's topology.

Software selection. One of the relatively understudied factors that may produce conflicting topologies between studies is the choice of software. While it is well-known that different programs often produce different topologies, the actual differences are rarely examined. As noted in the Methods, comparisons of previous studies suggest that the choice of PAUP* versus TNT is exerting a meaningful influence on dissorophid topology. Analysis 8 (trematopid-focused; Fig. 17) did not recover any differences in the strict consensus. Conversely, Analysis 9A (original matrix of Dilkes, 2020; Fig. 19) identified a few topological differences between strict consensus trees of the restricted taxon sample. TNT recovered more resolution in the parallel of Dilkes' (2020) original matrix, but all newly recovered nodes are compatible with the equivalent polytomies of the original study (e.g., the resolution of the trichotomy of Broiliellus brevis, Broiliellus olsoni, and Broiliellus texensis; Fig. 19D).

Because some of the inherent differences between programs (e.g., default branch collapsing rule, rounding rule for nodal frequency) do not correlate with biological principles that would clearly support using one parameter over another (compared to a parameter like character ordering), the topology of one program is not more "biologically accurate" or an "overestimate." These specific programs have purportedly recovered different topologies for the same matrix in other studies (e.g., Schoch, 2013, claimed to have recovered less resolution using TNT), but Marjanović \& Laurin (2019:4) have addressed many of these findings and note that they were in fact the result of errors or a non-equivalent search between programs. At least some of these likely relate to poorly documented nuances of various programs (e.g., the need to run a second round of TBR branch-swapping from a stored set of MPTs in TNT in order to obtain all MPTs) or to different heuristic algorithms for relatively large datasets (e.g., the New Technology Search in TNT and the parsimony ratchet [PAUPRat] that is used in tandem with PAUP*). For example, neglecting to run a second round of branch-swapping in TNT could produce more resolution if the first set of MPTs (suboptimal) was only a small subset of the total MPTs. Lessthan-best practices, such as running a heuristic search with a relatively low number of replicates (either to identify MPTs or for bootstrapping), could also explain the recovery of an incomplete set of MPTs or suboptimal trees. 
1251

1252

1253

1254

1255

1256

1257

1258

1259

1260

1261

1262

1263

1264

1265

1266

1267

1268

1269

1270

1271

1272

1273

1274

1275

1276

1277

1278

1279

1280

1281

1282

1283

1284

1285

1286

1287

1288

1289

1290

1291

1292

1293

1294

1295
Other studies not addressed by Marjanović \& Laurin (2019) have reported different topologies recovered by heuristic TNT and PAUP* (e.g., Kurochkin et al., 2009; Han et al., 2016; Audo, Barriel \& Charbonnier, 2021), but assessing whether these too might have failed to obtain all MPTs is beyond the scope of this study. A recent comparison of performance of different parsimony programs on phylogenomic data by Goloboff, Catalano \& Torres (2021) noted that PAUP* recovered optimal trees in all datasets but one compared to TNT. Other paleontological studies have recovered the same number and length of MPTs between programs, both with large numbers of MPTs (e.g., Spaulding, O'Leary \& Gatesy, 2009; Ford \& Benson, 2020) and with small numbers of MPTs (e.g., Davesne et al., 2016; Villalobos-Segura, Underwood \& Ward, 2021). Most studies do not report the majority of employed parameters, so while it can be reasonably assumed that most studies use the default settings (with various differences between TNT and PAUP*, e.g., branch-collapsing rule, TBR reconnection limit), this is not actually known. These factors also should not result in different results for exact searches, regardless of whether they in fact influence heuristic ones, but many analyses also have taxon samples that exceed the typical computational threshold for exact searches. In this case, it may be that the algorithms for such searches are not in fact the same ('branch-and-bound' in PAUP* versus 'implicit enumeration' in TNT). Broadly speaking, implicit enumeration is usually considered to be a specific form of a branch-and-bound algorithm for programming problems with variables of a "0-1" nature (e.g., Balas, 1965; Geoffrion, 1969; Davis, Kendrick \& Weitzman, 1971; Breu \& Burdet, 1974). Further exploration of possible differences between exact search algorithms in these programs is beyond the scope of this study but should be a focus of future studies.

Given that the explanators for differences between programs are not fully documented, it would be preferable if workers would use the same program as the previous iteration of the same foundational matrix to be properly comparative or to restrict any comparisons made with analyses that used a different program. It would also be beneficial if workers would provide the complete set of MPTs in supporting information (as I do here) rather than merely depictions of different consensus trees. This would have the advantage of allowing workers to compute additional consensus topologies not presented in the paper and is a key step towards reproducibility.

Support metrics. In theory, support metrics could be one means of comparing disparate topologies of the same matrix that were recovered from different programs. In Analysis 9 (Fig. 19D), all of the nodes that were recovered in TNT but not in PAUP* had Bremer support of 1 and bootstrap support below 10\%. Unfortunately, reporting of support metrics for dissorophid studies is rather uneven (Table 3), which prevents a full comparison of previous studies. Holmes, Berman \& Anderson (2013) and Schoch \& Sues (2013) did not report any support metric. Maddin et al. (2013) reported bootstrap values, whereas Liu (2018) reported Bremer values. Schoch (2012) and Dilkes (2020) reported both metrics. There are thus two issues: (1) it is not possible to directly compare a node's Bremer support in one study to the equivalent node's bootstrap support in another study; and (2) even if the same metric is reported, if the analyses were conducted in different programs, the nodes are not necessarily properly equivalent (e.g., they may not contain the same subset of taxa). This holds especially true for heuristic searches, which may not recover all (or any) MPTs. Therefore, the only proper comparison is between Dilkes' PAUP* analysis and Schoch's PAUP* analysis (Table 3), which shows that both Bremer 
1296 and bootstrap support has declined for dissorophid nodes, sometimes substantially so (e.g.,

1297 Kamacops + Zygosaurus).

1298 Reporting of at least one support metric is standard practice in contemporary

1299 phylogenetics, so in my opinion, studies without any support metrics should be regarded

1300 skeptically (Holmes, Berman \& Anderson, 2013, and Schoch \& Sues, 2013, in this context). As

1301 aptly put by Sanderson (1995:299), "without some assessment of reliability, a phylogeny has

1302 limited value. It may still function as an efficient summary of available information on character-

1303 state distributions among taxa [...] but it is effectively mute on the evolutionary history of those

1304 taxa". Although expressed more in the context of standard parsimony bootstrapping, this stance

1305 is also valid for Bayesian analyses; not reporting posterior probabilities is concerning, especially

1306 because posteriors tend to overestimate support (Alfaro, Zoller \& Lutzoni, 2003; Cummings et

1307 al., 2003; Douady et al., 2003; Erixon et al., 2003; Simmons, Pickett \& Mia, 2004; Zander, 2004)

1308 and especially with all-clades compatible trees, which force full resolution. This is a shortcoming

1309 of the study by Atkins, Reisz, \& Maddin (2019), which was the previous densest sampling of

1310 olsoniforms but which presents only the all-clades compatible tree without posterior probabilities

1311 (figures 2 and 3 therein).

1312 Aiming to achieve resolution regardless of support, or interpreting topologies without

1313 consideration of support, is problematic because it encourages tinkering with the matrix to

1314 produce either some semblance of resolution where none previously existed or to produce a

1315 topology consistent with previous analyses or with the authors' preconceived notions. The same

1316 is true of dismissing studies that recover poor resolution or that only emphasize well-supported

1317 nodes. It is always better to conservatively derive conclusions from only well-supported nodes

1318 rather than basing them on poorly supported, possibly spurious relationships. Indeed, methods to

1319

1320

1321 penalize spurious relationships (e.g., Rineau, Zaragüeta i Bagils \& Laurin, 2018) should be better utilized. A polytomy may be unsatisfactory and is unlikely to depict the actual evolutionary

1322

1323

1324

1325

1326

1327

1328

1329

1330

1331 history of a clade, but it is more likely to be correct insofar as it encompasses a genuine clade. This point is salient here because nodes of the in-groups of this study's analyses tended to be poorly supported except in relatively restricted analyses. Some of this is clearly associated with the sampling of poorly known taxa, reflected in the weakly resolved strict consensus topologies (e.g., Figs. 6, 9-10). However, it bears noting that in previous studies of both dissorophids and trematopids, most dissorophid nodes fail to meet the threshold for meaningful support for at least one metric (Tables 3-4). My identification of widespread "assumed" scores also questions the robusticity of previously recovered nodes (like the falsely homogenous Cacops).

One other point to emphasize is that bootstrap support in any TNT analysis is surprisingly low - often below $50 \%$ - even for many nodes that have strong Bremer support, which is hardly unique to this study (see Schoch, 2013, and other studies cited below). Many of these nodes are for major clades, like Dissorophidae (Figs. 8B, 10B, 12, 15B, 15D), and some nodes are not even recovered in the bootstrap tree ( $<1 \%$ of bootstrap replicates; Figs. 10, 19D). I have personally never run a PAUP* analysis in which a node recovered in the strict consensus was not recovered in the bootstrap tree, but this occurred in some analyses of the much larger dataset of Marjanović \& Laurin (2019:figs. 10,11,14, 18,19) and presumably could occur in other studies that recover poorly resolved strict consensus trees.

Conversely, some nodes that were not recovered in the strict consensus topologies of this study were recovered in a small $(<20 \%)$ of bootstrap replicates; these tended to be historical relationships (e.g., Acheloma cumminsi + Phonerpeton pricei). This may relate to limitations of

1341 TNT, which does not allow the user to define additional parameters of the heuristic search when 
1342 bootstrapping (presumably TNT uses its default heuristic search parameters: 10 replicates, 1343 holding 10 trees per replication, and with TBR), in contrast to PAUP*. The weak support of 1344 these nodes underscores the essentiality of reporting support metrics alongside the topology. A 1345 cursory survey of recent temnospondyl studies that used TNT reveals three main clusters: (1) 1346 studies that do not report any support metrics (e.g., Liu, 2016; Schoch, 2018b, 2019; Schoch \& 1347 Voigt, 2019; Schoch, Henrici \& Hook, 2020; Schoch, Werneburg \& Voigt, 2020; Schoch \& 1348 Milner, 2021); (2) studies that only report Bremer support (e.g., Marsicano et al., 2017; Schoch, 2018a); and (3) studies that report the same pattern of weak bootstrap support within the ingroup, even for nodes with very strong Bremer support (e.g., Eltink et al., 2016, 2017; Marzola et al., 2017; Pacheco et al., 2017; Chakravorti \& Sengupta, 2018; Eltink, Schoch \& Langer, 2019).

One source of comparatively low(er) bootstrap values could be a default setting in TNT. Bootstrapping in TNT displays frequency differences (Group present/Contradicted [GC]) by default, not absolute frequencies, following Goloboff et al.'s (2003) preference for using GC frequencies to assess support. Because TNT is only available as command-line for Mac users, that this is the default may not be readily apparent. However, informal comparisons of a few of my analyses did not recover GC frequencies that were substantially lower $(>10 \%)$ than the absolute frequencies. One example comparison is provided in Table 5 for Analysis 9A (TNT analysis of Dilkes' original matrix, without wildcards); the greatest difference between frequencies is $4 \%$, although two nodes dropped below the $50 \%$ cutoff for meaningful support. The same pattern of generally minimal difference is noted in other paleontological studies that report both absolute and GC frequencies (e.g., Ezcurra, Scheyer \& Butler, 2014; Nesbitt \& Ezcurra, 2015; Schultz, Langer \& Montefeltro, 2016; Marsh et al., 2019; Agnolin et al., 2020; Scheyer et al., 2020). The temnospondyl studies noted above only reported one type of bootstrap frequency and did not specify which one it was.

\section{Phylogenetic relationships of olsoniforms.}

A defensible consensus. The above discussion has cast substantial doubts on essentially all facets of olsoniform phylogenetics, ranging from topological differences between studies to substantial errors introduced in the character matrices to disparity between programs and in reporting of support metrics. Clearly there are many more unknowns than resolved quandaries that will require significant work to address. Given this, what can be confidently concluded regarding the phylogenetic relationships of Olsoniformes?

The monophyly of Olsoniformes, Trematopidae, and Dissorophidae is universally recovered and well-supported. The only previous study with appreciable olsoniform sampling that did not recover Olsoniformes was Fröbisch \& Reisz (2012); the dissorophid sample (five species) is instead more closely related to the terrestrial amphibamiforms (historical 'amphibamids'). Limited sampling may also explain why Olsoniformes was not recovered in Marjanović \& Laurin's (2019) analysis of early tetrapods, which only sampled five taxa (Acheloma cumminsi, Broiliellus brevis, Ecolsonia cutlerensis, Phonerpeton pricei, and a composite of Mattauschia laticeps and Mordex calliprepes as "Mordex laticeps"). A lack of monophyly was consistent throughout analyses of the original matrix of Ruta \& Coates (2007) to the unaltered reanalysis of this matrix to various other derivates with constraints, updated scores, and the addition of "M. laticeps" (not in the original matrix).

The relationships of trematopids remain poorly resolved regardless of the improved resolution in the new analyses (Figs. 14, 17-18). The only node that is almost always recovered 
1388 and with good Bremer and bootstrap support is Acheloma + Phonerpeton (usually A. cumminsi

1389

1390

1391

1392

1393

1394

1395

1396

1397

1398

1399

1400

1401

1402

1403

1404

1405

1406

1407

1408

1409

1410

1411

1412

1413

1414

1415

1416

1417

1418

1419

1420

1421

1422

1423

1424

1425

1426

1427

1428

1429

1430

1431

1432

1433 and $P$. pricei). The pairing of Anconastes vesperus and Tambachia trogallas is also recovered in most studies, both trematopid-focused (Figs. 5, 14, 17) and non-trematopid-focused (Figs. 10, 12B, 15, 19-20), but it generally has low Bremer and bootstrap support (Table 4). Relationships of other taxa seem to be highly susceptible to sampling of other trematopids, as I previously noted (Gee, 2020b) and as seen in comparing different islands recovered in Analysis 8 (Fig. 18). In analyses that recovered appreciable resolution, Ecolsonia cutlerensis remains a trematopid regardless of whether the sampling focuses on dissorophids, on trematopids, or on olsoniforms in general (Figs. 10, 12-16, 19-20). The main exception is Analysis 8 (Fig. 17), in which one MPT recovered the nominal trematopids as a grade (Fig. 18C).

The classic concept of dissorophid relationships is a base of Platyhystrix rugosa and Aspidosaurus binasser and two higher nested subfamilies, Cacopinae and Dissorophinae. This is recovered in most analyses of Dilkes' (2020) matrix or the revised version (Analyses 7, 9; Figs. $15,19-20)$ here, as well as in the mirrored analysis with his taxon sample and my matrix (Analysis 5; Fig. 12B). However, both the post-Platyhystrix and the post-Aspidosaurus nodes are weakly supported (Bremer decay index never higher than 2; bootstrap frequency never higher than 56\%). As mentioned above, although P. rugosa is usually recovered as diverging first, the weak nodal support for all post-Platyhystrix dissorophids may be linked to the interpretation of osteoderms (or lack thereof) in P. rugosa (see also Dilkes, 2020:fig. 12B). Cacopinae consists of at least Cacops and usually the three sampled middle Permian dissorophids (Anakamacops, Kamacops, Zygosaurus). However, the intrarelationships remain poorly resolved (e.g., Liu, 2018; Dilkes, 2020; Figs. 4, 15, 19-20), and the erroneous scorings found in other matrices are not the only confounding factor; the extremely fragmentary nature of Zygosaurus (historically scored the same as Kamacops for all overlapping characters) and the loss of its holotype are probably the more pressing matter. The closer relationship of Cacops morrisi to Cacops aspidephorus than to Cacops woehri that I recovered for the first time is in agreement with qualitative comparisons and diagnoses of these species. The composition of Kamacopini remains unresolved (Figs. 4, 15, 19-20). Dissorophinae typically includes at least Broiliellus, Diploseira, and Dissorophus (Figs. 3-4, 7-8, 10B, 12B, 15D, 19D, 20C). However, the intrarelationships of these taxa remain poorly resolved; there are either large polytomies or very poorly supported resolution. The placement of Brevidorsum profundum, Conjunctio multidens, Scapanops neglectus, and Reiszerpeton renascentis is hardly resolved, and they should only be considered as unplaced dissorophids (contra Schoch \& Milner, 2014, who consider all four as cacopines).

A review of the taxonomic composition of Dissorophidae. This section discusses the state of affairs with an eye towards future work. Having previously discussed the state and prospects of trematopid research (Gee, 2020b; see also, Milner, 2018) I now focus on dissorophids, summarizing the present state of knowledge for the four subfamilies (Aspidosaurinae, Cacopinae, Dissorophinae, and Platyhystricinae) and highlighting future areas in need of redress that will hopefully help to refine phylogenetic analyses.

The status of Cacops. Currently, there is a consensus that there are three nominal species of Cacops: C. aspidephorus (type species), C. morrisi, and C. woehri (Fig. 21). For over a century, the cranial morphology of $C$. aspidephorus was largely unknown, in stark contrast to the recently discovered material of $C$. morrisi and $C$. woehri from Richards Spur (Reisz, Schoch \& Anderson, 2009; Fröbisch \& Reisz, 2012; Fröbisch, Brar \& Reisz, 2015; Gee \& Reisz, 2018a; Gee, Bevitt

Peer] reviewing PDF | (2021:02:58550:3:0:NEW 7 Oct 2021) 
$1434 \&$ Reisz, 2019). Some previous analyses have surprisingly failed to recover a monophyletic 1435 Cacops, and all others could not resolve the interrelationships of the three species (Fig. 21). In 1436 fact, Dilkes (2020) is the only study to recover a monophyletic Cacops when all three species 1437 were sampled (Fig. 21J); while bootstrap support was strong ( $>70 \%$ ), Bremer support was not 1438 (1).

The historic results are surprising given the stark dissimilarity of Cacops woehri to the

The status of Broiliellus. Broiliellus is the most speciose dissorophid genus, with five valid species: B. arroyoensis, B. brevis, B. olsoni, B. reiszi, and B. texensis (Williston, 1914; Carroll, 1964a; DeMar, 1967; Holmes, Berman \& Anderson, 2013). However, even with the exclusion of "Broiliellus" hektotopos, the concept of Broiliellus remains convoluted (Fig. 22). In all previous analyses but one, the sampled species of Broiliellus do not form a clade. The one analysis that does recover a clade only sampled two species and three dissorophines in total (Schoch \& Sues, 2013; Fig. 22B).

Perhaps the most outstanding issue is that most species of Broiliellus have also not been (re)described in decades. The type species, B. texensis, has never been revised since Williston's (1914) original description (but see DeMar, 1966b:fig. 4). Material of Broiliellus olsoni is neither substantial nor well-preserved, and that of Broiliellus arroyoensis has no identifiable cranial sutures (DeMar, 1967). As I previously noted, the descriptions of Broiliellus brevis and Broiliellus texensis are dated, short, and with limited figures (Williston, 1914; Carroll, 1964a). Isolated parts of the anatomy (e.g., LEP) are occasionally revised in comparative discussions (e.g., Bolt, 1974b; Dilkes, 2020), but at least the type species would benefit from a thorough redescription with contemporary photography. There are no modern photographs of any of these species other than a cropped palatal view of B. brevis (Witzmann \& Werneburg, 2017:fig. 13B), and as a result, some data exist only as scores in matrices. These are probably based on personal observations that cannot be substantiated or reproduced from the literature alone.

A detailed revision of the entire genus might recover a monophyletic Broiliellus, but this possibility seems unlikely at present. One possibility is that these taxa appear morphologically disparate in part because they are differently sized (i.e. this may be partially confounded by ontogenetic disparity). However, it seems more likely that some of the species warrant placement in novel genera if the goal is to ensure monophyly of Broiliellus, perhaps all of them other than 
1480 the type species. The present topological instability and lack of resolution does not allow for a

1481 confident determination of which taxa warrant reassignment or whether any subset of Broiliellus

1482 might form its own clade. Therefore, I refrain from erecting novel genera for the non-type

1483 species and recommend the use of quotation marks for these species.

1484

The status of Aspidosaurus. This taxon has a convoluted history and likely represents a wastebasket taxon encompassing a semi-conserved osteoderm morphotype (Schoch \& Milner, 2014). Most of the species are represented only by fragmentary isolated postcranial material and cannot even be determined to be valid without a good understanding of axial variation (if such variation exists). With the loss of all material of the type species, Aspidosaurus chiton, the functional representative is Aspidosaurus binasser, which preserves substantial axial variation, at least as interpreted. This discussion addresses this taxon and its peculiar mosaicism as part of this broader discussion of the state of affairs within Dissorophidae.

Aspidosaurus binasser is known only from the holotype, which consists of a partial skull (in several pieces) and numerous osteoderms and vertebral fragments (Berman \& Lucas, 2003). Among the postcranial material are three types of osteoderms; the type 2 of Berman \& Lucas is the stereotypical Aspidosaurus morphotype, while types 1 and 3 are hyperelongate, ornamented spines similar to those of Platyhystrix rugosa. The material that I show in Figure 23, collected in the late $19^{\text {th }}$ century from Wichita County, TX, consists of similar spines that lack the tubercles and the curvature of the spine (at least where preserved) that diagnose Platyhystrix. The style of ornamentation and the transverse compression of the spines are thus very similar to the type 1 and type 3 osteoderms in A. binasser. Notably, if previous workers' conjecture on the Wichita County sites is correct (see Romer, 1928:80; Romer 1935:1617; Milner \& Schoch, 2013:116), the Wichita County localities are in the lower-middle part of the Wichita Group (NoconaPetrolia Formations), much lower in section than the type locality of $A$. binasser (Arroyo Formation at the base of the Clear Fork Group). While stratigraphic occurrence is not diagnostic in a taxonomic sense, it is highly informative for dissorophid taxonomy. Despite a continuous record of the clade throughout the Early Permian of Texas, no species is known to extend beyond one formation-level unit.

At the time of the description of Aspidosaurus binasser, the type 1 and type 3 osteoderm morphotypes had never been reported from another locality, let alone from another formation. This implicitly strengthened the cranial-postcranial association because it suggested that these types were not like the stereotypical Aspidosaurus morphotype or like Platyhystrix - almost always fragmentary, isolated postcrania with a relatively wide stratigraphic range. Material of these taxa is often found at the same sites as cranial material of other dissorophids or temnospondyls, but there is usually not an assumption that the postcrania pertain to an isolated skull just because there are no duplicated skeletal regions. The new observation that the type 1 and type 3 morphotypes appear much lower in section suggests that these purportedly diagnostic morphotypes might in fact belong to a taxon (or taxa) that has a similarly skewed fossil record.

If there was direct articulation between the cranial and postcranial remains attributed to the holotype of Aspidosaurus binasser, the question could be settled quickly. However, there is no direct articulation between the preserved occiput and any of the postcrania. Berman \& Lucas (2003) gave no indication as to the nature of the locality, such as the distribution or association of remains. Their mention of indeterminate synapsid material implies that no other distinct dissorophid was identified. Secondly, despite the preservation of the occiput and enough presacral vertebrae to estimate at least 20 positions, neither the atlas nor axis were identified. 
1526 Thirdly, there is no direct articulation between any two of the three osteoderm morphotypes; they 1527 are either isolated fragments or short blocks with only one type. The same applies to the newly 1528 reported material. Lastly, no other dissorophid preserves the same stark variation along the axial 1529 column purported for Aspidosaurus binasser (Berman \& Lucas, 2003, argued for some variation 1530 in Aspidosaurus chiton based on Broili, 1904), but numerous taxa preserve essentially no variation in either osteoderms or vertebrae throughout the presacral column (e.g., Broiliellus, Cacops, Dissorophus). The most substantial variation is either in the curvature of different positions in Platyhystrix rugosa to form the sail (e.g., Lewis \& Vaughn, 1965) or the transition from a double to a single series in Diploseira angusta (Dilkes, 2020). The former is not apparent in A. binasser, and the latter is characterized mostly by a change in the number of series and the ventral flanges, not regional hyperelongation as in $A$. binasser. Therefore, the cranial-postcranial association essentially hinges on the assumption that there is likely only one dissorophid at any given site.

Berman \& Lucas (2003:244) indeed argued that "there is no reason to suspect more than one individual is represented." Prior to 2003, there were almost no localities with more than one named dissorophid (e.g., Coffee Creek / Romer's locality 34), which supported the assumption that dissorophid-bearing localities preserve only one dissorophid taxon (like the Cacops Bone Bed; Williston, 1910; or the Parioxys bone bed of Moustafa, 1952). Since then, however, the presence of multiple dissorophids at a single locality has been documented, and their skeletal representation can be highly uneven. Richards Spur is an excellent case study; Cacops morrisi is known from abundant cranial and postcranial material, and Cacops woehri is only known from semi-abundant cranial material. In contrast, an indeterminate dissorophine is represented only by a headless skeleton and isolated forelimb material, which I left unnamed and not associated with another taxon represented only by cranial material (C. woehri in this case; Gee \& Reisz, 2018b; Gee, Bevitt \& Reisz, 2019), and Aspidosaurus is represented by a single pair of articulated osteoderms (Gee, Bevitt \& Reisz, 2019). Corn Hill in Archer County, TX; the type locality of Brevidorsum profundum and Reiszerpeton renascentis in Archer County; and the Archer City Bonebed are all additional examples of multi-dissorophid sites. Most dissorophid-bearing sites with only one documented dissorophid are type localities that have not produced much, if any, other tetrapod material. Collectively, these observations further the possibility that the holotype of Aspidosaurus binasser could really be a chimera of two taxa, one represented largely or exclusively by cranial fragments and one represented only by fragmentary postcrania.

I have not been able to examine the holotype of Aspidosaurus binasser myself given the present circumstances, but I doubt that I would be able to identify new evidence either definitively proving (e.g., cranial-postcranial articulation) or definitively disproving the association (e.g., identification of duplicated elements). Therefore, I doubt that a redescription is warranted, which is why I raised these points here. Nonetheless, I believe that there is good reason to suspect that not all of the elements attributed to the holotype of $A$. binasser belong to either a single individual or to the same taxon. The purportedly diagnostic type 1 and type 3 osteoderms are probably more like the stereotypical Aspidosaurus morphotype: one that persists for long time intervals and which does not constitute a true clade, let alone one species, across its range. I do not rule out that some species could have been more stratigraphically extensive than others, but the appreciable fossil record of dissorophids indicates that morphospecies were shortlived. The scoring of $A$. binasser is not greatly influenced by the cranial-postcranial association in either my matrix or that of other workers, but it would be preferable to restrict the

1571 characterization in the future if characters related to spine hyperelongation or axial variation are 
1572 introduced. Chimerism of $A$. binasser would affect the validity of both $A$. chiton and $A$. binasser

1573 since the latter's diagnosis is based only on the combination of osteoderm types. I make no

1574 nomenclatural acts without having examined the type of $A$. binasser but highlight these issues

1575 since the interpretation has not been previously questioned.

1576

1577

1578

The status of Platyhystrix. There has only ever been one species of Platyhystrix, so it may be

1579 surprising to see this taxon discussed. Here I focus on the status of the holotype. AMNH FARB

1580

1581

1582

1583

1584

1585

1586

1587

1588

1589 4785 is a multi-taxic batch of material that was first designated as the holotype of "Aspidosaurus apicalis" (Cope, 1881). That taxon is of dubious validity, but the holotype of Platyhystrix rugosa, extracted from this batch by Case in 1910 (as "Ctenosaurus rugosus"), has retained the same number in the literature despite that number representing two taxa. Apparently, the Platyhystrix component was given a subletter designation (4785a) to differentiate them, per a collections tag with "Ctenosaurus rugosus" written on it, but this differentiated number never appeared in the original description or the subsequent literature. Since at least DeMar (1966b:76), the portion considered to be the holotype of "A. apicalis" (AMNH FARB 4785 proper) was considered lost (e.g., Bolt, 1974a; Berman \& Lucas, 2003; Schoch \& Milner, 2014). During a collection visit in October 2017, I came across a specimen labeled as AMNH FARB 4785, without subletter designation (Fig. 24), and it matches the description of the holotype of "Aspidosaurus apicalis" instead of that for the holotype of Platyhystrix rugosa. The material assigned to $P$. rugosa is stated to be several neural spines, while that assigned to " $A$. apicalis" is specifically the apices ("summits") of the neural spines (Cope, 1881; Schoch \& Milner, 2014), which we would now recognize as osteoderms associated with the spine. As far as I am aware, AMNH FARB 4785a has never been figured, probably because more complete specimens were figured and subsequently utilized as "proxy holotypes" for P. rugosa (Williston, 1911; Langston, 1953; Carroll, 1964a; Lewis \& Vaughn, 1965). Williston described a spine that he compared favorably to Case's holotype, and his figure (pl. 26.1 therein) is of the stereotypical Platyhystrix morphology. This confirms that Case's (1911:fig. 15) illustrations of AMNH FARB 4785 represent the part that is properly " $A$. apicalis," the same subset that I examined. These are distinctly only osteoderms (and one intercentrum of questionable association), not neural spines, and they are much smaller than $11 \mathrm{~cm}$ in length (the listed size of one spine per Case). They are, however, in line with the size range given by Cope (less than $4 \mathrm{~cm}$ long and $3.5 \mathrm{~cm}$ wide). Therefore, as I mentioned previously (Gee, 2018), the holotype of "A. apicalis" (AMNH FARB 4785 ) is not lost. Instead, that specimen has been repeatedly mistaken for the holotype of $P$. rugosa (AMNH FARB 4785a), which is missing. There is no record of AMNH FARB 4785a in the museum database, nor was the specimen identified in the most recent inventory $(\mathrm{C}$. Mehling, pers. comm., 2020). No personally examined specimen in the AMNH collection that was assigned to Platyhystrix, Aspidosaurus, or Zatrachys (these being frequently conflated in the early $20^{\text {th }}$ century) matches the description of the holotype of P. rugosa save for one.

AMNH FARB 11544 is a collection of postcrania with a large number of neural spines (Fig. 25), first described, though mostly unfigured, by Berman, Reisz \& Fracasso (1981). These purportedly belong to the same individual as AMNH FARB 11545, the only skull of Platyhystrix. The number of spines designated as the holotype of Platyhystrix rugosa was never specified, but it is inferred that "several" is more than two, and the size of some spines of AMNH FARB 11544 is consistent with the measurements given by Case (1910). Some would certainly 1617 that AMNH FARB 4785(a) was collected by David Baldwin in 1881 from the Cutler Formation 
1618 of Rio Arriba County, NM, the same formation, collector, and collection date as AMNH FARB

1619 11544. Furthermore, Case (1910) mentioned "fragments of scapulae and limb bones associated

1620 with the holotype of P. rugosa are typically pelycosaurian in form," with the association deriving

1621 from his interpretation of the spines of "Ctenosaurus" rugosus as those of a pelycosaur. AMNH

1622 FARB 11544 includes three large fragments, one of which is a partial glenoid (Fig. 25D), and

1623 one of which is a limb end. These were not described by Berman, Reisz \& Fracasso (1981),

1624 which implies that they also did not believe these fragments belonged to P. rugosa.

1625

1626

1627

1628

1629

1630

1631

1632

1633

1634

1635

1636

1637

In my opinion, it seems quite likely that AMNH FARB 4785a was renumbered as AMNH FARB 11544, but that records of this were either not made or were subsequently lost. If the value of AMNH FARB 11545 as the only skull of Platyhystrix rugosa was not recognized for decades after its collection, that would explain why these two specimens were not described for a century. The postcranial material would have drawn little attention until it was determined that it articulated with the cranial material. However, there are no collection records indicating the transfer of the holotype of P. rugosa to a new number (C. Mehling, pers. comm., 2020). Without a record, their equivalency cannot be confirmed, as it remains possible that AMNH FARB 4785a was simply lost. Therefore, the type status designation remains with AMNH FARB 4785a, and I present the conundrum here in the hopes that perhaps other workers may be able to contribute new information to help resolve this matter.

1638

Other dissorophids. Relevant points of the remaining taxa are collated here. Dissorophus multicinctus, while known from an extensive amount of material, would benefit from a systematic redescription. The osteoderms and vertebrae were described by Dilkes (2009) but were otherwise neglected since DeMar (1968). Similarly, the skull has not been redescribed since DeMar, who figured only one complete skull (MCZ 2122-1). While some studies cite Schoch (2012) for the cranial osteology, Schoch only presented a reconstruction, some of which Dilkes (2020) explicitly disagreed with (e.g., position of the jaw articulation). In addition to numerous specimens that were mentioned but not illustrated by DeMar, a number of specimens have been subsequently mentioned or photographed at a low resolution in a single profile. However, these brief documentations are insufficient for a full characterization of the anatomy (e.g., MCZ 1468; Schoch \& Milner, 2014:fig. 37C; MCZ 4170, MCZ 4186, and MCZ 4188; Dilkes, 2020:22).

Most of the wildcard taxa (or taxa not previously sampled) have poor prospects for resolving their relationships without new material (e.g., Aspidosaurus novomexicanus, Brevidorsum profundum, "Broiliellus" arroyoensis). Two very fragmentary taxa can only be inferred to be dissorophids if it is assumed that they are dissorophoids (i.e. if these taxa belong to Dissorophoidea, apomorphies of which they generally lack, they most likely belong to Dissorophidae): Iratusaurus vorax and Nooxobeia gracilis. Neither preserves dissorophid synapomorphies (sensu Schoch \& Milner, 2014), although the single series of median osteoderms in $N$. gracilis is suggestive of dissorophid affinities as Olson (1972) proposed. It seems doubtful that $N$. gracilis would represent a chroniosuchian, another tetrapod clade with median osteoderms, as Permian representatives of this group are mostly known from Russia and China (e.g., Golubev, 1998a, 1998b, 1999; Jiang, Ji \& Mo, 2017; Liu \& Abdala, 2017; Liu, 2020). However, chroniosuchian material is rare and fragmentary, and most records come from the Middle and Late Permian, intervals from which there is little to no record of terrestrial tetrapods in North America (e.g., Lucas, 2001, 2002, 2005, 2013; Reisz \& Laurin, 2001, 2002; Lozovsky, 2005; Benton, 2012, 2013; Olroyd \& Sidor, 2017; Brocklehurst, 2020). Recent studies 
1664 have expanded their range, including to the Upper Permian of Germany (Witzmann et al., 2019), 1665 where a single osteoderm-bearing vertebra ascribed to an indeterminate dissorophid was reported 1666 from slightly older deposits (Witzmann, 2005). Iratusaurus vorax does not appear like any other 1667 temnospondyl with a closed otic notch (e.g., capitosaurs), but its description by Gubin (1980) 1668 was extremely cursory, and the material is extremely fragmentary.

1669 Finally, Parioxys bolli may not belong to Parioxys, regardless of the relationship of

1670 Parioxys ferricolus to Cacops. The ilium of $P$. bolli indicates olsoniform affinities, but the

1671 remainder of the known skeleton is uninformative; the two sacral ribs that Carroll (1964b)

1672 emphasized are not a dissorophid or an olsoniform synapomorphy. The limbs are relatively long,

1673 more like those of dissorophids, but ring-like intercentra are a feature found only in Ecolsonia

1674 cutlerensis and nearly so in Acheloma cumminsi (Olson, 1941; Berman, Reisz \& Eberth, 1985;

1675 Dilkes \& Reisz, 1987). Of note are lateral projections from each side of the base of the neural

1676 arch; these are otherwise found only in E. cutlerensis and in the type 1 vertebrae attributed to

1677 Aspidosaurus binasser (Berman, Reisz \& Eberth, 1985; Berman \& Lucas, 2003). This taxon may

1678 well prove to be a trematopid.

1679

1680 Ontogenetic disparity. Although I did not exhaustively test whether ontogenetic disparity might

1681 confound or bias the phylogenetic inference of dissorophids, this remains an open question in

1682 light of the size disparity across the clade. Within Dissorophidae, this disparity is essentially an

1683 order of magnitude, greater than that observed for trematopids (Fig. 26). The temporal

1684 distribution of sizes is also non-random, as it was for trematopids. With the latter group, the

1685 earliest appearing taxon, Mattauschia laticeps, reached a skull length comparable to that of the

1686 much later appearing Ecolsonia cutlerensis (Milner, 2018), but there are other taxa between or

1687 concurrent with these occurrences that are represented by smaller individuals. In dissorophids, all

1688 of the Middle Permian taxa had skulls with a length of at least $18 \mathrm{~cm}$ (there are not even any

1689 individual specimens of an inferred smaller size), whereas most Early Permian taxa did not

1690 exceed 12-13 cm. Only two, Aspidosaurus binasser and Platyhystrix rugosa, exceed this

1691 (Cacops aspidephorus may be a third depending on whether the reidentification of "Trematopsis

1692 seltini" to the species level by Milner, 1985, can be substantiated). Therefore, it is possible that

1693 dissorophids did increase in size in the late stages of their evolution, perhaps correlated with the

1694 extirpation of trematopids and other large-bodied temnospondyls thought to be capable of

1695 terrestrial locomotion like edopoids and eryopoids (note that the degree of terrestriality remains

1696 contentious for many clades; e.g., Pawley \& Warren, 2006; Sanchez et al., 2010; Fortuny et al.,

1697 2011; Quemeneur et al., 2013; Carter et al., 2021). Whether increased dissorophid size would be

1698 a driver or a product of other clades' extinction is unclear.

1699 While Aspidosaurus binasser and Platyhystrix rugosa are traditionally recovered as the

1700 earliest diverging dissorophids (suggesting that large size could characterize most taxa, but that

1701 the majority are represented only by juveniles; Gee, 2020a), it is important to note the extremely

1702 poor Carboniferous record of dissorophids. Quite possibly, the true earliest diverging

1703 dissorophids remain to be discovered. A third hypothesis is that only certain clades of

1704 dissorophids achieved large sizes. It is conspicuous that no dissorophine, including the well-

1705 sampled Dissorophus multicinctus, exceeded a skull length of $13 \mathrm{~cm}$, while the other three

1706 subfamilies did. Size disparity among dissorophids could also relate to ecological differences

1707 from trematopids. In contrast to trematopids, for which there are only two localities in Europe

1708 (Nýřany, Bromacker) where multiple taxa co-occur, there are many localities where several

1709 dissorophids co-occur. Along with anatomical differences such as tooth count, skull proportions,

Peer] reviewing PDF | (2021:02:58550:3:0:NEW 7 Oct 2021) 
1710 and osteoderm morphology, size differences could also be predicted as an aspect of niche 1711 partitioning.

1712 The one analysis that I ran to assess whether ontogenetic disparity might confound

1713 dissorophid phylogeny (Analysis 4; Fig. 11) did not recover any clear signals of directional bias.

1714 No taxon sampled at the specimen level is recovered as a clade, but most specimens are simply

1715 single branches in a cacopine polytomy. Conjunctio multidens is the only taxon in which OTUs

1716 are recovered in different positions, and in this case, the large holotype diverges first. On one

1717 hand, this taxon's OTUs contradict one prediction of ontogenetic disparity (stemward slippage of

1718 smaller, more immature specimens due to a higher number of what present as "retained"

1719

1720

1721

1722

1723

1724

1725

1726

1727

1728

1729

1730

1731

1732

1733

1734

1735

1736

1737

1738

1739

1740 plesiomorphies). Conversely, in the context of olsoniforms, the early diverging position of the largest specimen may still indicate support for an influence of ontogenetic disparity, as the smallest specimens cluster away from the large trematopids. A lack of skeletal overlap seems to produce the pattern of Cacops woehri, in which the holotype (partial skull) and one referred specimen (BMRP 2007.3.5, partial posterior skull) cluster even though they belonged to disparately sized individuals. Specimens of Anakamacops petrolicus have essentially no skeletal overlap, and an ontogenetic range was not sampled for Cacops aspidephorus.

In short, there remain many unknowns and confounding factors that limit the study of size patterns in dissorophids. In an unpublished chapter of my dissertation (Gee, 2020a:388394), I suggested that niche partitioning between life stages of a given taxon could result in a skewed sample that biases interpretations of "adult" size. For example, numerous skulls of Cacops between 10 and $12 \mathrm{~cm}$ in length are known and have thus been dubbed "adults" under a presumption of relative maturity (e.g., Reisz, Schoch \& Anderson, 2009; Gee \& Reisz, 2018a). In fact, this size range does not come close to approximating the maximum size of Cacops, which could have been nearly double that size based on the single specimen of "Trematopsis seltini," estimated to $22 \mathrm{~cm}$ (= Cacops $\mathrm{cf}$. C. aspidephorus; Milner, 1985). Isolated postcranial remains from Richards Spur suggest that at least one of Cacops morrisi and Cacops woehri also reached a larger size than is reflected by the cranial remains (Sullivan, Reisz \& May, 2000; Gee, Bevitt \& Reisz, 2019; Gee, 2020a). Intraspecific niche partitioning has not been previously suggested in olsoniforms, but it offers one explanation for the skewed record of even wellsampled taxa like Cacops and for the size disparity between dissorophids if this partitioning extended to physical habitat occupancy. As with trematopids, size evolution in dissorophids remains a quandary that can likely only be resolved with additional collection, although a survey of existing collections might identify outlier datapoints (probably isolated postcrania or fragmentary cranial remains) that document larger body size than traditional proxies (e.g., complete skulls).

1746 Considerations in backbone selection. With increasing computational abilities, paleontologists can sample broad taxonomic swaths while maintaining appreciable in-group sampling of any given clade. Technological advances have also expanded the range of analyses that can be conducted, leading to a proliferation of "big data" studies addressing macroevolutionary questions on scales that were previously infeasible. Most of these studies are phylogenetically informed by an underlying backbone, the selection and design of which is obviously of great import but which is not always rationalized or explained in detail. This final section provides some preliminary comments on temnospondyl backbones in light of this study's findings.

The most widely utilized topology of Temnospondyli is the computer-assisted supertree

1755 of Ruta et al. (2007), which has been incorporated into numerous studies, usually in concert with 
1756 other tetrapod (super)trees to form a larger informal supertree (e.g., Fortuny et al., 2011; Soul \& 1757 Friedman, 2016; Dunne et al., 2018; Carter et al., 2021; Dickinson et al., 2021). It is noteworthy

1758 that this particular topology remains popular among non-taxonomic specialists, whereas

1759 temnospondyl workers tend to opt for a variety of alternative backbones. For example,

1760 Angielczyk \& Ruta (2012) manually modified the topology of Ruta et al. (2007); Witzmann

1761 (2013) and Witzmann \& Werneburg (2017) used the topology of Schoch's (2013) non-supertree

1762 analysis; Tarailo (2018) used Schoch (2013) as the large-scale backbone, with additions from

1763 Ruta et al. (2007) and Marsicano et al. (2017) for small-scale resolution; Witzmann \& Ruta

1764 (2018) and Pérez-Ben, Báez \& Schoch (2019) manually modified the topology of Schoch (2013);

1765 and Pardo et al. (2019) and Ruta et al. (2019) used the topology of Pardo, Small \& Huttenlocker

1766 (2017).

$1767 \quad$ Ruta et al.'s supertree may remain appealing in spite of its datedness because it is fully

1768 resolved and includes numerous wildcard taxa that are rarely sampled in other studies and that

1769 are highly unstable when they are sampled (e.g., Bashkirosaurus, Capetus, Collidosuchus,

1770 Kashmirosaurus, Lapillopsis, Lysipterygium, Palatinerpeton, Parioxys, Peltobatrachus,

1771 Sassenisaurus, Stegops). Of course, the fact that these taxa are excluded from analyses reflects

1772 the continued uncertainty over their placement, even in a phenetic framework, but this may only

1773 be well-known among taxonomic specialists. Some of these taxa are recovered in the proper

1774 clade in Ruta et al.'s supertree, but with uncertain relationships to other in-group taxa (e.g.,

1775 Collidosuchus), while others remain of uncertain placement in general (e.g., Lapillopsis). The

1776 latter are of greater concern because there is a higher likelihood that their positions in the Ruta et

1777 al. topology are spurious.

1778 In general, this topology, while consistent in broad strokes with more recent non-

1779

1780 supertree analyses (e.g., Schoch, 2013; Pardo, Small \& Huttenlocker, 2017; Eltink, Schoch \&

1781 Langer, 2019), differs markedly in some areas. Specifically for dissorophoids, branchiosaurids

1782 are accepted as nesting within the historical 'Amphibamidae' rather than as its sister group (e.g.,

1783

1784

1785 Schoch \& Milner, 2008; Fröbisch \& Schoch, 2009); micromelerpetids are a clade at the base of Dissorophoidea rather than a grade of early-diverging branchiosaurids (e.g., Schoch, 2018a); trematopids and dissorophids are sister taxa, not successively diverging branches within Dissorophoidea (e.g., Anderson et al., 2008b); Ecolsonia is a trematopid, not a dissorophid (Polley \& Reisz, 2011; Schoch, 2018a; Gee, 2020b; this study); and Parioxys is probably a dissorophid, not an eryopoid (Schoch \& Milner, 2014). The taxon sample is naturally outdated as well, but this manifests as what appears to be uneven sampling based on the present body of recognized taxa. Olsoniforms are among the undersampled clades, with only six nominal trematopids and five nominal dissorophids.

These points are not meant as a criticism of the original Ruta et al. study but rather evidence the predictable datedness after nearly two decades of anatomical and phylogenetic work. Nonetheless, it is clear that Ruta et al.'s supertree is no longer an accurate reflection of the consensus of temnospondyl relationships and should not be employed as such. Pardo et al. (2019) commented on potential issues of supertree construction and pseudoreplication, especially in light of newer non-supertree analyses performed by taxonomic specialists that challenge historical paradigms and that frequently contradict widely used, but more dated, supertrees. I endorse these authors' approach to informal supertree construction (p. 11 of their supplemental file) in which they collate non-supertree topologies recovered by studies whose primary aim was to assess the phylogenetic relationships of a clade and in which they allow taxa with unresolved relationships (or that have never been included in an analysis) to be placed in a polytomy. Such 
1802 an approach is preferable to enforcing resolution of dubious nature simply in order to achieve 1803 full resolution. I encourage non-specialists to consult with relevant phylogenetic / systematic 1804 experts with respect to the construction or selection of a backbone. Temnospondyli, like most 1805 other speciose clades, continues to be recovered with major areas of instability or weak support.

1806 This instability underscores the continued import not only of phylogenetic method refinement 1807 and analysis but also of the primary data collection (e.g., fieldwork, descriptive anatomy) that 1808 underpins the analysis.

1809

\section{Conclusions}

1811 Originally, I had intended to focus this study on expanding my character and taxon sample to 1812 broadly represent dissorophids, which I hoped would improve the resolution for trematopids as 1813 well. In the process of assessing explanators for topological differences, some of them

1814 substantial and often related more to differing degrees of resolution than to drastically different positions of taxa, this study shifted towards a focus on reproducibility and robusticity of previous topologies. This endeavor admittedly became much more exhaustive (and exhausting) than even I had anticipated, and like my trematopid analysis (Gee, 2020b), seems to have identified far more issues than it has resolved. In the end, this study has demonstrated that the phylogeny of Dissorophidae is not resolved, reproducible, or robust. Other key conclusions are outlined below:

1821

1822

1823

1824

1825

1826

1827

1828

1829

1830

1831

1832

1833

1834

1835

1. The widely propagated matrix of Schoch (2012) contains substantial scoring errors that appear to represent "assumed" scores; these scores are for characters where the entire feature is not even preserved, let alone sufficient to be assessed (e.g., postcrania of Cacops woehri). These are unequivocally unfounded and should be regarded as erroneous unless future studies prove otherwise. Almost all of these originated early in the propagation of this matrix and have thus been carried forward into essentially every dissorophid analysis. It is possible that either new material or simply better documentation of existing material might validate these assumptions, but at present, they have no reproducible basis. There are also numerous scores for taxa where a complete element is required to score a character, but none is available for a given taxon (e.g., characters related to skull length for "Broiliellus" olsoni). Given the extensive number of unequivocal errors, missing scores, and unfounded scores (Appendix 5), previous topologies should be treated skeptically, especially with respect to weakly supported nodes, as the corrected matrix recovers an overall less resolved topology.

2. The use of different programs and variable reporting of support metrics confounds proper comparisons between studies, but these are not the only factors that result in drastically different topologies from studies that are using largely identical character matrices. Persistent wildcards, character construction, and character scoring clearly exert strong influences as well, and a few changes to the matrix can result in drastic changes to the resultant topology. Workers should test for the effects of these phenomena (e.g., analyses with and without wildcard taxa and consensus trees with and without wildcard taxa) and clearly state and justify their preferred approaches.

3. The intrarelationships of both Dissorophidae and Trematopidae can be resolved through selective taxon sampling, but most in-group nodes fail to meet the thresholds to be considered as "well-supported" for at least one metric: Bremer decay index $(>2)$ or bootstrapping $(>50 \%)$. Support metrics are one means of comparing topologies produced 
1847

1848

1849

1850

1851

1852

1853

1854

1855

1856

1857

1858

1859

1860

1861

1862

1863

1864

1865

1866

1867

1868

1869

1870

1871

1872

1873

1874

1875

1876

1877

1878

1879

1880

1881

1882

1883

1884

1885

1886

1887

1888

1889

1890

1891

1892

by different studies, and topologies that are reported without support metrics or with weak support should be treated skeptically.

4. The only "consensus" relationships within Dissorophidae are the early-diverging position of Aspidosaurus binasser and Platyhystrix rugosa; a Cacopinae that includes Cacops and probably Anakamacops, Kamacops, and Zygosaurus; and a Dissorophinae that includes Broiliellus, Diploseira, and Dissorophus. While the interrelationships of cacopines can be further resolved with some confidence, those of dissorophines cannot at present. Any worker seeking a topology for a backbone in a quantitative analysis should place all other taxa in a polytomy either above or with As. binasser, rather than selecting one of the many different resolved topologies that lack strong support for most nodes.

\section{Acknowledgements}

I thank the many collections managers and curators who granted me access to their dissorophoid specimens, either first-hand or through loans to my doctoral advisor, Robert Reisz: Mark Norell and Carl Mehling (American Museum); Dave Berman and Amy Henrici (Carnegie Museum); Ken Angielczyk, Bill Simpson, and Adrienne Stroupe (Field Museum); Chris Beard and Dave Burnham (Kansas University Museum of Natural History); Rich Cifelli and Jennifer Larsen (Sam Noble Museum); and Pat Holroyd (University of California Museum of Paleontology). Thanks to Carl Mehling for assistance in trying to elucidate the history of the holotype of Platyhystrix rugosa. Jason Anderson (University of Calgary) also kindly allowed me to examine the material of Cacops aspidephorus on loan to him and transferred the loan of the material of "Fayella chickashaensis" and what is now Nooxobeia gracilis (and took me out to lunch) when I visited his lab in the fall of 2017. Thanks to Jason Anderson, Dave Berman, Adam Huttenlocker, Hillary Maddin, Arjan Mann, David Marjanović, and Jason Pardo for discussions. Thanks to Michel Laurin, David Marjanović, two anonymous reviewers, and the editor, John Hutchinson, for constructive feedback that greatly improved this manuscript. TNT is graciously provided freely by the Willi Hennig Society. My current postdoctoral fellowship, under which I conducted this study, is supported by NSF ANT-1947094 (to Chris Sidor).

\section{References}

[ICZN] International Commission on Zoological Nomenclature. 1999. International Code of Zoological Nomenclature. Fourth Edition. London: International Trust for Zoological Nomenclature. Openly accessible at: https://www.iczn.org/the-code/the-internationalcode-of-zoological-nomenclature/the-code-online/.

Agnolin F, de Souza Carvalho I, Rolando AMA, Novas FE, Xavier-Neto J, Andrade JAFG, Freitas FI. 2020. Early Cretaceous neobatrachian frog (Anura) from Brazil sheds light on the origin of modern anurans. Journal of South American Earth Sciences 101:102633. DOI: $10.1016 /$ j.jsames.2020.102633

Alfaro ME, Zoller S, Lutzoni F. 2003. Bayes or bootstrap? A simulation study comparing the performance of Bayesian Markov chain Monte Carlo sampling and bootstrapping in assessing phylogenetic confidence. Molecular Biology and Evolution 20:255-266. DOI: $10.1093 / \mathrm{molbev} / \mathrm{msg} 028$

Anderson JS, Henrici AC, Sumida SS, Martens T, Berman DS. 2008b. Georgenthalia clavinasica, a new genus and species of dissorophoid temnospondyl from the Early Permian of Germany, and the relationships of the family Amphibamidae. Journal of 
1893

1894

1895

1896

1897

1898

1899

1900

1901

1902

1903

1904

1905

1906

1907

1908

1909

1910

1911

1912

1913

1914

1915

1916

1917

1918

1919

1920

1921

1922

1923

1924

1925

1926

1927

1928

1929

1930

1931

1932

1933

1934

1935

1936

Vertebrate Paleontology 28:61-75. DOI: 10.1671/0272-

4634(2008)28[61:GCANGA]2.0.CO;2

Anderson JS, Reisz RR, Scott D, Fröbisch NB, Sumida SS. 2008a. A stem batrachian from the Early Permian of Texas and the origin of frogs and salamanders. Nature 453:515-518. DOI: $10.1038 /$ nature 06865

Anderson JS, Scott D, Reisz RR. 2020. The anatomy of the dermatocranium and mandible of Cacops aspidephorus Williston, 1910 (Temnospondyli: Dissorophidae), from the Lower Permian of Texas. Journal of Vertebrate Paleontology 40:e1776720. DOI: $10.1080 / 02724634.2020 .1776720$

Anderson JS. 2001. The phylogenetic trunk: maximal inclusion of taxa with missing data in an analysis of the Lepospondyli (Vertebrata, Tetrapoda). Systematic Biology 50:170-193. DOI: $10.1080 / 10635150119889$

Anderson JS. 2005. On the skull of Cacops aspidephorus Williston (Tetrapoda; Temnospondyli; Dissorophidae) from the Lower Permian of Texas. Part 1: lower jaw anatomy. New Mexico Museum of Natural History \& Science Bulletin 30:15.

Angielczyk KD, Ruta M. 2012. The roots of amphibian morphospace: a geometric morphometric analysis of Paleozoic temnospondyls. Fieldiana Life and Earth Sciences 2012:40-59. DOI: $10.3158 / 2158-5520-5.1 .40$

Atkins JB, Reisz RR, Maddin HC. 2019. Braincase simplification and the origin of lissamphibians. PLOS ONE 14:e0213694. DOI: 10.1371/journal.pone.0213694

Audo D, Barriel V, Charbonnier S. 2021. Phylogeny and evolutionary history of polychelidan lobsters. Journal of Systematic Palaeontology 19:417-439. DOI: 10.1080/14772019.2021.1918773

Balas E. 1965. An additive algorithm for solving linear programs with zero-one variables. Operations Research 13:517-546. DOI: 10.1287/opre.13.4.517

Benton MJ. 2012. No gap in the Middle Permian record of terrestrial vertebrates. Geology 40:339-342. DOI: $10.1130 / \mathrm{G} 32669.1$

Berman DS, Berman SL. 1975. Broiliellus hektotopos sp. nov. (Temnospondyli: Amphibia), Washington Formation, Dunkard Group. In: Barlow JA, Burkhammer S, eds. Proceedings of the First IC White Memorial Symposium, the Age of the Dunkard. Morgantown: West Virginia Geological and Economic Survey, 69-78.

Berman DS, Henrici AC, Brezinski DK, Kollar AD. 2010. A new trematopid amphibian (Temnospondyli: Dissorophoidea) from the Upper Pennsylvanian of western Pennsylvania: earliest record of terrestrial vertebrates responding to a warmer, drier climate. Annals of Carnegie Museum 78:289-319. DOI: 10.2992/007.078.0401

Berman DS, Henrici AC, Martens T, Sumida SS, Anderson JS. 2011. Rotaryus gothae, a new trematopid (Temnospondyli: Dissorophoidea) from the Lower Permian of Central Germany. Annals of Carnegie Museum 80:49-66. DOI: 10.2992/007.080.0106

Berman DS, Lucas SG. 2003. Aspidosaurus binasser (Amphibia, Temnospondyli), a new species of Dissorophidae from the Lower Permian of Texas. Annals of Carnegie Museum $72: 241-262$.

Berman DS, Reisz R, Eberth DA. 1985. Ecolsonia cutlerensis, an Early Permian dissorophid amphibian from the Cutler Formation of north-central New Mexico. New Mexico Bureau of Mines and Minerals Research Circular 191:1-31.

Peer] reviewing PDF | (2021:02:58550:3:0:NEW 7 Oct 2021) 
1937 Berman DS, Reisz RR, Eberth DA. 1987. A new genus and species of trematopid amphibian

1938

1939

1940

1941

1942

1943

1944

1945

1946

1947

1948

1949

1950

1951

1952

1953

1954

1955

1956

1957

1958

1959

1960

1961

1962

1963

1964

1965

1966

1967

1968

1969

1970

1971

1972

1973

1974

1975

1976

1977

1978

1979

1980

1981

1982 from the Late Pennsylvanian of north-central New Mexico. Journal of Vertebrate Paleontology 7:252-269. DOI: 10.1080/02724634.1987.10011659

Berman DS, Reisz RR, Fracasso, MA. 1981. Skull of the Lower Permian dissorophid amphibian Platyhystrix rugosus. Annals of Carnegie Museum 50:391-416.

Bolt JR, Lombard RE. 2001. The mandible of the primitive tetrapod Greererpeton, and the early evolution of the tetrapod lower jaw. Journal of Paleontology 75:1016-1042. DOI: 10.1666/0022-3360(2001)075<1016:TMOTPT>2.0.CO;2

Bolt JR. 1974a. Armor of dissorophids (Amphibia: Labyrinthodontia): an examination of its taxonomic use and report of a new occurrence. Journal of Paleontology, 48:135-142. DOI:

Bolt JR. 1974b. Evolution and functional interpretation of some suture patterns in Paleozoic labyrinthodont amphibians and other lower tetrapods. Journal of Paleontology 48:434458.

Brazeau MD. 2011. Problematic character coding methods in morphology and their effects. Biological Journal of the Linnean Society 104:489-498. DOI: 10.1111/j.10958312.2011.01755.x

Breu R, Burdet CA. 1974. Branch and bound experiments in zero-one programming. In Approaches to integer programming (pp. 1-50). Springer, Berlin, Heidelberg. DOI: 10.1007/BFb0120687

Brocklehurst N, Dunne EM, Cashmore DD, Fröbisch J. 2018. Physical and environmental drivers of Paleozoic tetrapod dispersal across Pangaea. Nature Communications 9:1-12.

Brocklehurst N. 2020. Olson's Gap or Olson's Extinction? A Bayesian tip-dating approach to resolving stratigraphic uncertainty. Proceedings of the Royal Society B 287:20200154. DOI: $10.1098 / \mathrm{rspb} .2020 .0154$

Broili F. 1904. Permische Stegocephalen und Reptilien aus Texas. Palaeontographica 46:61-84.

Campbell JA, Frost DR. 1993. Anguid lizards of the genus Abronia: revisionary notes, descriptions of four new species, a phylogenetic analysis, and key. Bulletin of the American Museum of Natural History 216:1-121.

Carroll RL. 1964a. Early evolution of the dissorophid amphibians. Bulletin of the Museum of Comparative Zoology 131:161-250.

Carroll RL. 1964b. The relationships of the rhachitomous amphibian Parioxys. American Museum Novitates 2167:1-11.

Carroll RL. 2007. The Palaeozoic ancestry of salamanders, frogs and caecilians. Zoological Journal of the Linnean Society 150:1-140. DOI: 10.1111/j.1096-3642.2007.00246.x

Carter AM, Hsieh ST, Dodson P, Sallan L. 2021. Early amphibians evolved distinct vertebrae for habitat invasions. PLOS ONE 16:e0251983. DOI: 10.1371/journal.pone.0251983

Case EC, Williston SW. 1913. A description of Aspidosaurus novomexicanus. Publications of the Carnegie Institution of Washington 181:7-9.

Case EC. 1910. New or little known reptiles and amphibians from the Permian (?) of Texas. Bulletin of the American Museum of Natural History 28:17.

Chakravorti S, Sengupta DP. 2018 (for 2019). Taxonomy, morphometry and morphospace of cranial bones of Panthasaurus gen. nov. maleriensis from the Late Triassic of India. Journal of Iberian Geology 45:317-340. DOI: 10.1007/s41513-018-0083-1

Cope ED. 1881. The Permian formation of New Mexico. American Naturalist 12:327-328. Cope ED. 1896a. The ancestry of the Testudinata. American Naturalist 30:398-400. 
1983 Cope ED. 1896b. Second contribution to the history of the Cotylosauria. Proceedings of the

1984 American Philosophical Society 35:122-139.

1985

1986

1987

1988

1989

1990

1991

1992

1993

1994

1995

1996

1997

1998

1999

2000

2001

2002

2003

2004

2005

2006

2007

2008

2009

2010

2011

2012

2013

2014

2015

2016

2017

Cummings MP, Handley SA, Myers DS, Reed DL, Rokas A, Winka K. 2003. Comparing bootstrap and posterior probability values in the four-taxon case. Systematic Biology 52:477-487. DOI: 10.1080/10635150390218213

Daly E. 1994. The Amphibamidae (Amphibia: Temnospondyli), with a description of a new genus from the Upper Pennsylvanian of Kansas, Miscellaneous Publication of the University of Kansas Museum of Natural History 85:1-59.

Davesne D, Gallut C, Barriel V, Janvier P, Lecointre G, Otero O. 2016. The phylogenetic intrarelationships of spiny-rayed fishes (Acanthomorpha, Teleostei, Actinopterygii): fossil taxa increase the congruence of morphology with molecular data. Frontiers in Ecology and Evolution 4:129. DOI: 10.3389/fevo.2016.00129

Davis RE, Kendrick DA, Weitzman M. 1971. A branch-and-bound algorithm for zero-one mixed integer programming problems. Operations Research 19:1036-1044. DOI: 10.1287/opre.19.4.1036

Daza JD, Stanley EL, Bolet A, Bauer AM, Arias JS, Čerňanský A, Bevitt JJ, Wagner P, Evans SE. 2020. Enigmatic amphibians in mid-Cretaceous amber were chameleon-like ballistic feeders. Science 370:687-691. DOI: 10.1126/science.abb6005

DeMar R. 1968. The Permian labyrinthodont amphibian Dissorophus multicinctus, and adaptations and phylogeny of the family Dissorophidae. Journal of Paleontology 42:1210-1242.

DeMar RE. 1966a. Longiscitula houghae, a new genus of dissorophid amphibian from the Permian of Texas. Fieldiana: Geology 16:45-53.

DeMar RE. 1966b. The functional and phylogenetic significance of the armor of dissorophid amphibians. Fieldiana: Geology 16:55-88.

DeMar RE. 1967. Two new species of Broiliellus (Amphibians) from the Permian of Texas. Fieldiana: Geology 16:117-129.

Dickson BV, Clack JA, Smithson TR, Pierce SE. 2021. Functional adaptive landscapes predict terrestrial capacity at the origin of limbs. Nature 589:242-245. DOI: 10.1038/s41586020-2974-5

Dilkes DW, Reisz R. 1987. Trematops milleri Williston, 1909, identified as a junior synonym of Acheloma cumminsi Cope, 1882: with a revision of the genus. American Museum Novitates 2902:1-12.

Dilkes DW. 2009. Comparison and biomechanical interpretations of the vertebrae and osteoderms of Cacops aspidephorus and Dissorophus multicinctus (Temnospondyli,

2018

2019

2020

2021

2022

2023

2024

2025

2026

2027

2028 Dissorophidae). Journal of Vertebrate Paleontology 29:1013-1021. DOI: $10.1671 / 039.029 .0410$

Dilkes DW. 2020. Revision of the Early Permian dissorophid 'Dissorophus' angustus (Temnospondyli: Dissorophoidea). Journal of Vertebrate Paleontology 40:e1801704. DOI: $10.1080 / 02724634.2020 .1801704$

Dilkes, D, Brown LE. 2007. Biomechanics of the vertebrae and associated osteoderms of the Early Permian amphibian Cacops aspidephorus. Journal of Zoology 271:396-407. DOI: 10.1111/j.1469-7998.2006.00221.x

Douady CJ, Delsuc F, Boucher Y, Doolittle WF, Douzery EJ. 2003. Comparison of Bayesian and maximum likelihood bootstrap measures of phylogenetic reliability. Molecular Biology and Evolution 20:248-254. DOI: 10.1093/molbev/msg042 
2029 Dunne EM, Close RA, Button DJ, Brocklehurst N, Cashmore DD, Lloyd GT, Butler RJ. 2018.

2030

2031

2032

2033

2034

2035

2036

2037

2038

2039

2040

2041

2042

2043

2044

2045

2046

2047

2048

2049

2050

2051

2052

2053

2054

2055

2056

2057

2058

2059

2060

2061

2062

2063

2064

2065

2066

2067

2068

2069

2070

2071

2072
Diversity change during the rise of tetrapods and the impact of the 'Carboniferous rainforest collapse'. Proceedings of the Royal Society B: Biological Sciences 285:20172730. DOI: 10.1098/rspb.2017.2730

Efremov IA. 1937. On the Permo-Triassic labyrinthodonts from USSR. IV. A note on the lost forms Zygosaurus Eichwald and Chalcosaurus von Meyer. Trudy Paleontologichesko Instituta Akademiyi Nauk SSSR 8:17-27. [in Russian]

Eichwald ED. 1848. Über die Saurier des kupferführenden Zechsteins Russlands. Bulletin de la Société Impériale des naturalistes de Moscou 21:136-204. [in German]

Eltink E, Da-Rosa ÁAS, Dias-da-Silva S. 2017. A capitosauroid from the Lower Triassic of South America (Sanga do Cabral Supersequence: Paraná Basin), its phylogenetic relationships and biostratigraphic implications. Historical Biology 29:863-874. DOI: 10.1080/08912963.2016.1255736

Eltink E, Dias EV, Dias-da-Silva S, Schultz CL, Langer MC. 2016. The cranial morphology of the temnospondyl Australerpeton cosgriffi (Tetrapoda: Stereospondyli) from the MiddleLate Permian of Paraná Basin and the phylogenetic relationships of Rhinesuchidae. Zoological Journal of the Linnean Society 176:835-860. DOI: 10.1111/zoj.12339

Eltink E, Schoch RR, Langer MC. 2019. Interrelationships, palaeobiogeography and early evolution of Stereospondylomorpha (Tetrapoda: Temnospondyli). Journal of Iberian Geology 45:251-267. DOI: 10.1007/s41513-019-00105-z

Erixon P, Svennblad B, Britton T, Oxelman B. 2003. Reliability of Bayesian posterior probabilities and bootstrap frequencies in phylogenetics. Systematic Biology 52:665-673. DOI: $10.1080 / 10635150390235485$

Ezcurra MD, Scheyer TM, Butler RJ. 2014. The origin and early evolution of Sauria: reassessing the Permian saurian fossil record and the timing of the crocodile-lizard divergence. PLOS ONE 9:e89165. DOI: 10.1371/journal.pone.0089165

Ford DP, Benson RB. 2020. The phylogeny of early amniotes and the affinities of Parareptilia and Varanopidae. Nature Ecology \& Evolution 4:57-65. DOI: 10.1038/s41559-0191047-3

Fortuny J, Marcé-Nogué J, de Esteban-Trivigno S, Gil L, Galobart À. 2011. Temnospondyli bite club: ecomorphological patterns of the most diverse group of early tetrapods. Journal of Evolutionary Biology 24:2040-2054. DOI: 10.1111/j.1420-9101.2011.02338.x

Fröbisch NB, Brar A, Reisz RR. 2015. New specimen of Cacops woehri indicates differences in the ontogenetic trajectories among cacopine dissorophids. Fossil Record 18:73-80. DOI: $10.5194 / \mathrm{fr}-18-73-2015$

Fröbisch NB, Reisz RR. 2008. A new Lower Permian amphibamid (Dissorophoidea, Temnospondyli) from the fissure fill deposits near Richards Spur, Oklahoma. Journal of Vertebrate Paleontology 28:1015-1030. DOI: 10.1671/0272-4634-28.4.1015

Fröbisch NB, Reisz RR. 2012. A new species of dissorophid (Cacops woehri) from the Lower Permian Dolese quarry, near Richards Spur, Oklahoma. Journal of Vertebrate Paleontology 32:35-44. DOI: 10.1080/02724634.2012.633586

Fröbisch NB, Schoch RR. 2009. Testing the impact of miniaturization on phylogeny: Paleozoic dissorophoid amphibians. Systematic Biology 58:312-327. DOI: 10.1093/sysbio/syp029 
2073

2074

2075

2076

2077

2078

2079

2080

2081

2082

2083

2084

2085

2086

2087

2088

2089

2090

2091

2092

2093

2094

2095

2096

2097

2098

2099

2100

2101

2102

2103

2104

2105

2106

2107

2108

2109

2110

2111

2112

2113

2114

2115

2116

2117

2118

Garbin RC, Ascarrunz E, Joyce WG. 2018. Polymorphic characters in the reconstruction of the phylogeny of geoemydid turtles. Zoological Journal of the Linnean Society 184:896-918. DOI: 10.1093/zoolinnean/zlx106

Gee BM, Berman DS, Henrici AC, Pardo JD, Huttenlocker AK. 2021. New information on the dissorophid Conjunctio (Temnospondyli) based on a specimen from the Cutler Formation of Colorado, U.S.A. Journal of Vertebrate Paleontology 40:e1877152. DOI:

$10.1080 / 02724634.2020 .1877152$

Gee BM, Bevitt JJ, Reisz RR. 2019. Dissorophid diversity at the early Permian cave system near Richards Spur, Oklahoma. Palaeontologica Electronica 22.2.46A:1-32. DOI: $10.26879 / 976$

Gee BM, Reisz RR. 2018a. Cranial and postcranial anatomy of Cacops morrisi, a eucacopine dissorophid from the early Permian of Oklahoma. Journal of Vertebrate Paleontology 38:e1433186. DOI: 10.1080/02724634.2018.1433186

Gee BM, Reisz RR. 2018b. Postcrania of large dissorophid temnospondyls from Richards Spur, Oklahoma. Fossil Record 21:79-91. DOI: 10.5194/fr-21-79-2018

Gee BM, Reisz RR. 2019 (for 2020). The amphibamiform Nanobamus macrorhinus from the early Permian of Texas. Journal of Paleontology 94:366-377. DOI: 10.1017/jpa.2019.72

Gee BM, Scott D, Reisz RR. 2018. Reappraisal of the Permian dissorophid Fayella chickashaensis. Canadian Journal of Earth Sciences 55:1103-1114. DOI: 10.1139/cjes2018-0053

Gee BM. 2018. Reappraisal of the early Permian dissorophid Alegeinosaurus from Texas, USA. Paläontologische Zeitschrift 92:661-669. DOI: 10.1007/s12542-018-0421-9

Gee BM. 2020a. Ecology, ontogeny, and taxonomy of the diverse early Permian dissorophoid assemblage from Richards Spur, Oklahoma. D. Phil. Thesis, University of Toronto. Available at: https://search.proquest.com/dissertations-theses/ecology-ontogenytaxonomy-diverse-early-permian/docview/2467471016/se-2?accountid $=14784$

Gee BM. 2020b. Size matters: the effects of ontogenetic disparity on the phylogeny of Trematopidae (Amphibia: Temnospondyli). Zoological Journal of the Linnean Society, 190:79-113. DOI: 10.1093/zoolinnean/zlz170

Geoffrion AM. 1969. An improved implicit enumeration approach for integer programming. Operations Research 17:437-454. DOI: 10.1287/opre.17.3.437

Godfrey SJ. 1989a. Ontogenetic changes in the skull of the Carboniferous tetrapod Greererpeton burkemorani Romer, 1969. Philosophical Transactions of the Royal Society of London. B, Biological Sciences 323:135-153. DOI: 10.1098/rstb.1989.0003

Godfrey SJ. 1989b. The postcranial skeletal anatomy of the Carboniferous tetrapod Greererpeton burkemorani Romer, 1969. Philosophical Transactions of the Royal Society of London. B, Biological Sciences 323:75-133. DOI: 10.1098/rstb.1989.0002

Goloboff PA, Farris JS, Källersjö M, Oxelman B, Ramírez MJ, Szumik CA. 2003. Improvements to resampling measures of group support. Cladistics 19:324-332. DOI: 10.1111/j.10960031.2003.tb00376.x

Goloboff PA, Catalano SA. 2016. TNT version 1.5, including a full implementation of phylogenetic morphometrics. Cladistics 32:221-238. DOI: 10.1111/cla.12160

Goloboff PA, Catalano SA, Torres A. 2021. Parsimony analysis of phylogenomic datasets (II): evaluation of PAUP*, MEGA and MPBoot. Cladistics. DOI: 10.1111/cla.12476

Golubev VK. 1998a. Narrow-armored chroniosuchians (Amphibia, Anthracosauromorpha) from the late Permian of Eastern Europe. Paleontologicheskii Zhurnal 32:278-287.

Peer) reviewing PDF | (2021:02:58550:3:0:NEW 7 Oct 2021) 
2119 Golubev VK. 1998b. Revision of the Late Permian chroniosuchians (Amphibia,

2120 Anthracosauromorpha) from Eastern Europe. Paleontologicheskii Zhurnal 32:390-401.

2121

2122

2123

2124

2125

2126

2127

2128

2129

2130

2131

2132

2133

2134

2135

2136

2137

2138

2139

2140

2141

2142

2143

2144

2145

2146

2147

2148

2149

2150

2151

2152

2153

2154

2155

2156

2157

2158

2159

2160

2161

2162

Golubev VK. 1999. A new narrow-armored chroniosuchian (Amphibia, Anthracosauromorpha) from the Upper Permian of Eastern Europe. Paleontologicheskii Zhurnal 33:166-173.

Grand A, Corvez A, Duque Velez LM, Laurin M. 2013. Phylogenetic inference using discrete characters: performance of ordered and unordered parsimony and of three-item statements. Biological Journal of the Linnean Society 100:914-930. DOI: 10.1111/bij.12159

Gubin YM. 1980. [New Permian dissorophids of the Ural forelands]. Paleontologicheskii Zhurnal 1980:82-90. [in Russian]

Gubin YM. 1987. [On the systematic position and age of some labyrinthodonts from the Upper Permian deposits of the region west of the Urals]. Paleontologicheskii Zhurnal 1987:9499. [in Russian]

Guillerme T, Cooper N. 2016. Effects of missing data on topological inference using a total evidence approach. Molecular Phylogenetics and Evolution 94:146-158. DOI: 10.1016/j.ympev.2015.08.023

Han J, Hu S, Cartwright P, Zhao F, Ou Q, Kubota S, Wang X, Yang X. 2016. The earliest pelagic jellyfish with rhopalia from Cambrian Chengjiang Lagerstätte. Palaeogeography, Palaeoclimatology, Palaeoecology 449:166-173. DOI: 10.1016/j.palaeo.2016.02.025

Holmes R, Berman DS, Anderson JS, 2013. A new dissorophid (Temnospondyli, Dissorophoidea) from the Early Permian of New Mexico (United States). Comptes Rendus Palevol 12:419-435. DOI: 10.1016/j.crpv.2013.07.002

Hook RW. 1989. Stratigraphic distribution of tetrapods in the Bowie and Wichita Groups, Permo-Carboniferous of north-central Texas. In: Hook RW, ed. Permo-Carboniferous vertebrate paleontology, lithostratigraphy and depositional environments of northcentral Texas. Austin: Society of Vertebrate Paleontology, 47-53.

Jiang, S., JI, S.A. and Mo, J., 2017. First record of bystrowianid chroniosuchians (Amphibia: Anthracosauromorpha) from the Middle Permian of China. Acta Geologica Sinica-English Edition, 91(5), pp.1523-1529. DOI: 10.1111/1755-6724.13397

Kearney M, Clark, JM. 2003. Problems due to missing data in phylogenetic analyses including fossils: a critical review. Journal of Vertebrate Paleontology 23:263-274. DOI: 10.1671/0272-4634(2003)023[0263:PDTMDI]2.0.CO;2

Kornet DJ, Turner H. 1999. Coding polymorphism for phylogeny reconstruction. Systematic Biology 48:365-379. DOI: 10.1080/106351599260346

Kurochkin EN, Zelenkov NV, Averianov AO, Leshchinskiy SV. 2011. A new taxon of birds (Aves) from the Early Cretaceous of Western Siberia, Russia. Journal of Systematic Palaeontology 9:109-117. DOI: 10.1080/14772019.2010.522202

Langston W. 1953. Permian amphibians from New Mexico. University of California Publications in Geological Sciences 29:349-416.

Laurin M, Reisz RR. 1997. A new perspective on tetrapod phylogeny. In: Sumida S, Martin K, eds. Amniote origins - completing the transition to land. London: Academic Press, 9-59.

Laurin M, Piñeiro G. 2018. Response: commentary: a reassessment of the taxonomic position of mesosaurs, and a surprising phylogeny of early amniotes. Frontiers in Earth Science 6:220. DOI: $10.3389 /$ feart.2018.00220 
2163 Lee MS, Anderson JS. 2006. Molecular clocks and the origin (s) of modern

2164

2165

2166

2167

2168

2169

2170

2171

2172

2173

2174

2175

2176

2177

2178

2179

2180

2181

2182

2183

2184

2185

2186

2187

2188

2189

2190

2191

2192

2193

2194

2195

2196

2197

2198

2199

2200

2201

2202

2203

2204

2205

2206

2207

2208 amphibians. Molecular Phylogenetics and Evolution 40:635-639. DOI: 10.1016/j.ympev.2006.03.013

Lewis GE, Vaughn PP. 1965. Early Permian vertebrates from the Cutler Formation of the Placerville area, Colorado, with a section on footprints from the Cutler Formation. U.S. Geological Survey Professional Paper 503:1-50.

Li J-L, Cheng Z-W. 1999. New anthracosaur and temnospondyl amphibians from Gansu, China - the fifth report on Late Permian Dashankou lower tetrapod fauna. Vertebrata PalAsiatica 37:234-247.

Liu J, Abdala F. 2017. Therocephalian (Therapsida) and chroniosuchian (Reptiliomorpha) from the Permo-Triassic transitional Guodikeng Formation of the Dalongkou Section, Jimsar, Xinjiang, China. Vertebrata PalAsiatica 55:24-40.

Liu J. 2016. Yuanansuchus maopingchangensis sp. nov., the second capitosauroid temnospondyl from the Middle Triassic Badong Formation of Yuanan, Hubei, China. PeerJ 4:e1903. DOI: $10.7717 /$ peerj.1903

Liu J. 2018. Osteology of the large dissorophid temnospondyl Anakamacops petrolicus from the Guadalupian Dashankou Fauna of China. Journal of Vertebrate Paleontology: 38:e1513407. DOI: 10.1080/02724634.2018.1513407

Liu J. 2020. New chroniosuchian materials from Xinjiang, China. Vertebrata PalAsiatica 58:283-292.

Lozovsky VR. 2005. Olson's gap or Olson's bridge, that is the question. New Mexico Museum of Natural History and Science Bulletin 30:179-184.

Lucas SG. 2001. A global hiatus in the Middle Permian tetrapod fossil record. Permophiles $38: 24-27$.

Lucas SG. 2002. Discussion and reply: The reptile Macroleter: First vertebrate evidence for correlation of Upper Permian continental strata of North America and Russia Discussion. Geological Society of America Bulletin 114:1174-1175. DOI: 10.1130/00167606(2002)114<1174:DARTRM>2.0.CO;2

Lucas SG. 2005. Olson's gap or Olson's bridge: an answer. New Mexico Museum of Natural History and Science Bulletin, 30:185-186.

Lucas SG. 2013. No gap in the Middle Permian record of terrestrial vertebrates: Comment. Geology 41:e293. DOI: 10.1130/G33734C.1

Mabee PM, Humphries J. 1993. Coding polymorphic data: Examples from allozymes and ontogeny. Systematic Biology 42:166-181. DOI: 10.1093/sysbio/42.2.166

Maddin HC, Fröbisch NB, Evans DC, Milner AR. 2013. Reappraisal of the Early Permian amphibamid Tersomius texensis and some referred material. Comptes Rendus Palevol 12:447-461. DOI: 10.1016/j.crpv.2013.06.007

Maddison WP, Maddison DR. 2020. Mesquite: a modular system for evolutionary analysis version 3.69. Available at: http://www.mesquiteproject.org

Marjanović D, Laurin M. 2019. Phylogeny of Paleozoic limbed vertebrates reassessed through revision and expansion of the largest published relevant data matrix. PeerJ 6:e5565. DOI: 10.7717/peerj.5565

Marsh AD, Parker WG, Langer MC, Nesbitt SJ. 2019. Redescription of the holotype specimen of Chindesaurus bryansmalli Long and Murry, 1995 (Dinosauria, Theropoda), from Petrified Forest National Park, Arizona. Journal of Vertebrate Paleontology 39:e1645682. DOI: 10.1080/02724634.2019.1645682 
2209

2210

2211

2212

2213

2214

2215

2216

2217

2218

2219

2220

2221

2222

2223

2224

2225

2226

2227

2228

2229

2230

2231

2232

2233

2234

2235

2236

2237

2238

2239

2240

2241

2242

2243

2244

2245

2246

2247

2248

2249

2250

2251

2252

2253

2254

Marsicano CA, Latimer E, Rubidge B, Smith RM. 2017. The Rhinesuchidae and early history of the Stereospondyli (Amphibia: Temnospondyli) at the end of the Palaeozoic. Zoological Journal of the Linnean Society 181:357-384. DOI: 10.1093/zoolinnean/zlw032

Marzola M, Mateus O. Shubin NH, Clemmensen LB. 2017. Cyclotosaurus naraserluki, sp. nov., a new Late Triassic cyclotosaurid (Amphibia, Temnospondyli) from the Fleming Fjord Formation of the Jameson Land Basin (East Greenland). Journal of Vertebrate Paleontology 37:e1303501. DOI: 10.1080/02724634.2017.1303501

May W, Huttenlocker AK, Pardo JD, Benca J, Small BJ. 2011. New Upper Pennsylvanian armored dissorophid records (Temnospondyli, Dissorophoidea) from the US midcontinent and the stratigraphic distributions of dissorophids. Journal of Vertebrate Paleontology 31:907-912. DOI: 10.1080/02724634.2011.582532

McGowan GJ. 2002. Albanerpetontid amphibians from the Lower Cretaceous of Spain and Italy: a description and reconsideration of their systematics. Zoological Journal of the Linnean Society 135:1-32. DOI: 10.1046/j.1096-3642.2002.00013.x

Milner AR, Schoch RR. 2013. Trimerorhachis (Amphibia: Temnospondyli) from the Lower Permian of Texas and New Mexico: cranial osteology, taxonomy and biostratigraphy. Neues Jahrbuch für Geologie und PaläontologieAbhandlungen 270:91-128. DOI: 10.1127/0077-7749/2013/0360

Milner AR. 1985. On the identity of Trematopsis seltini (Amphibia: Temnospondyli) from the Lower Permian of Texas. Neues Jahrbuch für Geologie und Paläontologie - Monatshefte 1985:357-367. DOI: 10.1127/njgpm/1985/1985/357

Milner AR. 2003. Longiscitula houghae DeMar, 1966 (Amphibia: Temnospondyli), a junior synonym of Dissorophus multicinctus Cope, 1895. Journal of Vertebrate Paleontology 23:941-944. DOI: 10.1671/18

Milner AR. 2018 (for 2019). Two primitive trematopid amphibians (Temnospondyli, Dissorophoidea) from the Upper Carboniferous of the Czech Republic. Earth and Environmental Science Transactions of the Royal Society of Edinburgh 109:201-223. DOI: $10.1017 / \mathrm{S} 1755691018000725$

Moustafa YS. 1952. Amphibian mass death in the Permian. Institute d'Egypt Bulletin 33:301304.

Moustafa YS. 1955a. The affinities of Parioxys ferricolus and the phylogeny of the 'eryopsoid'amphibians. Bulletin de l'Institut d'Egypte 36:77-104.

Moustafa YS. 1955b. The skeletal structure of Parioxys ferricolus, Cope. Bulletin de l'Institut d'Egypte 36:41-76.

Nesbitt SJ, Ezcurra MD. 2015. The early fossil record of dinosaurs in North America: a new neotheropod from the base of the Upper Triassic Dockum Group of Texas. Acta Palaeontologica Polonica 60:.513-526. DOI: 10.4202/app.00143.2014

Noble GK. 1931. The biology of the Amphibia. New York: McGraw-Hill Book Company.

Olroyd SL, Sidor CA. 2017. A review of the Guadalupian (middle Permian) global tetrapod fossil record. Earth-Science Reviews 171:583-597. DOI: 10.1016/j.earscirev.2017.07.001

Olson EC. 1941. The family Trematopsidae. The Journal of Geology 49:149-176. DOI: $10.1086 / 624952$

Olson EC. 1972. Fayella chickashaensis, the Dissorophoidea and the Permian terrestrial radiations. Journal of Paleontology 46:104-114.

Pacheco CP, Eltink E, Müller RT, Dias-da-Silva S. 2017. A new Permian temnospondyl with Russian affinities from South America, the new family Konzhukoviidae, and the

PeerJ reviewing PDF | (2021:02:58550:3:0:NEW 7 Oct 2021) 
2255

2256

2257

2258

2259

2260

2261

2262

2263

2264

2265

2266

2267

2268

2269

2270

2271

2272

2273

2274

2275

2276

2277

2278

2279

2280

2281

2282

2283

2284

2285

2286

2287

2288

2289

2290

2291

2292

2293

2294

2295

2296

2297

2298

2299

phylogenetic status of Archegosauroidea. Journal of Systematic Palaeontology 15:241256. DOI: $10.1080 / 14772019.2016 .1164763$

Pardo JD, Small BJ, Huttenlocker AK. 2017. Stem caecilian from the Triassic of Colorado sheds light on the origins of Lissamphibia. Proceedings of the National Academy of Sciences of the United States of America 114:E5389-E5395. DOI: 10.1073/pnas.1706752114

Pardo JD, Small BJ, Milner AR, Huttenlocker AK. 2019. Carboniferous-Permian climate change constrained early land vertebrate radiations. Nature Ecology \& Evolution 3:200-206. DOI: $10.1038 / \mathrm{s} 41559-018-0776-\mathrm{z}$

Pawley K, Warren A. 2006. The appendicular skeleton of Eryops megacephalus (Temnospondyli: Eryopoidea) from the lower Permian of North America. Journal of Paleontology 80:561-580. DOI: 10.1666/0022-3360(2006)80[561:TASOEM]2.0.CO;2

Pérez-Ben CM, Báez AM, Schoch RR. 2019 (for 2020). Morphological evolution of the skull roof in temnospondyl amphibians mirrors conservative ontogenetic patterns. Zoological Journal of the Linnean Society 188:163-179. DOI: 10.1093/zoolinnean/zlz068

Pérez-Ben CM, Schoch RR, Báez AM. 2018. Miniaturization and morphological evolution in Paleozoic relatives of living amphibians: a quantitative approach. Paleobiology 44:58 75. DOI: $10.1017 / \mathrm{pab} .2017 .22$

Polley BP, Reisz RR. 2011. A new Lower Permian trematopid (Temnospondyli: Dissorophoidea) from Richards Spur, Oklahoma. Zoological Journal of the Linnean Society 16:789-815. DOI: $10.1111 / j .1096-3642.2010 .00668 . x$

Prevosti FJ, Chemisquy MA. 2010. The impact of missing data on real morphological phylogenies: influence of the number and distribution of missing entries. Cladistics 26:326-339. DOI: $10.1111 /$ j.1096-0031.2009.00289.x

Pyron RA. 2011. Divergence time estimation using fossils as terminal taxa and the origins of Lissamphibia. Systematic Biology 60:466-481. DOI: 10.1093/sysbio/syr047

Quemeneur S, de Buffrenil V, Laurin M. 2013. Microanatomy of the amniote femur and inference of lifestyle in limbed vertebrates. Biological Journal of the Linnean Society 109:644-655. DOI: 10.1111/bij.12066

Reisz RR, Laurin M. 2001. The reptile Macroleter: First vertebrate evidence for correlation of Upper Permian continental strata of North America and Russia. Geological Society of America Bulletin 113:1229-1233. DOI: 10.1130/00167606(2001)113<1229:TRMFVE>2.0.CO;2

Reisz RR, Laurin M. 2002. Reply. Geological Society of America Bulletin 114:1176-1177. DOI: 10.1130/0016-7606(2002) $114<1176: \mathrm{R}>2.0 . \mathrm{CO} ; 2$

Reisz RR, Schoch RR, Anderson JS. 2009. The armoured dissorophid Cacops from the Early Permian of Oklahoma and the exploitation of the terrestrial realm by amphibians. Naturwissenschaften 96:789. DOI: 10.1007/s00114-009-0533-x

Rineau V, Grand A, Zaragüeta R, Laurin M. 2015. Experimental systematics: sensitivity of cladistic methods to polarization and character ordering schemes. Contributions to Zoology 8:129--148. DOI: 10.1163/18759866-08402003

Rineau V, Zaragüeta i Bagils RZ, Laurin M. 2018. Impact of errors on cladistic inference: simulation-based comparison between parsimony and three-taxon analysis. Contributions to Zoology 87:25-40. DOI: 10.1163/18759866-08701003

Romer AS. 1928. Vertebrate faunal horizons in the Texas Permo-Carboniferous red beds. The University of Texas Bulletin 2801:67-108.

Peer] reviewing PDF | (2021:02:58550:3:0:NEW 7 Oct 2021) 
2300 Romer AS. 1935. Early history of Texas redbeds vertebrates. Bulletin of the Geological Society

2301

2302

2303

2304

2305

2306

2307

2308

2309

2310

2311

2312

2313

2314

2315

2316

2317

2318

2319

2320

2321

2322

2323

2324

2325

2326

2327

2328

2329

2330

2331

2332

2333

2334

2335

2336

2337

2338

2339

2340

2341

2342

2343

2344 of America 46:1597-1657. DOI: 10.1130/GSAB-46-1597

Romer AS. 1952. Fossil vertebrates of the Tri-State area. 2. Late Pennsylvanian and early Permian vertebrates of the Pittsburgh-West Virginia region. Annals of Carnegie Museum 33:47-112.

Ruta M, Bolt JR. 2006. A reassessment of the temnospondyl amphibian Perryella olsoni from the Lower Permian of Oklahoma. Earth and Environmental Science Transactions of The Royal Society of Edinburgh 97:113-165. DOI: 10.1017/S0263593300001437

Ruta M, Coates MI, Quicke DL. 2003. Early tetrapod relationships revisited. Biological Reviews 78:251-345. DOI: 10.1017/S1464793102006103

Ruta M, Coates MI. 2007. Dates, nodes and character conflict: addressing the lissamphibian origin problem. Journal of Systematic Palaeontology 5:69-122. DOI: $10.1017 /$ S 1477201906002008

Ruta M, Krieger J, Angieczyk KD, Wiils MA. 2019. The evolution of the tetrapod humerus: Morphometrics, disparity, and evolutionary rates. Earth and Environmental Science Transactions of the Royal Society of Edinburgh 109:351-369. DOI: 10.1017/S1755691018000749

Ruta M, Pisani D, Lloyd GT, Benton MJ. 2007. A supertree of Temnospondyli: cladogenetic patterns in the most species-rich group of early tetrapods. Proceedings of the Royal Society B: Biological Sciences 274:3087-3095. DOI: 10.1098/rspb.2007.1250

Sanchez S, Germain D, de Ricqlès AD, Abourachid A, Goussard F, Tafforeau P. 2010. Limb-bone histology of temnospondyls: implications for understanding the diversification of palaeoecologies and patterns of locomotion of Permo-Triassic tetrapods. Journal of Evolutionary Biology 23:2076-2090. DOI: 10.1111/j.14209101.2010.02081.x

Sanderson MJ. 1995. Objections to bootstrapping phylogenies: a critique. Systematic Biology 44:299-320. DOI: 10.1093/sysbio/44.3.299

Scheyer TM, Spiekman SN, Sues H-D, Ezcurra MD, Butler RJ, Jones ME. 2020. Colobops: a juvenile rhynchocephalian reptile (Lepidosauromorpha), not a diminutive archosauromorph with an unusually strong bite. Royal Society Open Science 7:192179. DOI: $10.1098 /$ rsos.192179

Schoch RR, Henrici AC, Hook RW. 2020. A new dissorophoid temnospondyl from the Allegheny Group (late Carboniferous) of Five Points, Mahoning County, Ohio (USA). Journal of Paleontology 1-14 (FirstView). DOI: 10.1017/jpa.2020.101

Schoch RR, Milner AR. 2008. The intrarelationships and evolutionary history of the temnospondyl family Branchiosauridae. Journal of Systematic Palaeontology 6:409-431. DOI: $10.1017 / \mathrm{S} 1477201908002460$

Schoch RR, Milner AR. 2014. Handbook of Paleoherpetology Part 3A2. Temnospondyli I. München: Verlag Dr. Friedrich Pfeil.

Schoch RR, Milner AR. 2021. Morphology and relationships of the temnospondyl Macrerpeton huxleyi from the Pennsylvanian of Linton, Ohio (USA). Neues Jahrbuch für Geologie und Paläontologie - Abhandlungen 299:77-98. DOI: 10.1127/njgpa/2021/0956

Schoch RR, Rubidge BS. 2005. The amphibamid Micropholis from the Lystrosaurus assemblage zone of South Africa. Journal of Vertebrate Paleontology 25:502-522. DOI: 10.1671/0272-4634(2005)025[0502:TAMFTL]2.0.CO;2 
2345 Schoch RR, Sues H-D. 2013. A new dissorophid temnospondyl from the Lower Permian of

2346

2347

2348

2349

2350

2351

2352

2353

2354

2355

2356

2357

2358

2359

2360

2361

2362

2363

2364

2365

2366

2367

2368

2369

2370

2371

2372

2373

2374

2375

2376

2377

2378

2379

2380

2381

2382

2383

2384

2385

2386

2387

2388

2389 north-central Texas. Comptes Rendus Palevol 12:437-445. DOI:

10.1016/j.crpv.2013.04.002

Schoch RR, Voigt S. 2019. A dvinosaurian temnospondyl from the Carboniferous-Permian boundary of Germany sheds light on dvinosaurian phylogeny and distribution. Journal of Vertebrate Paleontology 39:e1577874. DOI: 10.1080/02724634.2019.1577874

Schoch RR, Werneburg R, Voigt S. 2020. A Triassic stem-salamander from Kyrgyzstan and the origin of salamanders. Proceedings of the National Academy of Sciences of the United States of America 117:11584-11588. DOI: 10.1073/pnas.2001424117

Schoch RR, Witzmann F, 2018. Morphology of the Late Carboniferous temnospondyl Limnogyrinus elegans, and the evolutionary history of the Micromelerpetidae. Neues Jahrbuch für Geologie und Paläontologie - Abhandlungen 289:293-310. DOI: 10.1127/njgpa/2018/0762

Schoch RR. 1999. Studies on braincases of early tetrapods: structure, morphological diversity, and phylogeny - 2. Dissorophoids, eryopids, and stereospondyls. Neues Jahrbuch für Geologie und Paläontologie - Abhandlungen 213:289-312. DOI: $10.1127 / \mathrm{njgpa} / 213 / 1999 / 289$

Schoch RR. 2012. Character distribution and phylogeny of the dissorophid temnospondyls. Fossil Record 15:121-137. DOI: 10.1002/mmng.201200010

Schoch RR. 2013. The evolution of major temnospondyl clades: an inclusive phylogenetic analysis. Journal of Systematic Palaeontology 11:73-705. DOI: $10.1080 / 14772019.2012 .699006$

Schoch RR. 2018a (for 2019). The putative lissamphibian stem-group: phylogeny and evolution of the dissorophoid temnospondyls. Journal of Paleontology 93:137-156. DOI: 10.1017/jpa.2018.67

Schoch RR. 2018b. The temnospondyl Parotosuchus nasutus (v. Meyer, 1858) from the Early Triassic Middle Buntsandstein of Germany. Palaeodiversity 11:107-126. DOI: 10.18476/pale.11.a6

Schoch RR. 2019. Osteology of the temnospondyl Trematosaurus brauni Burmeister, 1849 from the Middle Buntsandstein of Bernburg, Germany. Palaeodiversity 12:41-63. DOI: 10.18476/pale.v12.a4

Schultz CL, Langer MC, Montefeltro FC. 2016. A new rhynchosaur from south Brazil (Santa Maria Formation) and rhynchosaur diversity patterns across the Middle-Late Triassic boundary. PalZ 90:593-609. DOI: 10.1007/s12542-016-0307-7

Sereno PC. 2007. Logical basis for morphological characters in phylogenetics. Cladistics 23:565-587. DOI: $10.1111 / \mathrm{j} .1096-0031.2007 .00161 . x$

Sigurdsen T, Green DM. 2011. The origin of modern amphibians: a re-evaluation. Zoological Journal of the Linnean Society 162:457-469. DOI: 10.1111/j.1096-3642.2010.00683.x

Simmons MP, Pickett KM, Miya M. 2004. How meaningful are Bayesian support values?. Molecular Biology and Evolution 21:188-199. DOI: 10.1093/molbev/msh014

Simões TR, Caldwell MW, Palci A, Nydam RL. 2017. Giant taxon-character matrices: quality of character constructions remains critical regardless of size. Cladistics 33:198-219. DOI: $10.1111 /$ cla. 12163

Slowinski JB. 1993. "Unordered” versus “ordered” characters. Systematic Biology 42:155-165. DOI: $10.1093 / \mathrm{sysbio} / 42.2 .155$. 
2390

2391

2392

2393

2394

2395

2396

2397

2398

2399

2400

2401

2402

2403

2404

2405

2406

2407

2408

2409

2410

2411

2412

2413

2414

2415

2416

2417

2418

2419

2420

2421

2422

2423

2424

2425

2426

2427

2428

2429

2430

2431

2432

2433

Smithson TR. 1982. The cranial morphology of Greererpeton burkemorani Romer (Amphibia: Temnospondyli). Zoological Journal of the Linnean Society 76:29-90. DOI: 10.1111/j.1096-3642.1982.tb01955.x

Spaulding M, O'Leary MA, Gatesy J. 2009. Relationships of Cetacea (Artiodactyla) among mammals: increased taxon sampling alters interpretations of key fossils and character evolution. PLOS ONE 4:e7062. DOI: 10.1371/journal.pone.0007062

Soul LC, Friedman M. 2017. Bias in phylogenetic measurements of extinction and a case study of end-Permian tetrapods. Palaeontology 60:169-185. DOI: 10.1111/pala.12274

Sullivan C, Reisz RR, May WJ. 2000. Large dissorophoid skeletal elements from the Lower Permian Richards Spur fissures, Oklahoma, and their paleoecological implications. Journal of Vertebrate Paleontology 20:456-461. DOI: 10.1671/02724634(2000)020[0456:LDSEFT]2.0.CO;2

Swofford DL. 2021. PAUP*. Phylogenetic analysis using parsimony* 4.0a 169. Available at: http://phylosolutionscom/paup- test/

Tarailo DA. 2018. Taxonomic and ecomorphological diversity of temnospondyl amphibians across the Permian-Triassic boundary in the Karoo Basin (South Africa). Journal of Morphology 279:1840-1848. DOI: 10.1002/jmor.20906

Trinajstic K, Dennis-Bryan K. 2009. Phenotypic plasticity, polymorphism and phylogeny within placoderms. Acta Zoologica 90:83-102. DOI: 10.1111/j.1463-6395.2008.00363.x

Vallin G, Laurin M. 2004. Cranial morphology and affinities of Microbrachis, and a reappraisal of the phylogeny and lifestyle of the first amphibians. Journal of Vertebrate Paleontology 24:56-72. DOI: 10.1671/5.1

Vaughn PP. 1969. Further evidence of close relationship of the trematopsid and dissorophid labyrinthodont amphibians with a description of a new genus and new species. Bulletin of the Southern California Academy of Sciences 68:121-130.

Villalobos-Segura E, Underwood CJ, Ward DJ. 2021. The first skeletal record of the enigmatic Cretaceous sawfish genus Ptychotrygon (Chondrichthyes, Batoidea) from the Turonian of Morocco. Papers in Palaeontology 7:353-376. DOI: 10.1002/spp2.1287

Watanabe A. 2015 (for 2016). The impact of poor sampling of polymorphism on cladistic analysis. Cladistics 32:317-334. DOI: 10.1111/cla.12130

Wiens JJ, Servedio MR. 1997. Accuracy of phylogenetic analysis including and excluding polymorphic characters. Systematic Biology 46:332-345. DOI: 10.1093/sysbio/46.2.332

Wiens JJ, Servedio MR. 1998. Phylogenetic analysis and intraspecific variation: performance of parsimony, likelihood, and distance methods. Systematic Biology 47:228-253. DOI: 10.1080/106351598260897

Wiens JJ. 1995. Polymorphic characters in phylogenetic systematics. Systematic Biology 44:482-500. DOI: 10.1093/sysbio/44.4.482

Wiens JJ. 1998. Testing phylogenetic methods with tree congruence: phylogenetic analysis of polymorphic morphological characters in phrynosomatid lizards. Systematic Biology 47:427-444. DOI: 10.1080/106351598260806

Wiens JJ. 1999. Polymorphism in systematics and comparative biology. Annual Review of Ecology and Systematics 30:327-362. DOI: 10.1146/annurev.ecolsys.30.1.327

Wiens JJ. 2001. Character analysis in morphological phylogenetics: problems and solutions. Systematic Biology 50(5):689-699. DOI: 10.1080/106351501753328811. 
2434

2435

2436

2437

2438

2439

2440

2441

2442

2443

2444

2445

2446

2447

2448

2449

2450

2451

2452

2453

2454

2455

2456

2457

2458

2459

2460

2461

2462

2463

2464

2465

2466

2467

2468

2469

2470

2471

2472

2473

2474

2475

2476

Wiens JJ. 2003a. Incomplete taxa, incomplete characters, and phylogenetic accuracy: is there a missing data problem?. Journal of Vertebrate Paleontology 23:297-310. DOI: 10.1671/0272-4634(2003)023[0297:ITICAP]2.0.CO;2

Wiens JJ. 2003b. Missing data, incomplete taxa, and phylogenetic accuracy. Systematic Biology 52:528-538. DOI: 10.1080/10635150390218330

Wiens JJ. 2005. Can incomplete taxa rescue phylogenetic analyses from long-branch attraction?. Systematic Biology 54:731-742. DOI: 10.1080/10635150500234583

Wiens JJ. 2006. Missing data and the design of phylogenetic analyses. Journal of Biomedical Informatics 39:34-42. DOI: 10.1016/j.jbi.2005.04.001

Wiens JJ, Morrill MC. 2011. Missing data in phylogenetic analysis: reconciling results from simulations and empirical data. Systematic Biology 60:719-731. DOI: 10.1093/sysbio/syr025

Wilkinson, M., 2003. Missing entries and multiple trees: instability, relationships, and support in parsimony analysis. Journal of Vertebrate Paleontology 23:311-323. DOI: 10.1671/0272-4634(2003)023[0311:MEAMTI]2.0.CO;2

Williston SW. 1910. Cacops, Desmospondylus; new genera of Permian vertebrates. Bulletin of the Geological Society of America 21:249-284. DOI: 10.1130/GSAB-21-249

Williston SW. 1911. American Permian vertebrates. University of Chicago Press, Chicago, 130 pp.

Williston SW. 1914. Broiliellus, a new genus of amphibians from the Permian of Texas. The Journal of Geology 22:49-56.

Witzmann F, Ruta M. 2018. Evolutionary changes in the orbits and palatal openings of early tetrapods, with emphasis on temnospondyls. Earth and Environmental Science Transactions of the Royal Society of Edinburgh 109:333-350. DOI: 10.1017/S1755691018000919

Witzmann F, Soler-Gijón R. 2010. The bone histology of osteoderms in temnospondyl amphibians and in the chroniosuchian Bystrowiella. Acta Zoologica 91:96-114. DOI: 10.1111/j.1463-6395.2008.00385.x

Witzmann F, Sues H-D, Kammerer CF, Fröbisch J. 2019. A new bystrowianid from the upper Permian of Germany: first record of a Permian chroniosuchian (Tetrapoda) outside Russia and China. Journal of Vertebrate Paleontology 39:e1667366. DOI: 10.1080/02724634.2019.1667366

Witzmann F, Werneburg I. 2017. The palatal interpterygoid vacuities of temnospondyls and the implications for the associated eye- and jaw musculature. The Anatomical Record 300:1240-1269. DOI: 10.1002/ar.23582

Witzmann F. 2005. A dissorophid temnospondyl in the Upper Permian Kupferschiefer of Germany. Neues Jahrbuch für Geologie und Paläontologie - Monatshefte 2005:289-300. DOI: $10.1127 /$ njgpm/2005/2005/289

Witzmann F. 2013. Phylogenetic patterns of character evolution in the hyobranchial apparatus of early tetrapods. Earth and Environmental Science Transactions of the Royal Society of Edinburgh 104:145-167. DOI: 10.1017/S1755691013000480

Zander RH. 2004. Minimal values for reliability of bootstrap and jackknife proportions, decay index, and Bayesian posterior probability. Phyloinformatics 2:1-13. 


\section{Figure 1}

Cranial reconstructions of select representatives of Olsoniformes.

(A) the cacopine dissorophid Cacops morrisi (after Reisz, Schoch \& Anderson, 2009); (B) the dissorophine dissorophid Dissorophus multicinctus (after Schoch, 2012); (C) the long-snouted trematopid Acheloma cumminsi (after Dilkes \& Reisz, 1987; Polley \& Reisz, 2011); (D) the short-snouted trematopid Ecolsonia cutlerensis (after Berman, Reisz \& Eberth, 1985). Cool colors represent skull roof elements; warm colors represent palatal elements. Not to scale.
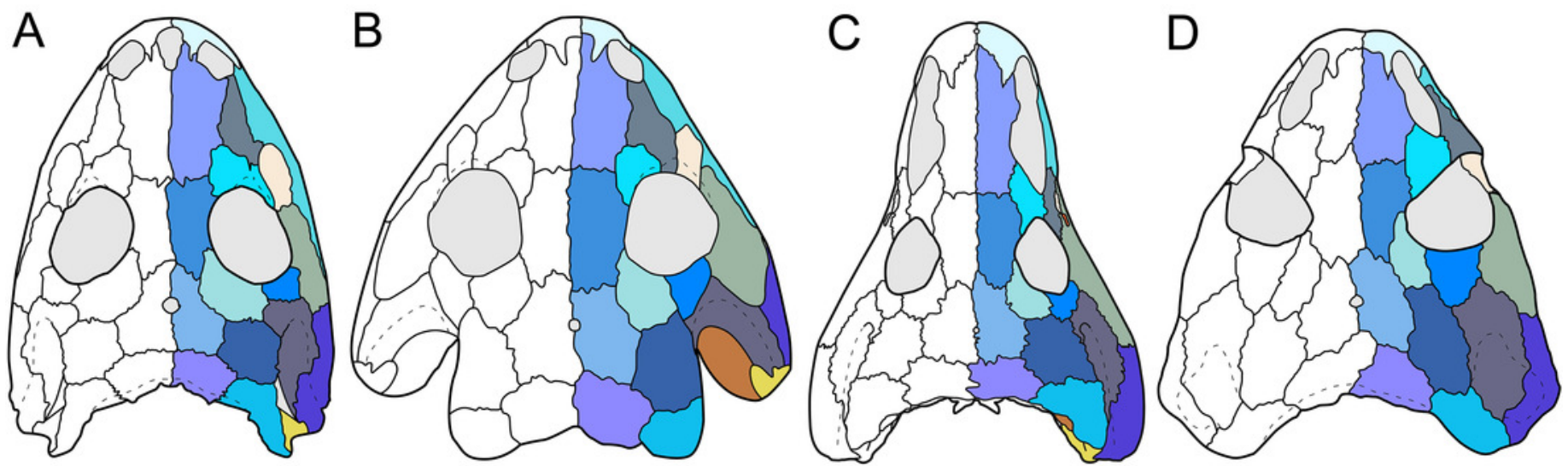


\section{Figure 2}

Genealogy of olsoniform-focused phylogenetic matrices.

Note that sources only reflect major contributions to character sampling. Number of characters is listed on the left, and number of all sampled taxa is listed on the right. 'Focal clade' refers to the most exclusive clade to which at least half of the sampled taxa belong. 'Amphibamidae' here refers to the historical concept of what is now Amphibamiformes (in part). Abbreviations: ARM, Atkins, Reisz \& Maddin (2019); BHBK, Berman et al. (2010); BHMSA, Berman et al. (2011); D, Dilkes (2020); FR, Fröbisch \& Reisz (2008, 2012); FS, Fröbisch \& Schoch (2009); G, Gee (2020b); G* (2021), this study; GBHPH, Gee et al. (2021); GR, Gee \& Reisz (2019); HBA, Holmes, Berman \& Anderson (2013); L, Liu (2018); MFEM, Maddin et al. (2013); PR, Polley \& Reisz (2011); RB, Ruta \& Bolt (2006); S, Schoch (2012, 2018a); SHH, Schoch, Henrici \& Hook (2020); SM, Schoch \& Milner (2008, 2021); SR, Schoch \& Rubidge (2005); SS, Schoch \& Sues (2013); SW, Schoch \& Witzmann (2018). 


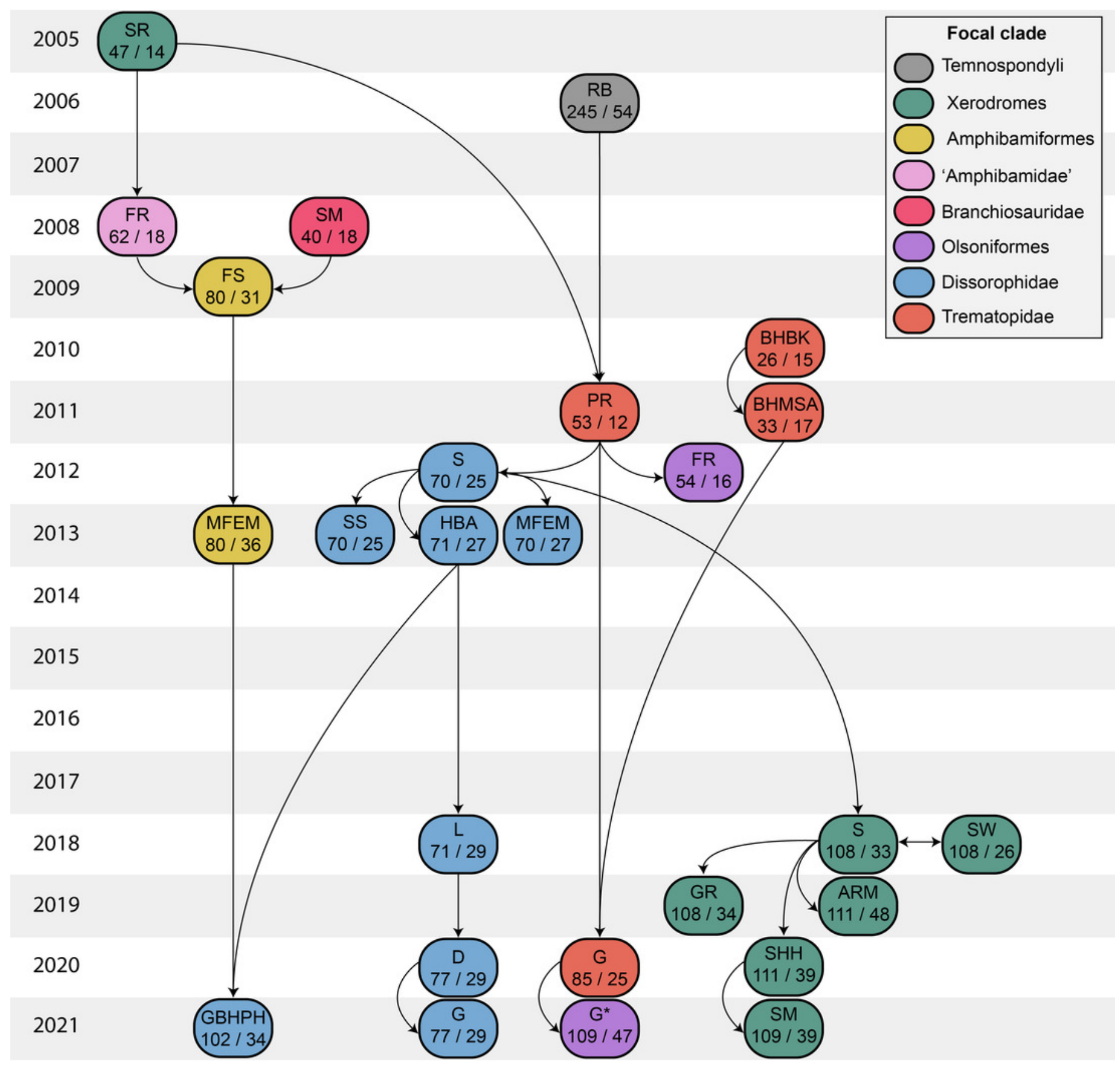




\section{Figure 3}

Comparison of tree topologies from early phylogenetic analyses of Dissorophidae.

All topologies represent strict consensus trees except for Schoch (2012) and are visually truncated to depict only dissorophids. Cacopinae and Dissorophinae are not annotated for Fröbisch \& Reisz's topology because the taxonomic specifiers (Cacops aspidephorus and Dissorophus multicinctus) were not sampled. Conjunctio multidens represents a composite OTU unless otherwise indicated by the differentiation of the holotype from the specimen historically referred to as the Rio Arriba Taxon (RAT; UCMP 40103).

A Fröbisch \& Reisz (2012)

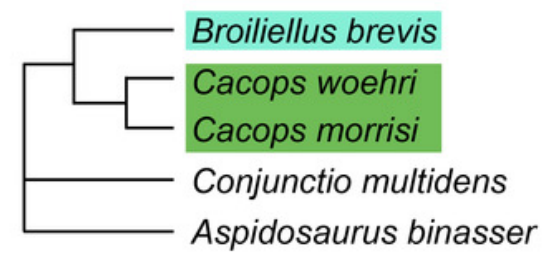

Maddin et al. (2013)

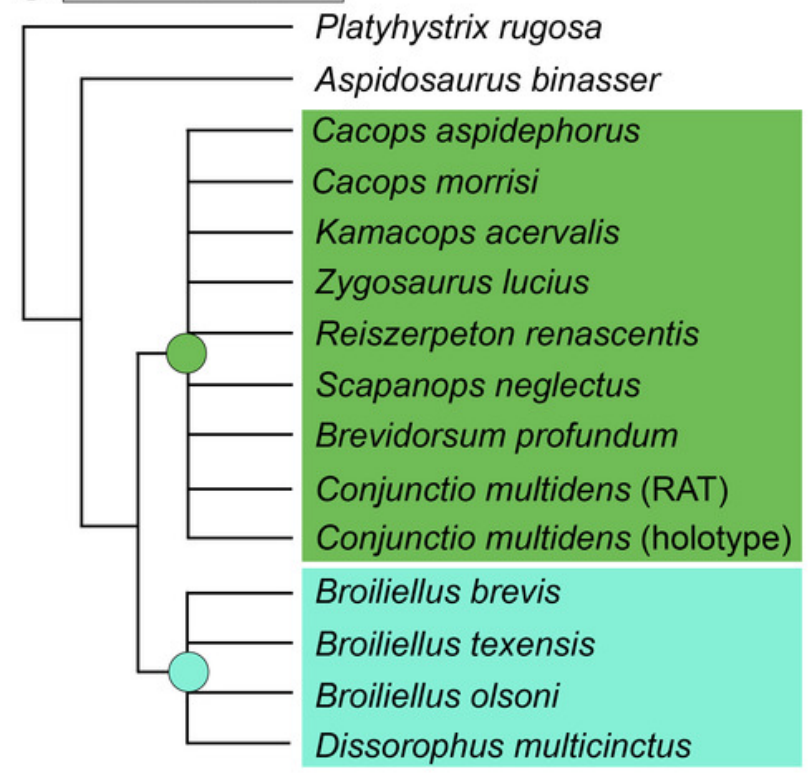

\section{B Schoch (2012)}

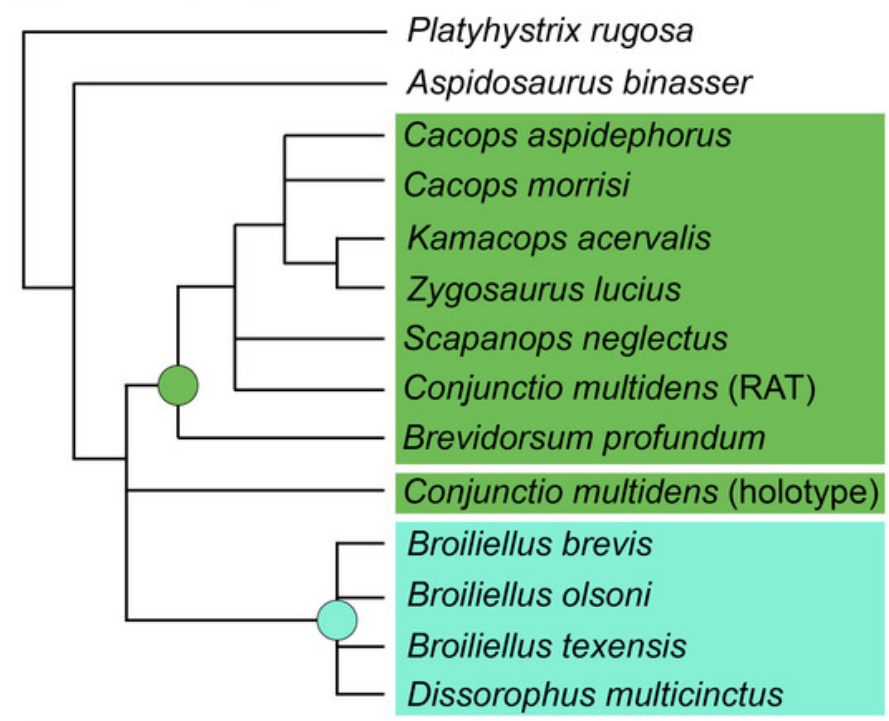

D Schoch \& Sues (2013)

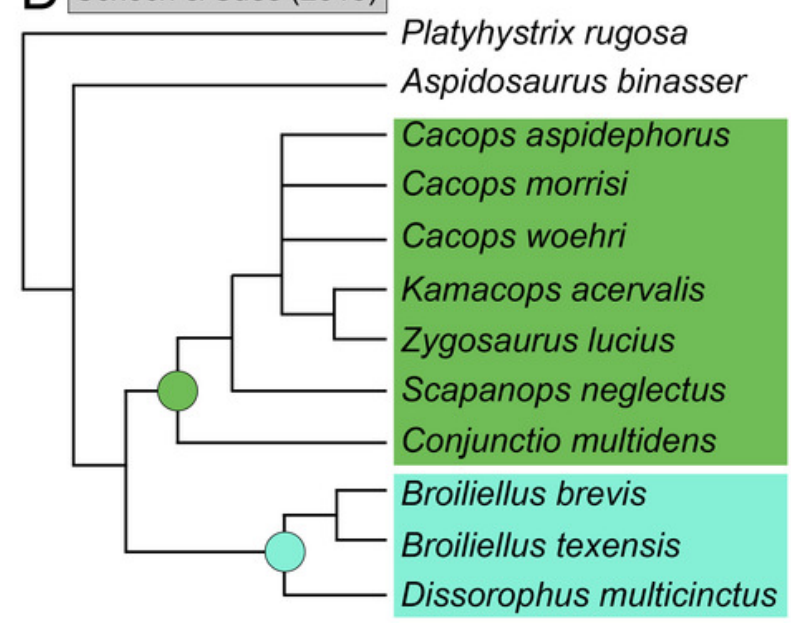




\section{Figure 4}

Comparison of reported tree topologies from recent phylogenetic analyses of Dissorophidae.

All topologies represent strict consensus trees and are visually truncated to depict only dissorophids. Colors and symbols as with Figure 3. Conjunctio multidens represents a composite OTU unless otherwise indicated; Gee et al. (2021) recovered all three specimens as a clade, so they are collapsed to a single visual OTU here. For Holmes, Berman \& Anderson (2013), the tree on the left represents the result of their analysis with scoring changes to the first referred specimen of $C$. multidens (UCMP 40103 [RAT]); the tree on the right represents the result with the original scorings from Schoch (2012). For Dilkes (2020), the tree on the left represents the result of his analysis with the full character and taxon sample; the tree on the right represents the result following the removal of wildcard taxa. 
A Holmes, Berman \& Anderson (2013)

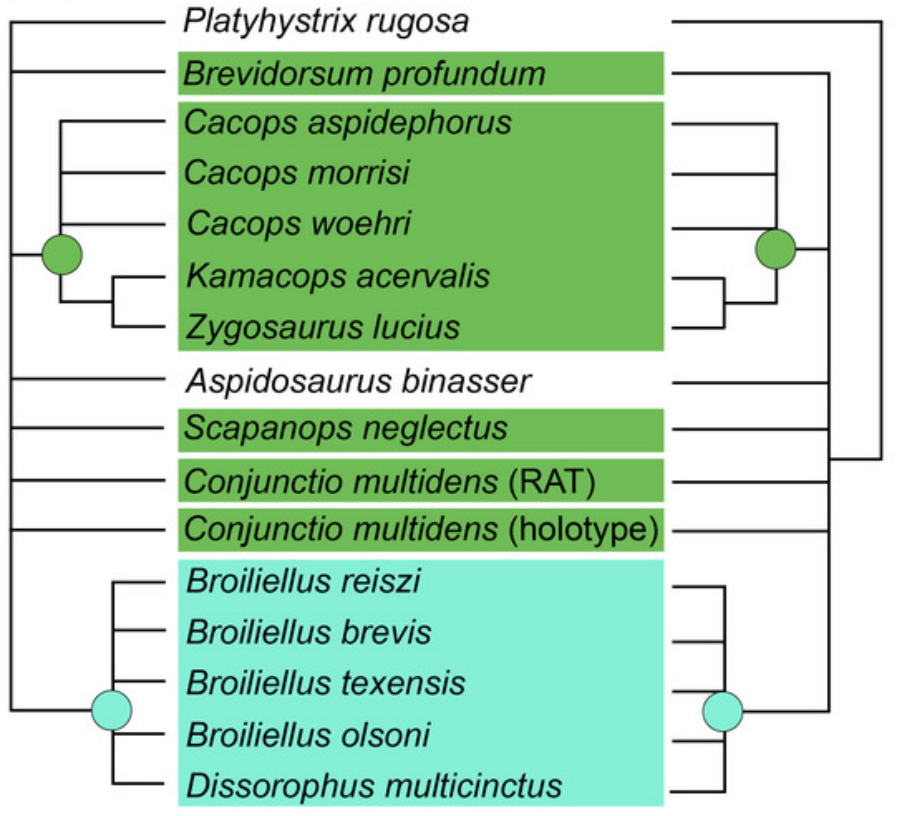

C Dilkes (2020)

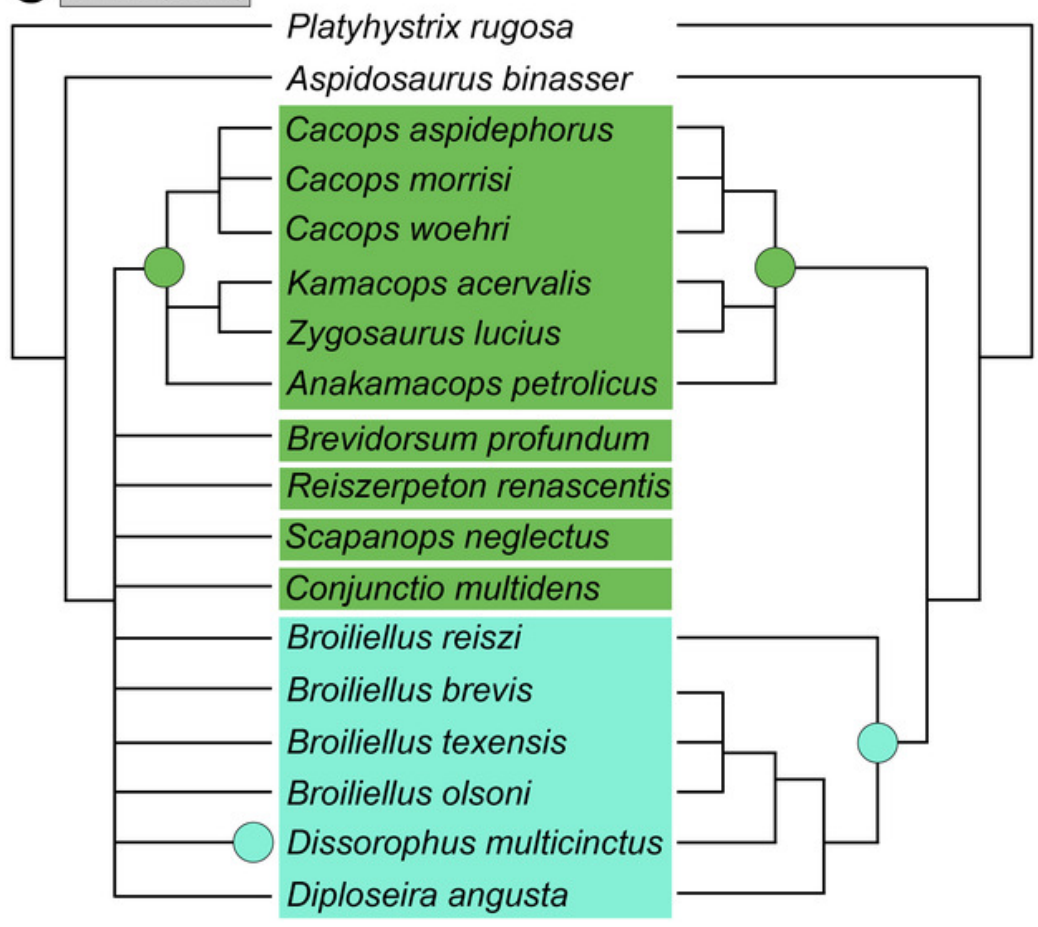

Biu (2018)

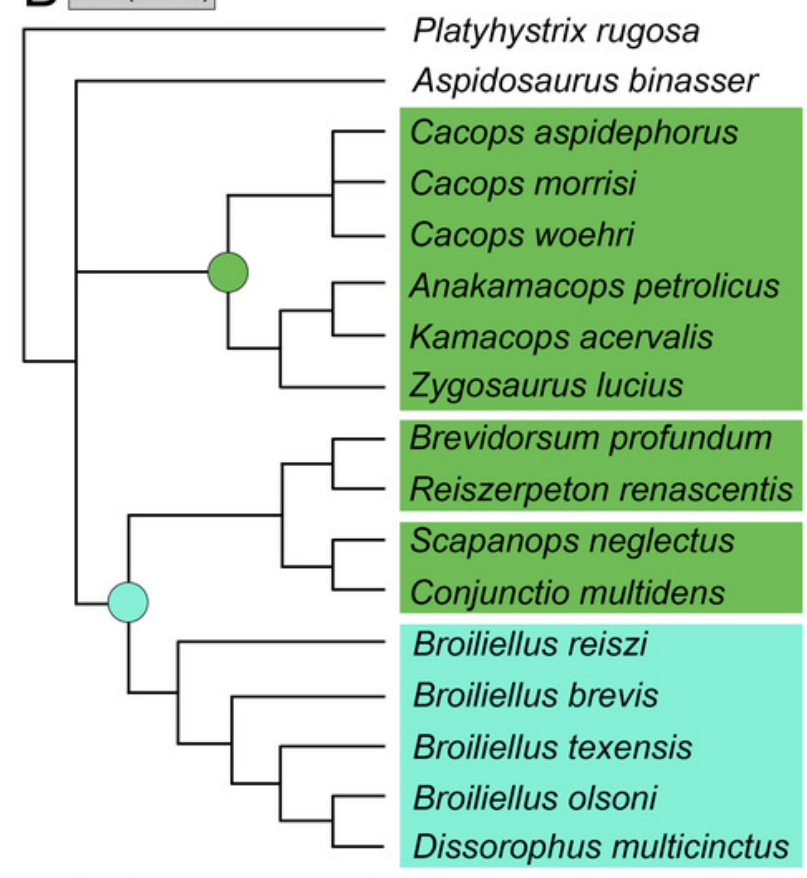

D Gee et al. (2021)

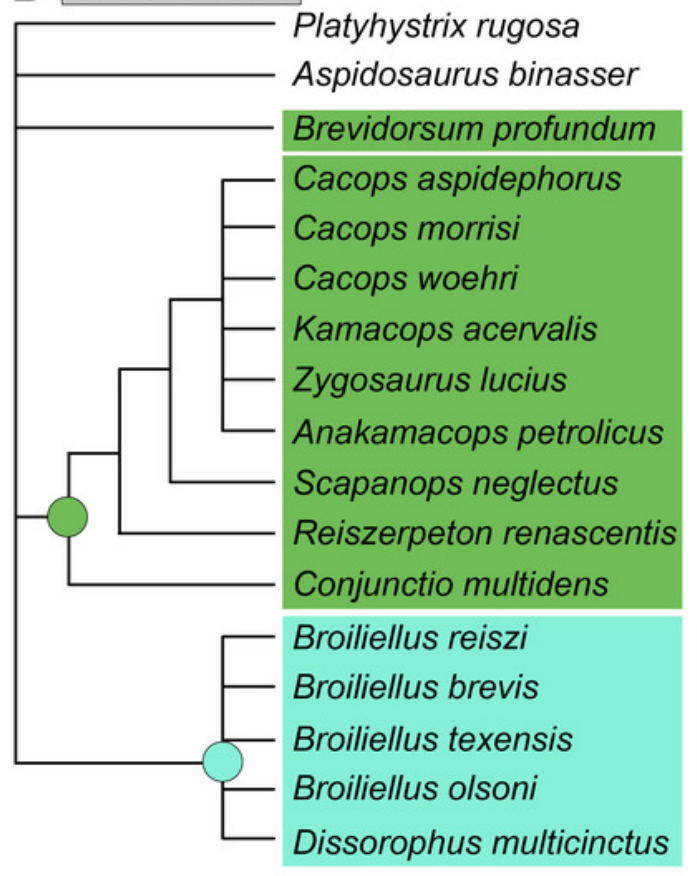




\section{Figure 5}

Comparison of tree topologies from previous phylogenetic analyses of Trematopidae.

All topologies represent strict consensus trees and are visually truncated to depict only xerodromes. Nominal placement and nodal definitions from Schoch \& Milner (2014).
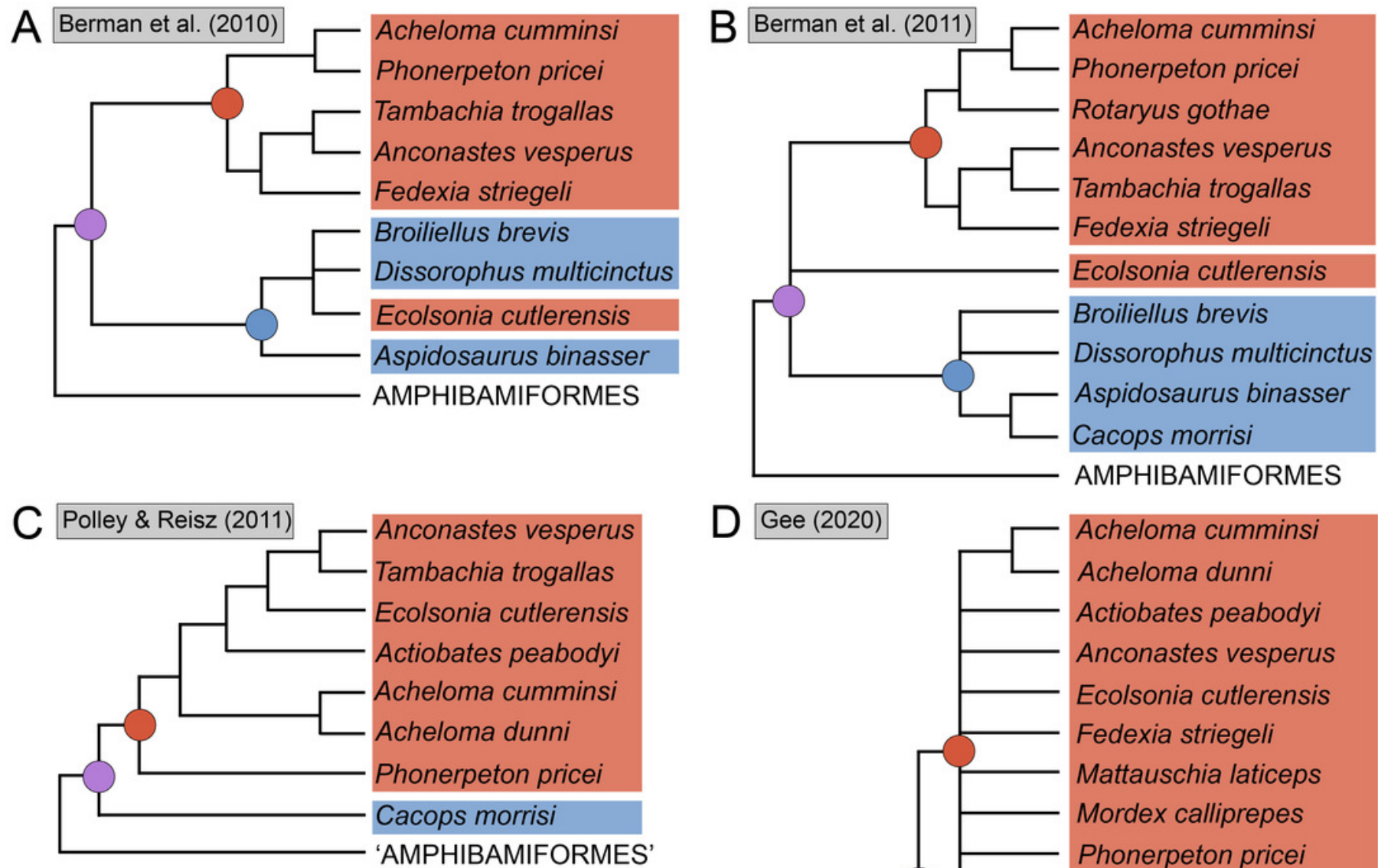

D Gee (2020) AMPHIBAMIFORMES

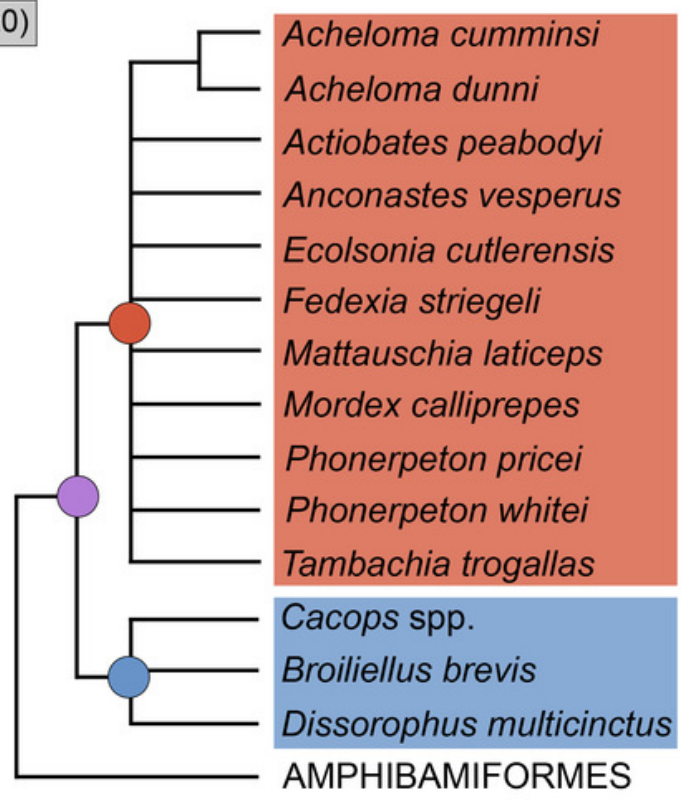


Figure 6

Adams consensus trees for Analysis 1A (all scored olsoniforms).

(A) tree resulting from the iteration using the 'conservative' OTU of Kamacops acervalis; (B) tree resulting from the iteration using the 'reconstructed' OTU of $K$. acervalis. Only Dissorophidae is depicted in part $B$ because the remainder of the consensus tree was unchanged from part $A$. 

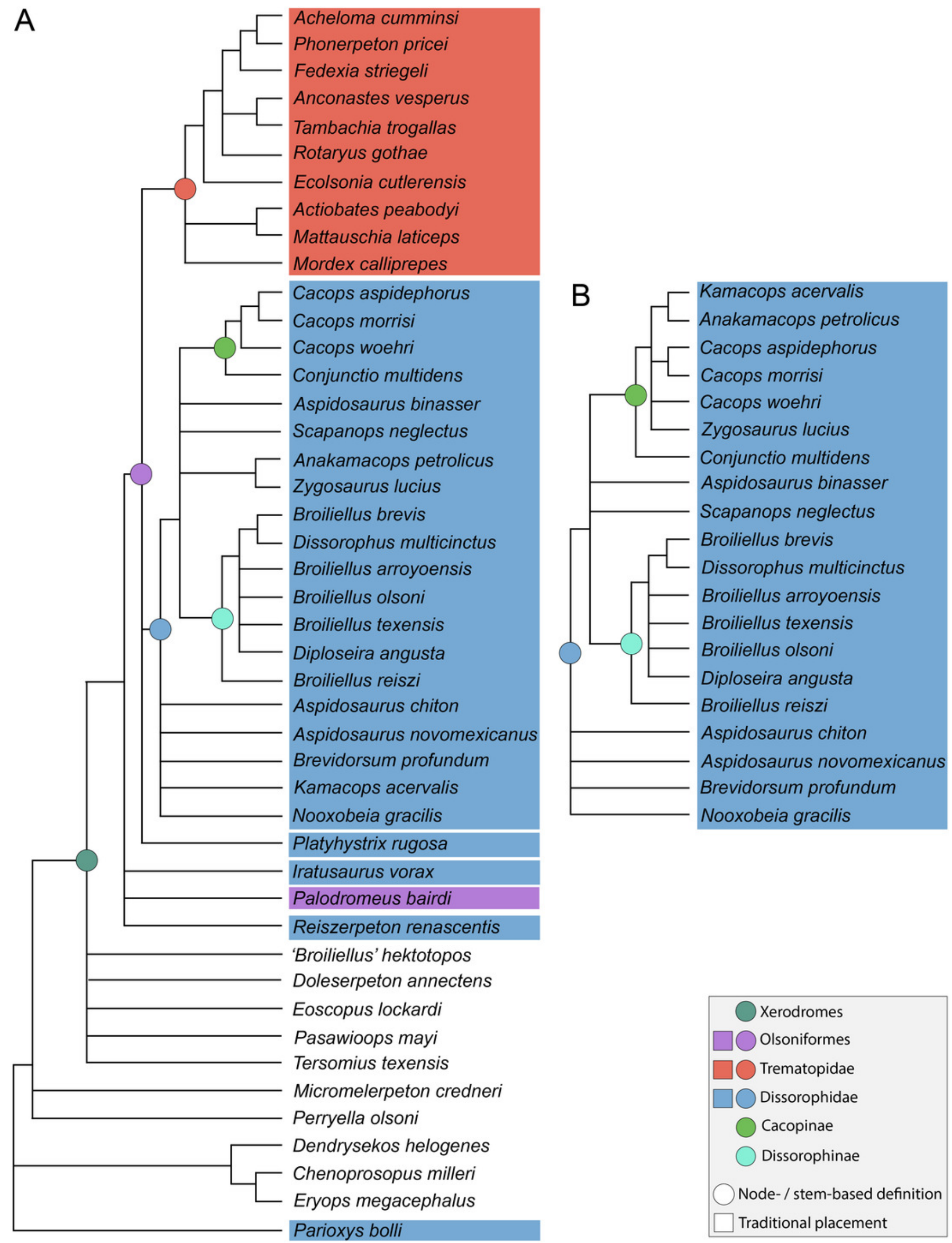


\section{Figure 7}

Strict consensus trees for Analysis 1A (all scored olsoniforms) following removal of wildcard taxa from MPTs.

(A) resultant tree from the iteration using the 'conservative' OTU of Kamacops acervalis; (B) resultant tree from the iteration using the 'reconstructed' OTU of $K$. acervalis. Only Dissorophidae is depicted in part $B$ because the remainder of the consensus tree was unchanged from part A. Colors and symbols as with Figure 6. 

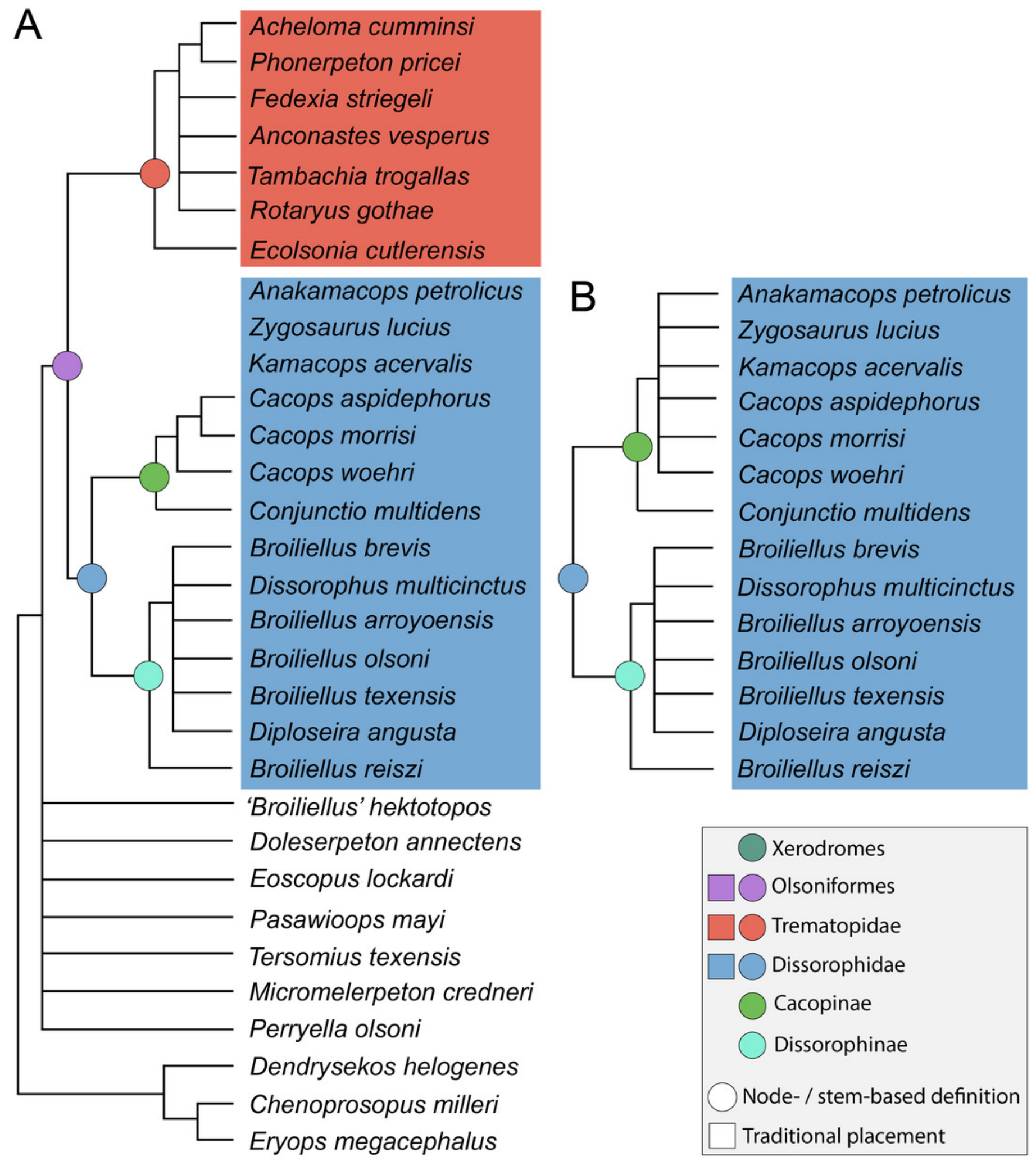
Figure 8

Strict consensus trees for Analysis 1B (all scored olsoniforms) following removal of wildcard taxa from the matrix.

(A) resultant tree from the iteration using the 'conservative' OTU of Kamacops acervalis; (B) resultant tree from the iteration using the 'reconstructed' OTU of $K$. acervalis. Only Dissorophidae is depicted in part $B$ because the remainder of the consensus tree was unchanged from part A. Colors and symbols as with Figure 6. 


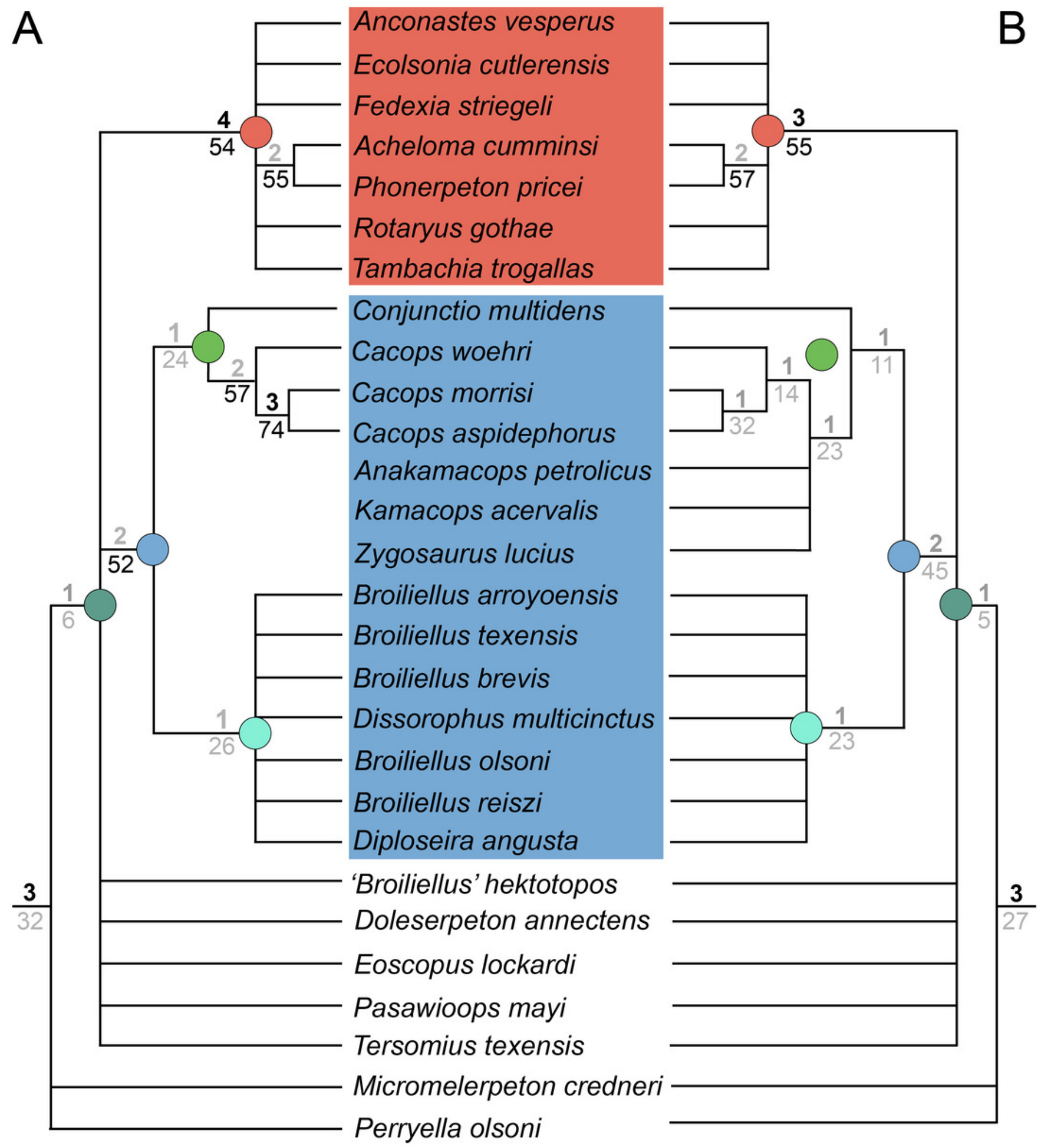


Figure 9

Strict consensus tree for Analysis 2 (best representatives) from the iteration using the 'conservative' OTU of Kamacops acervalis.

The iteration with the 'reconstructed' OTU recovered the same topology with only minor deviations in bootstrap support and is not figured here. Colors and symbols as with Figure 6. 


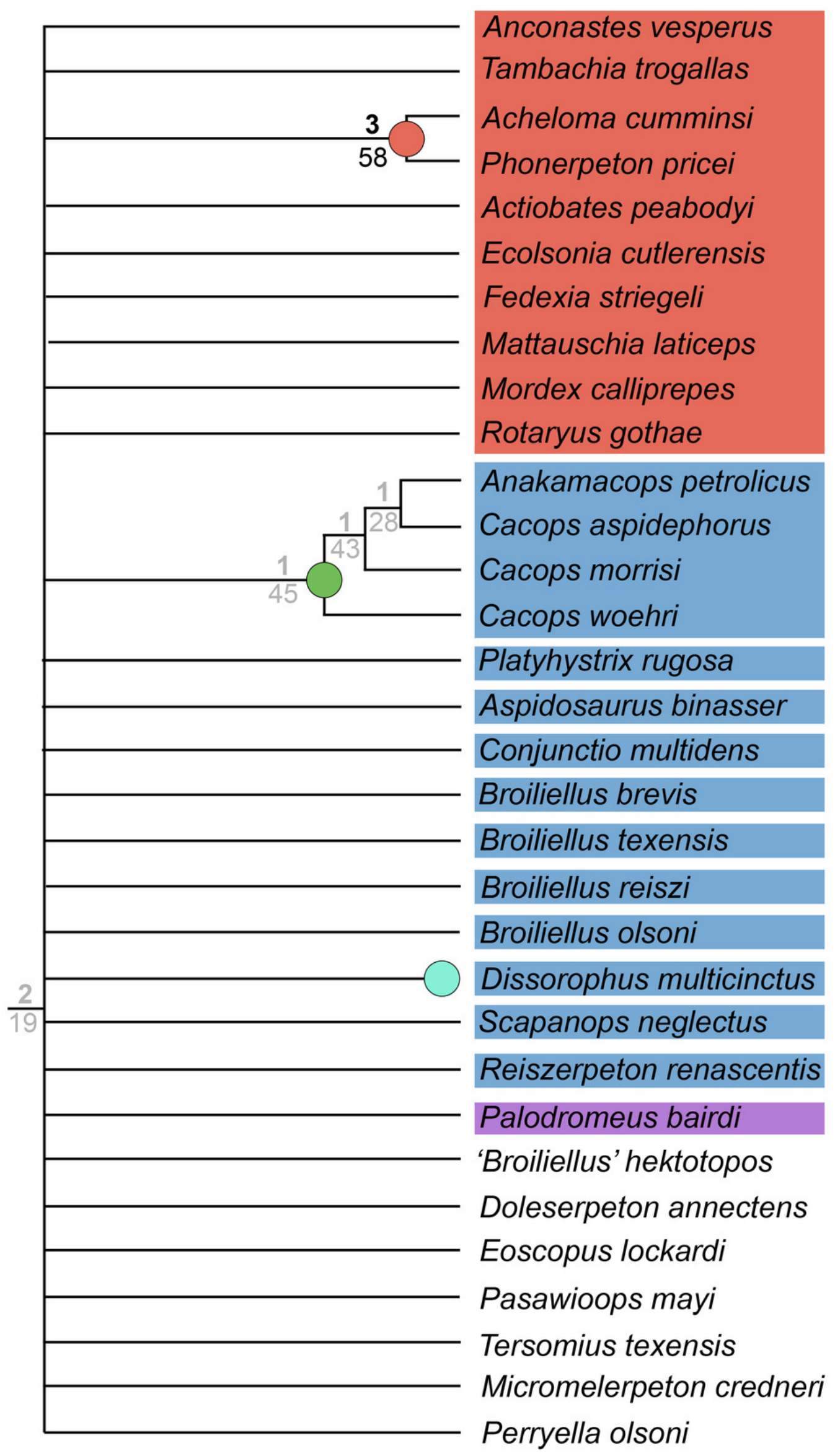


Figure 10

Strict consensus trees for Analysis 3 (dissorophid-focused).

(A) resultant tree from the iteration using the 'conservative' OTU of Kamacops acervalis; (B) resultant tree from the iteration using the 'reconstructed' OTU of $K$. acervalis. Colors and symbols as with Figure 6. 

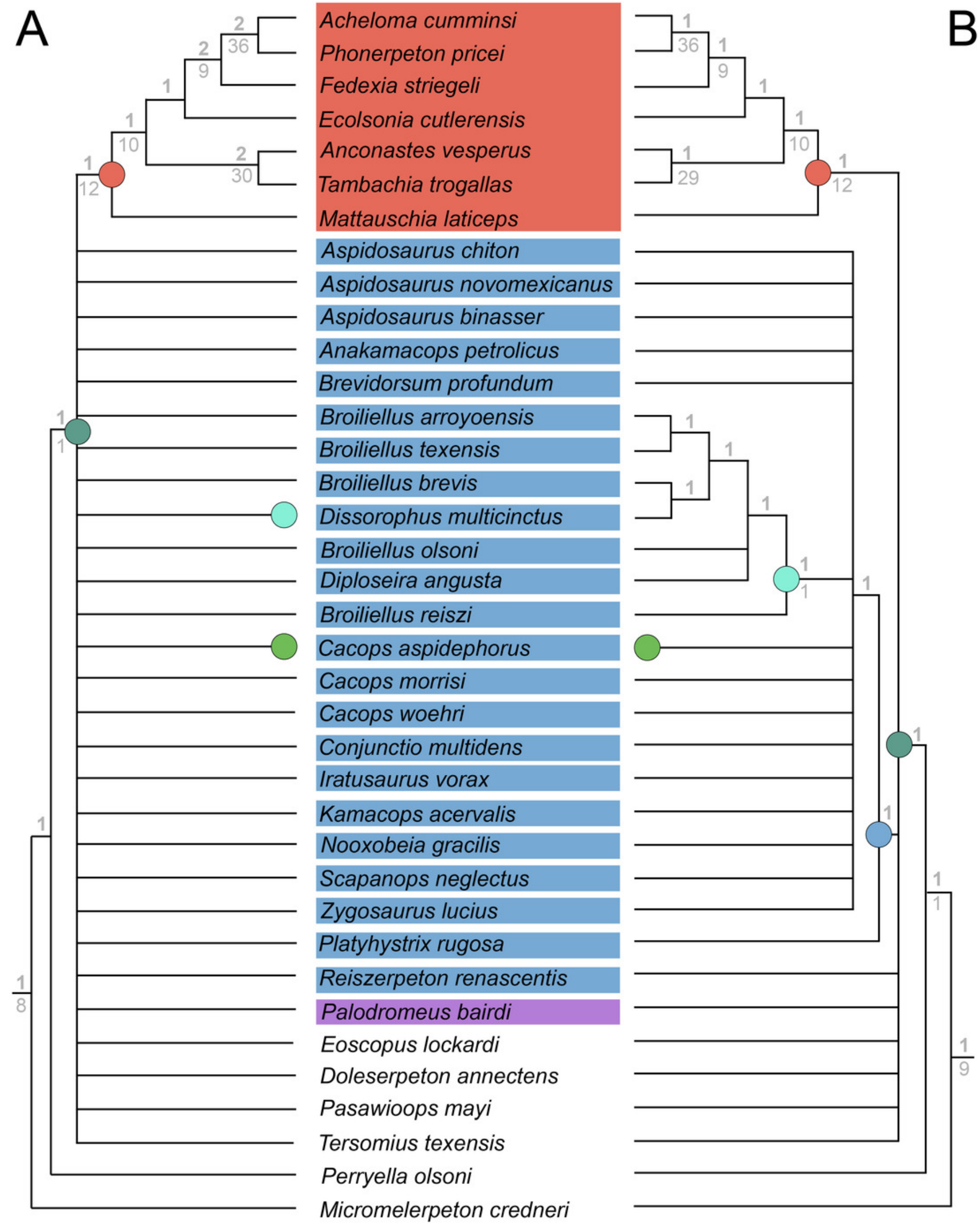
Figure 11

Strict consensus tree for Analysis 4 (specimen-level OTUs).

Node labels, colors, and symbols as with Figures 6-7. 


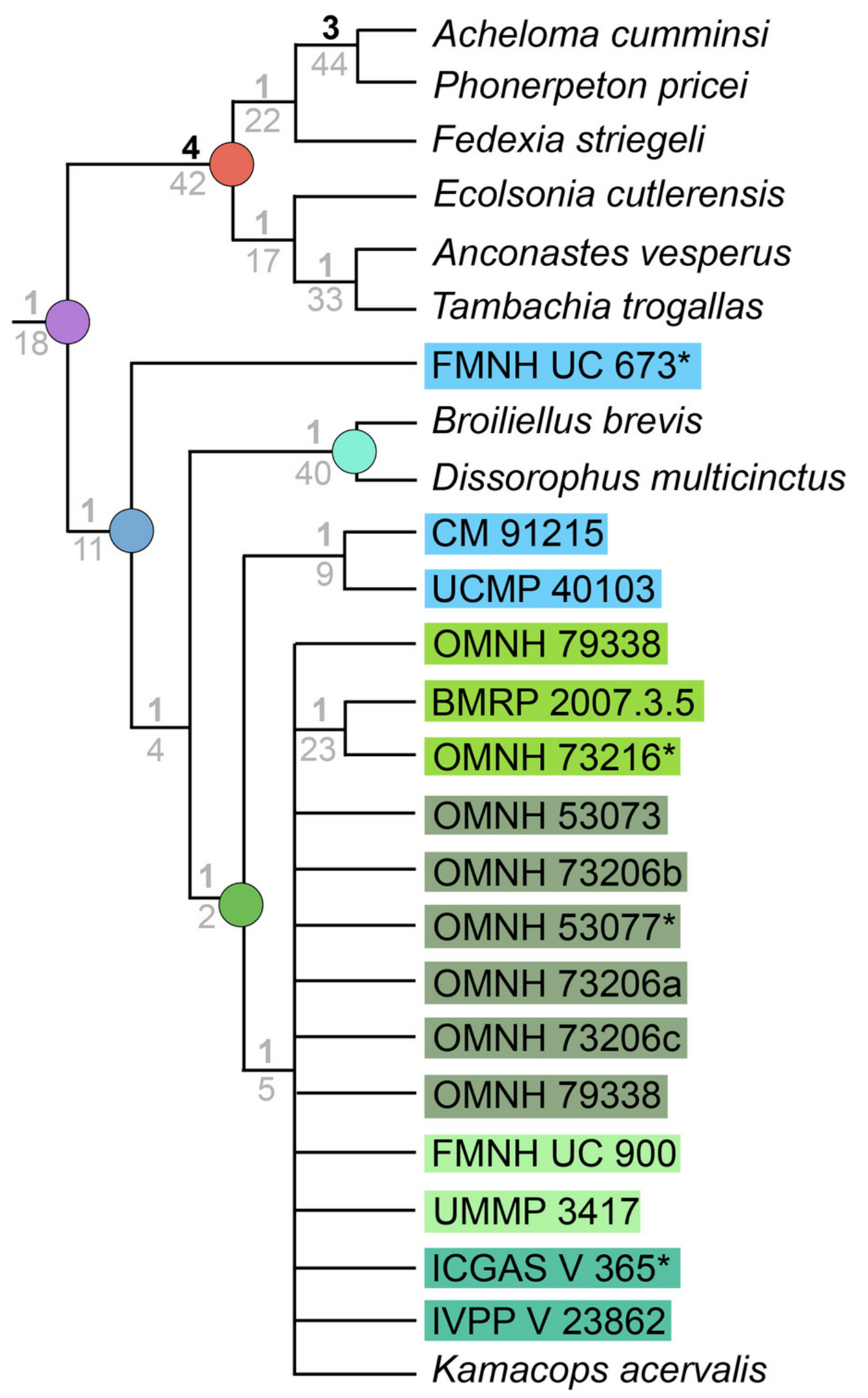

Anakamacops petrolicus Cacops aspidephorus

Cacops morrisi Cacops woehri Conjunctio multidens 


\section{Figure 12}

Strict consensus trees for Analysis 5 (taxon mirror of Dilkes, 2020).

(A) tree resulting from the analysis of this study's matrix with the same taxon sample as

Dilkes (2020); (B) tree resulting from the analysis of the same matrix without the four wildcard taxa identified by Dilkes (Brevidorsum, Conjunctio, Reiszerpeton, Scapanops). Colors and symbols as with Figure 6. 


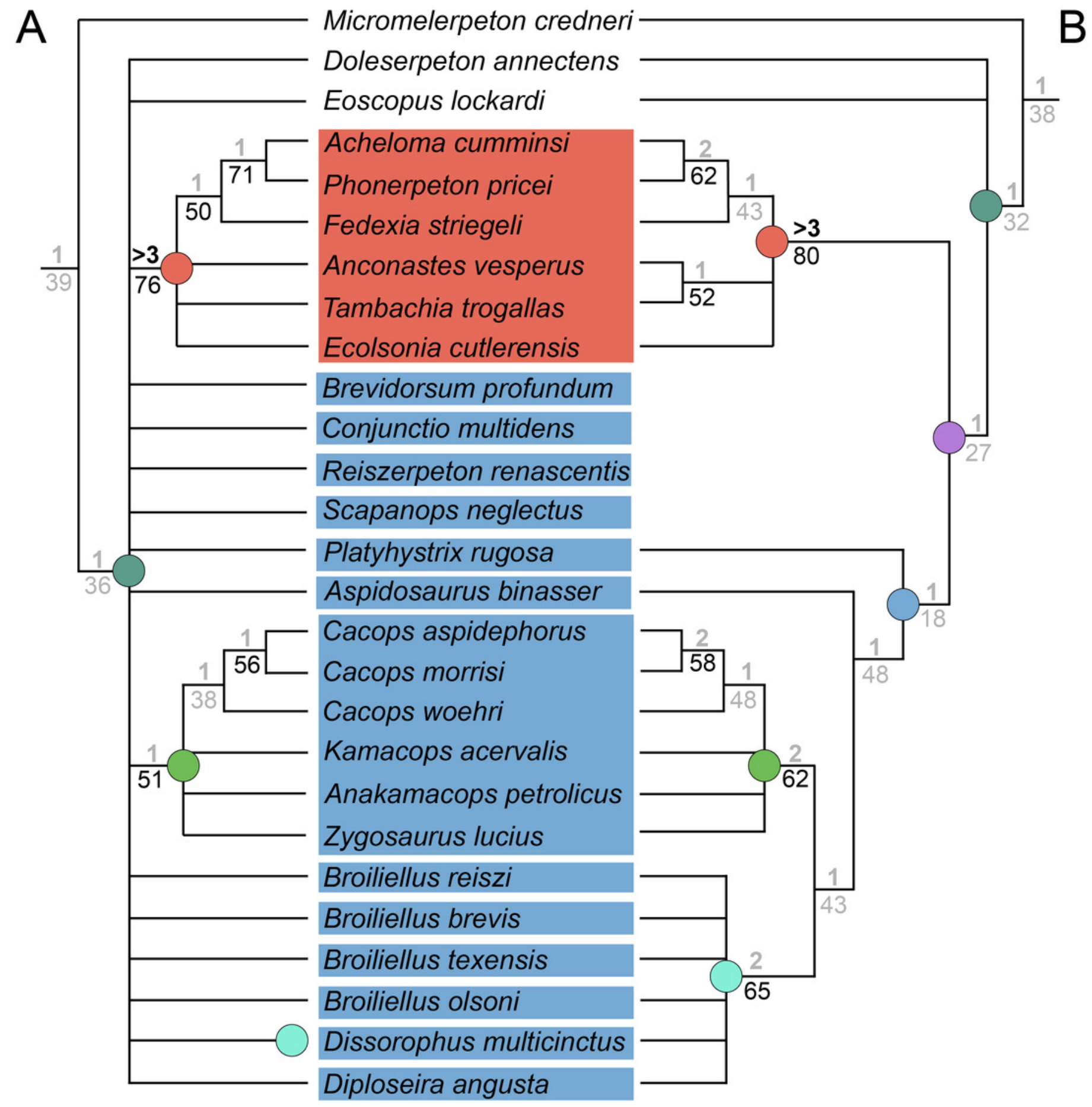


Figure 13

Strict consensus trees of individual islands recovered in Analysis 5.

(A) Island 1, consisting of 564 MPTs (trees 79-642); (B) Island 2, consisting of 108 MPTs

(trees 643-750); (C) Island 3, consisting of 78 MPTs (trees 1-78). Colors and symbols as with

Figure 6. 
A

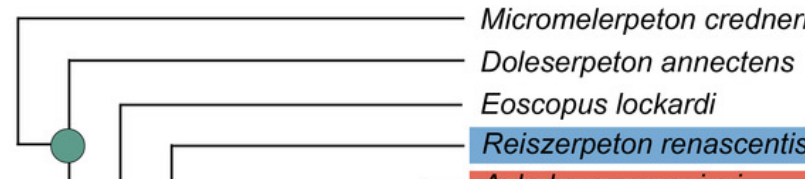

Reiszerpeton renascentis Acheloma cumminsi

Phonerpeton pricei

Fedexia striegeli

Anconastes vesperus

Ecolsonia cutlerensis

Tambachia trogallas

Aspidosaurus binasser

Scapanops neglectus

Conjunctio multidens

Cacops aspidephorus

Cacops morrisi

Cacops woehri

Anakamacops petrolicus

Kamacops acervalis

Zygosaurus lucius

Broiliellus reiszi

Broiliellus brevis

Broiliellus texensis

Broiliellus olsoni

- Dissorophus multicinctus

Diploseira angusta

Platyhystrix rugosa

Brevidorsum profundum

C

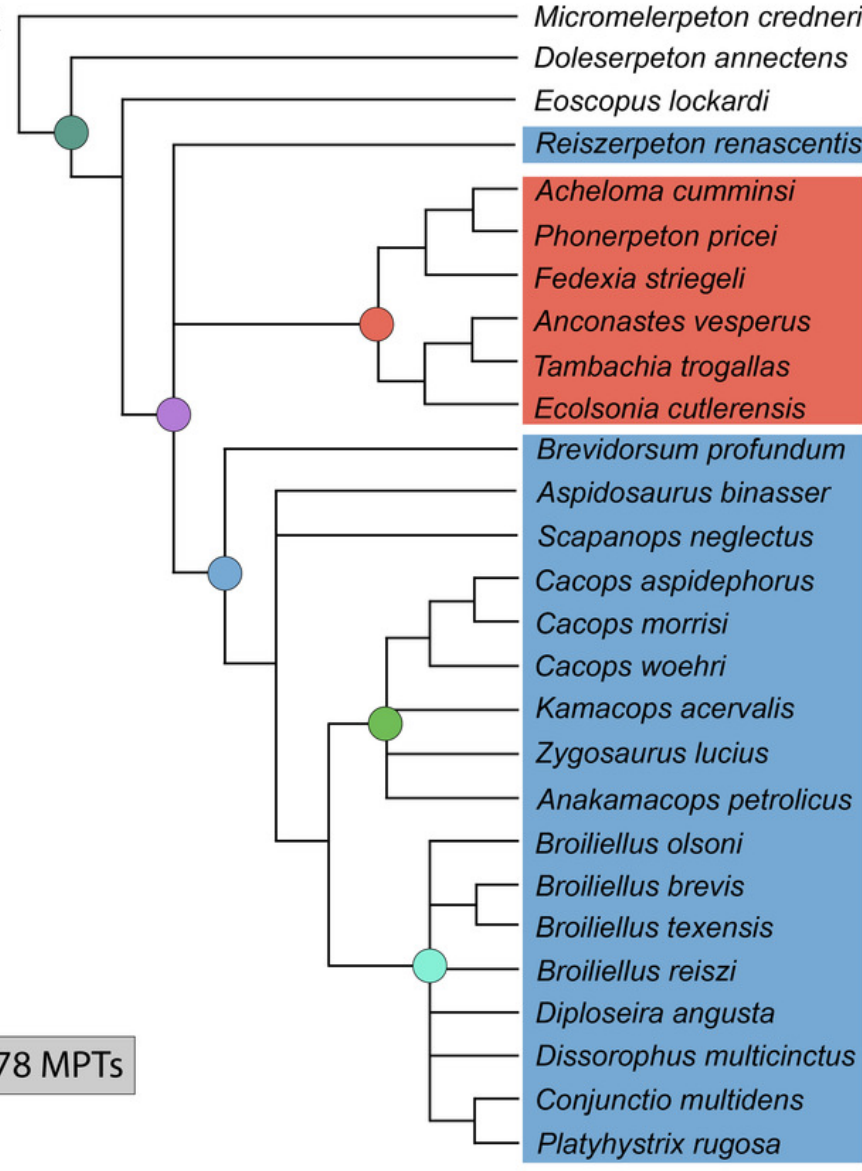

B

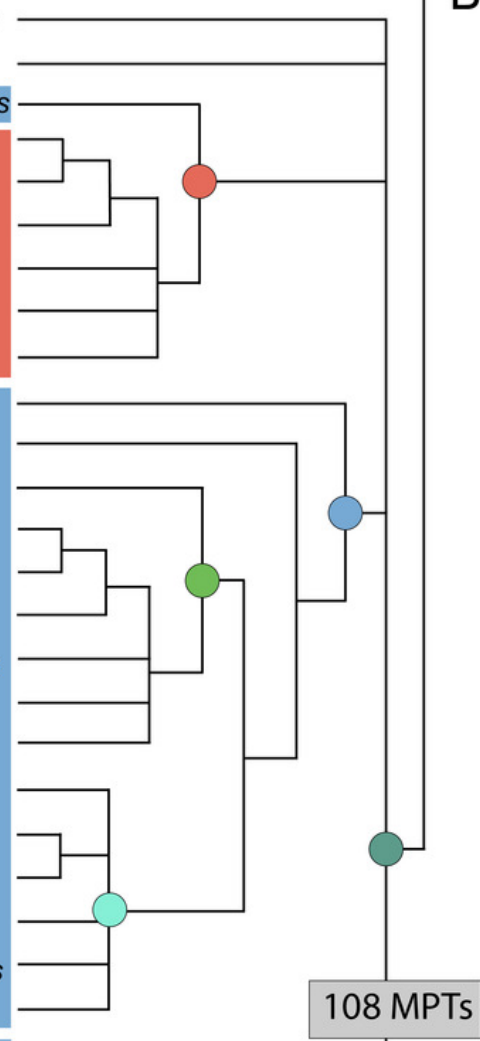




\section{Figure 14}

Comparison of strict consensus topologies for Analysis 6 (taxon mirror of Gee, 2020b).

(A) tree resulting from the analysis of Gee's (2020b) trematopid-focused matrix with a combined OTU of the previous scorings of Acheloma cumminsi and Acheloma dunni and with the exclusion of Phonerpeton whitei; (B) tree resulting from the same taxon sampling and the updated matrix of this study. Colors and symbols as with Figure 6.

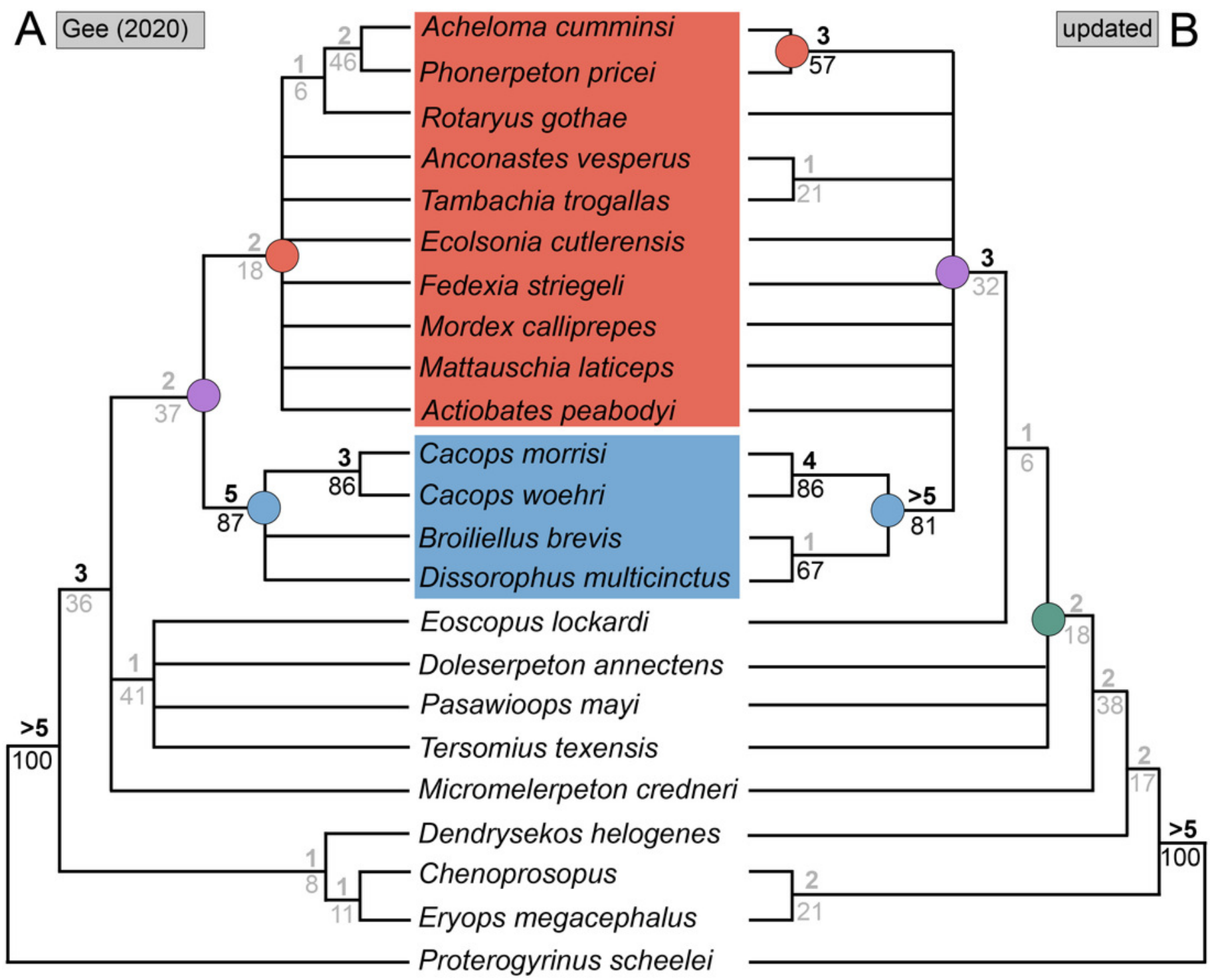




\section{Figure 15}

Comparison of strict consensus topologies for Analysis 7 (updated matrix from Dilkes, 2020).

(A) tree resulting from Dilkes' (2020) original analysis with the full taxon sample; (B) tree resulting from the analysis of the updated matrix with the full taxon sample; (C) tree resulting from Dilkes' original analysis without the four wildcard taxa that he identified (Brevidorsum, Conjunctio, Reiszerpeton, Scapanops); (D) tree resulting from the reanalysis of the updated matrix without his wildcard taxa. Colors and symbols as with Figure 6 . 

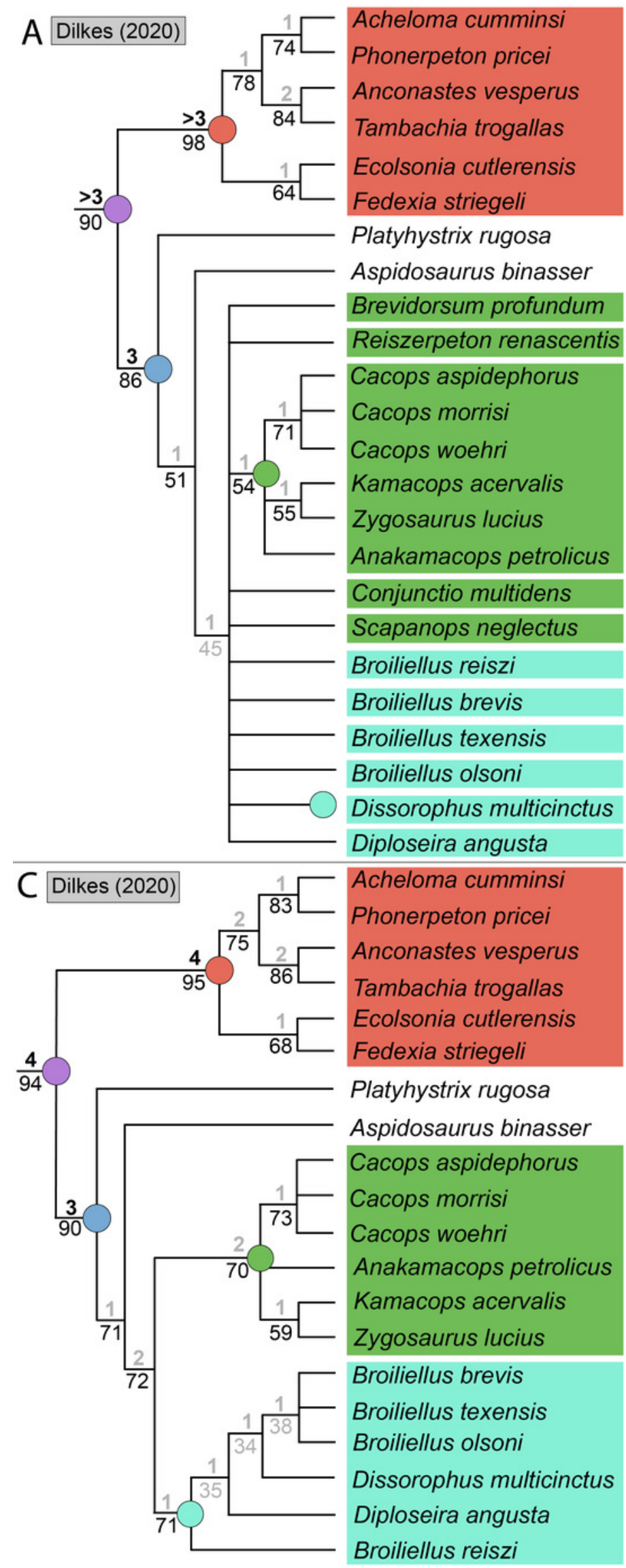

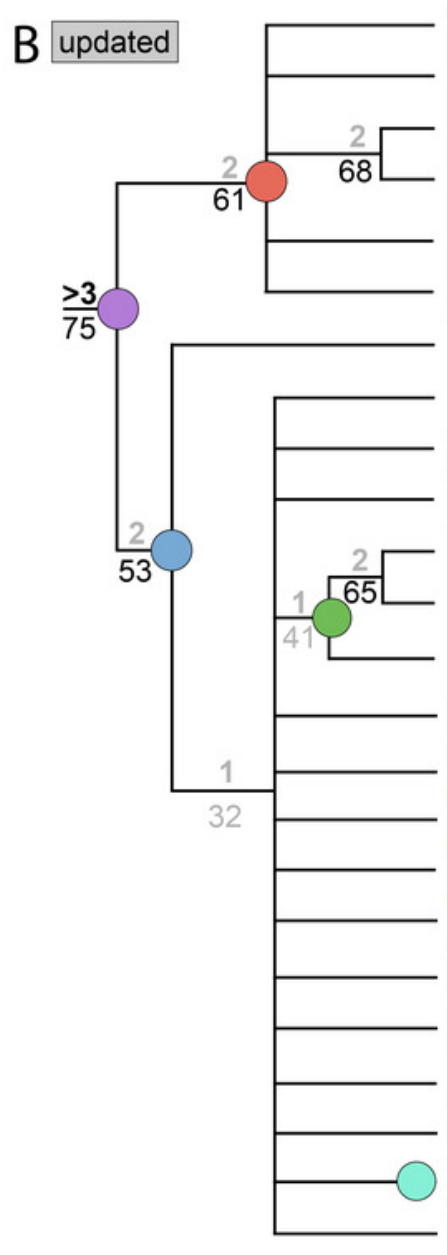

Acheloma cumminsi

Phonerpeton pricei

Anconastes vesperus

Tambachia trogallas

Ecolsonia cutlerensis

Fedexia striegeli

Platyhystrix rugosa

Aspidosaurus binasser

Brevidorsum profundum

Reiszerpeton renascentis

Cacops aspidephorus

Cacops morrisi

Cacops woehri

Kamacops acervalis

Zygosaurus lucius

Anakamacops petrolicus

Conjunctio multidens

Scapanops neglectus

Broiliellus reiszi

Broiliellus brevis

Broiliellus texensis

Broiliellus olsoni

Dissorophus multicinctus

Diploseira angusta

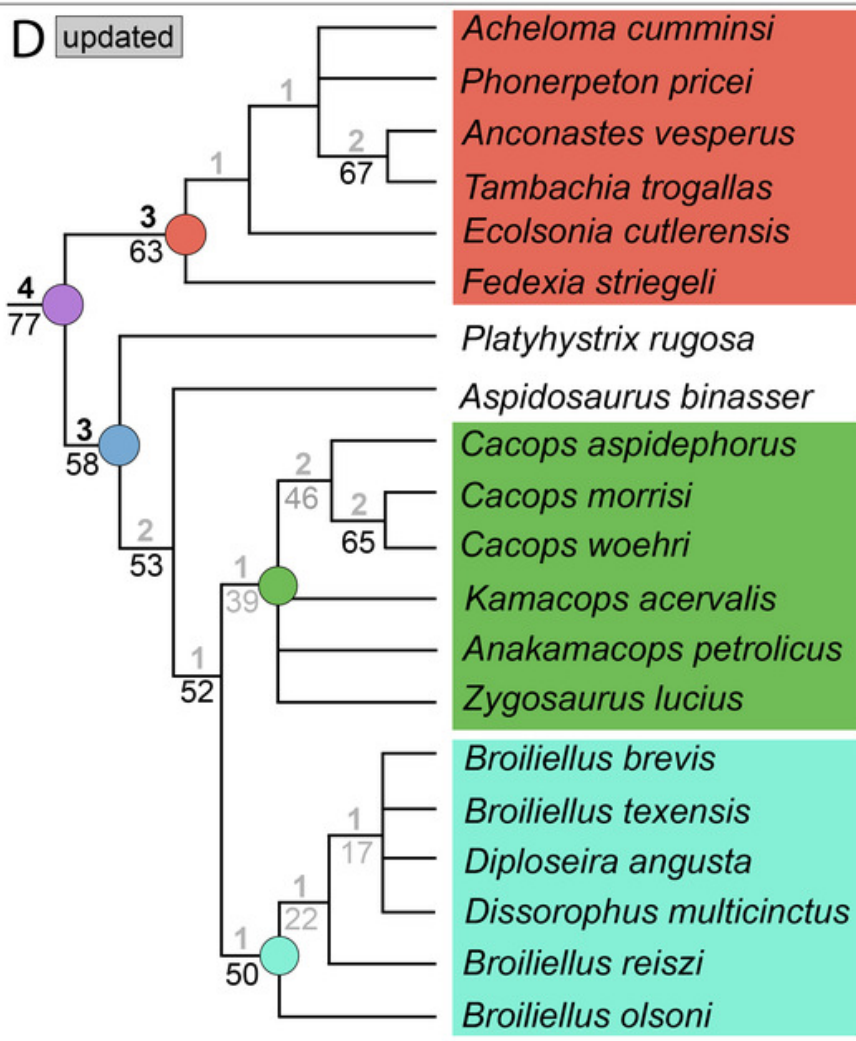




\section{Figure 16}

Strict consensus trees of individual islands recovered in Analysis 7.

(A) Island 1, consisting of 10 MPTs (trees 11-20); (B) Island 2, consisting of 10 MPTs (trees 1-10). Colors and symbols as with Figure 6.
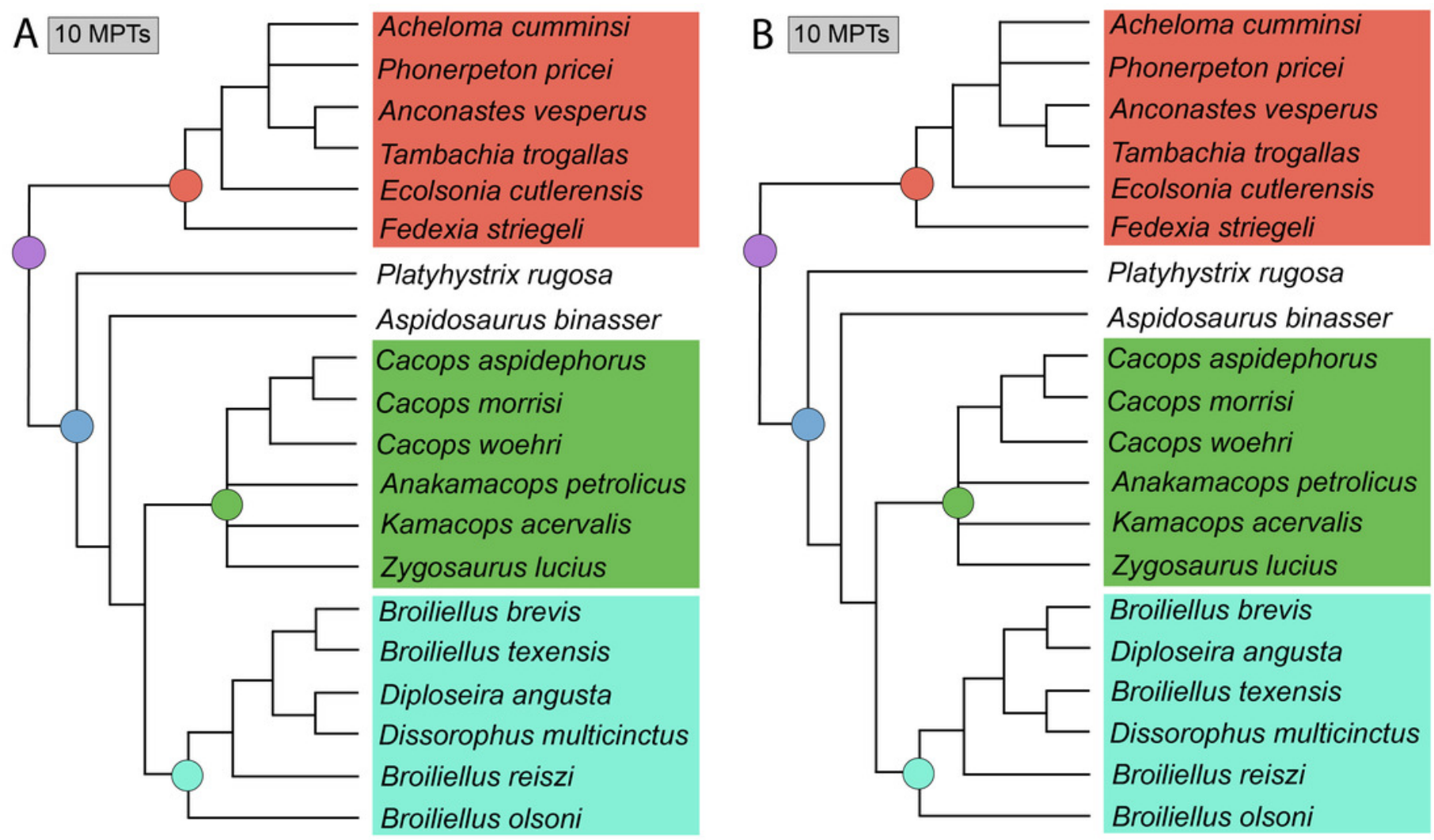


\section{Figure 17}

Comparison of strict consensus topologies for Analysis 8 (comparison of TNT and PAUP* on a trematopid-focused sample using this study's revised matrix from Gee, 2020b).

(A) tree resulting from the analysis using TNT (repeated from Fig. 14B); (B) tree resulting from the analysis with PAUP*. Colors and symbols as with Figure 6.

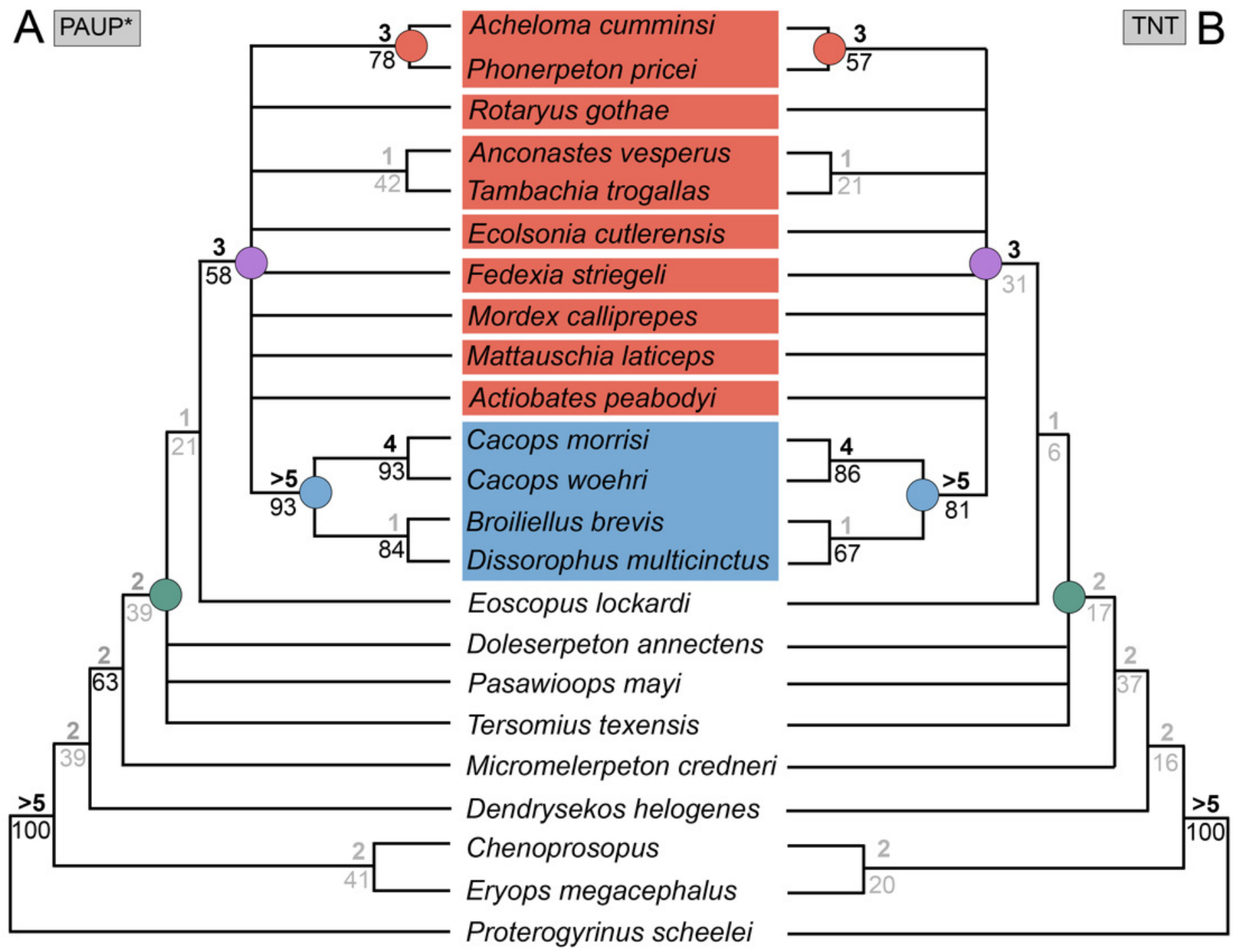


Figure 18

Strict consensus trees of individual islands recovered in Analysis 8.

(A) Island 1, consisting of 14 MPTs (trees 1-14); (B) Island 2, consisting of 8 MPTs (trees

15-22); (C) Island 3, consisting of 1 MPT (tree 23). Colors and symbols as with Figure 6. 
A 14 MPTs

\section{C $1 \mathrm{MPT}$}

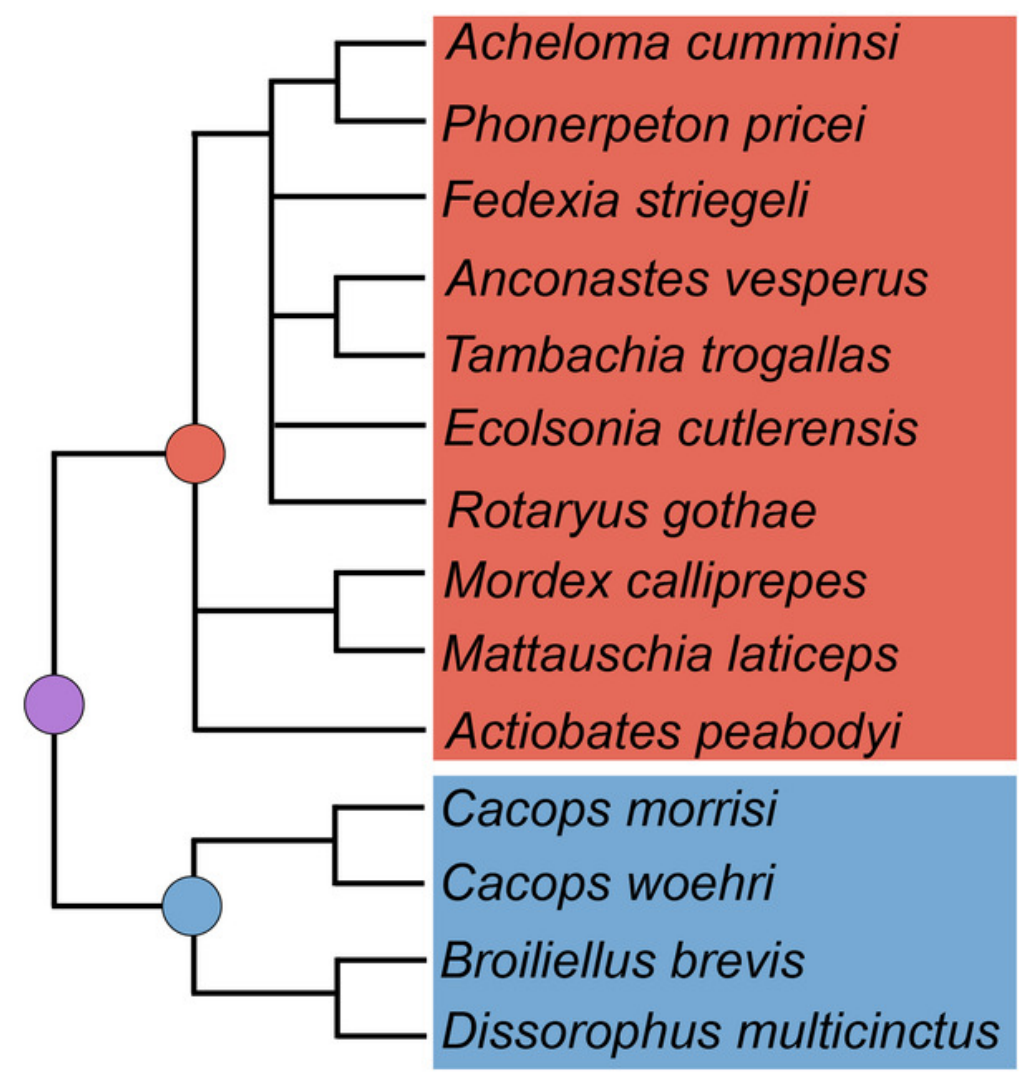

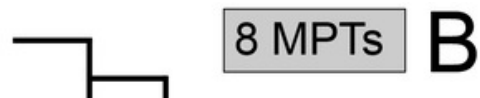

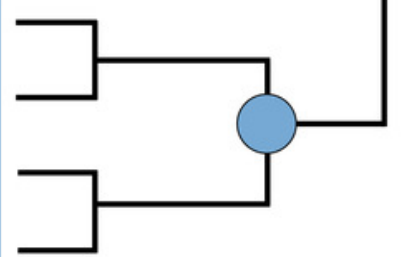

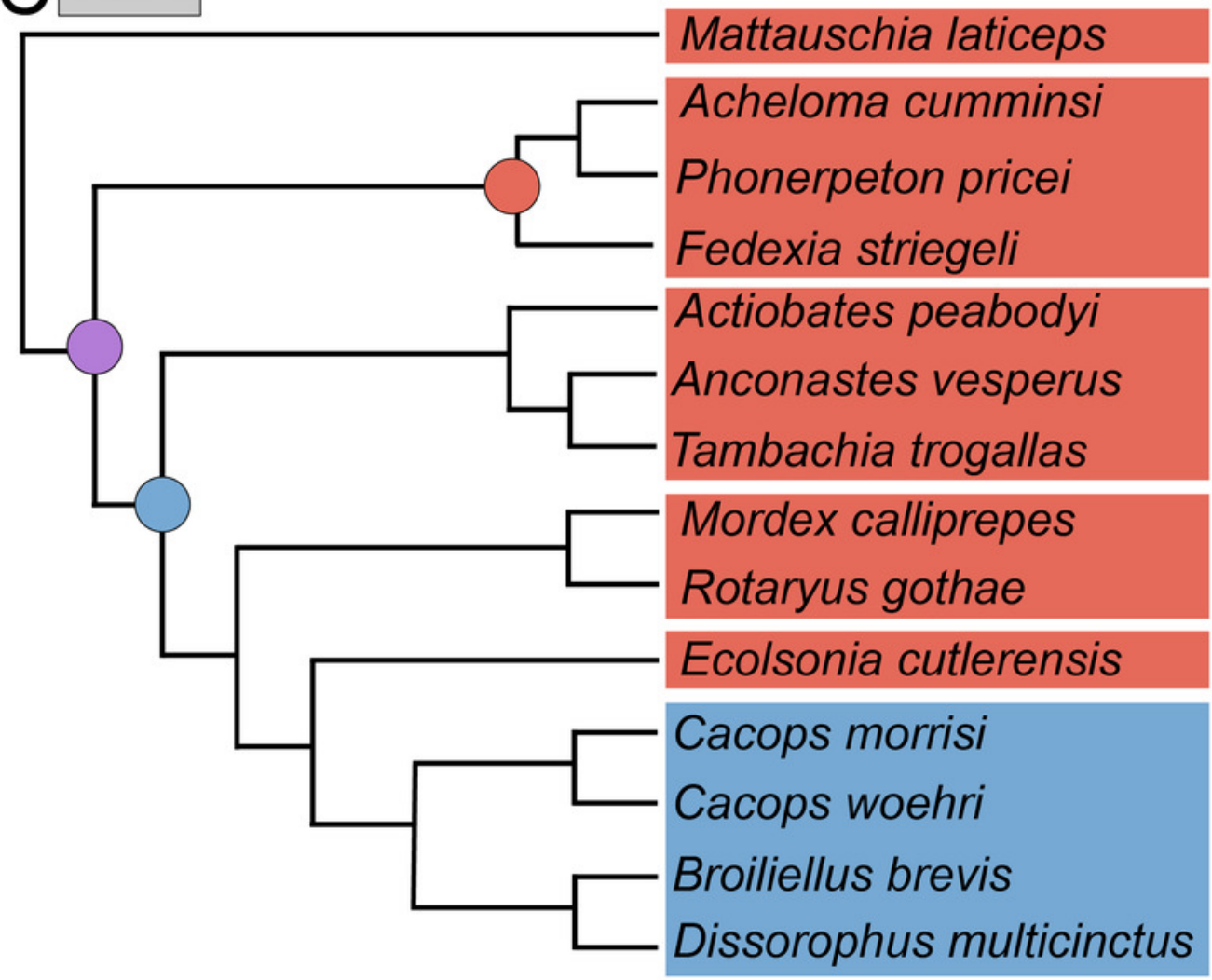




\section{Figure 19}

Comparison of strict consensus topologies for Analysis 9A (comparison of TNT and PAUP* with the original matrix of Dilkes, 2020).

(A) tree resulting from Dilkes' (2020) original analysis in PAUP* with the full taxon sample;

(B) tree resulting from the same matrix analyzed with TNT; (C) tree resulting from Dilkes' original analysis without the four wildcard taxa that he identified (Brevidorsum, Conjunctio, Reiszerpeton, Scapanops); (D) tree resulting from the same matrix analyzed with TNT. Colors and symbols as with Figure 6. 


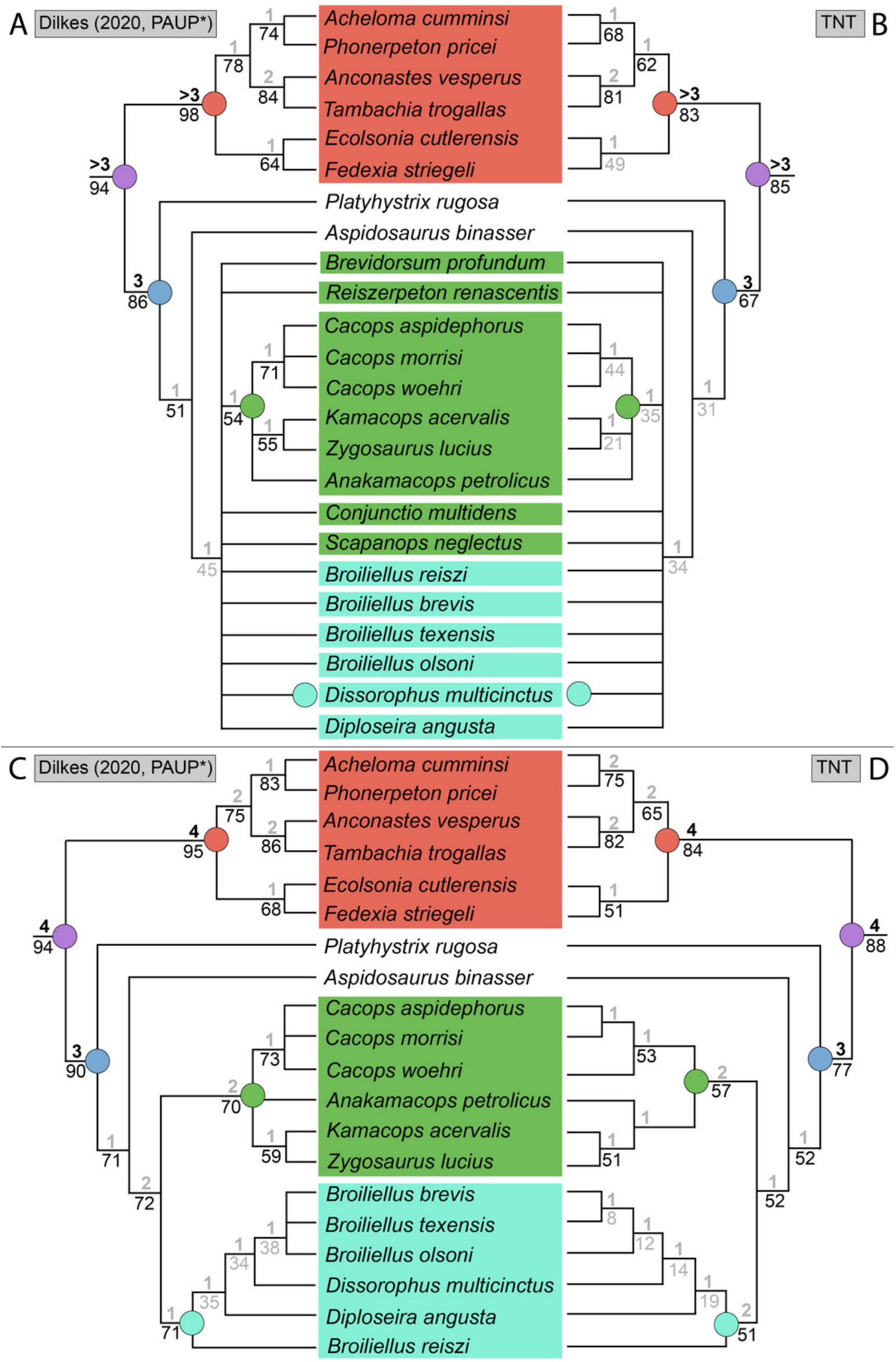




\section{Figure 20}

Comparison of strict consensus topologies for Analysis 9B (comparison of the original and updated versions of the matrix of Dilkes, 2020, using TNT).

(A) tree resulting from the reanalysis of the updated version of Dilkes' (2020) matrix with the full taxon sample; (B) tree resulting from the analysis of the original version of Dilkes' matrix (repeated from Fig. 19B); (C) tree resulting from the reanalysis of the updated version of Dilkes' (2020) matrix without the four wildcard taxa that were identified by Dilkes (Brevidorsum, Conjunctio, Reiszerpeton, Scapanops); (D) tree resulting from the analysis of the original version of Dilkes' matrix (repeated from Fig. 19D). Colors and symbols as with Figure 6. 


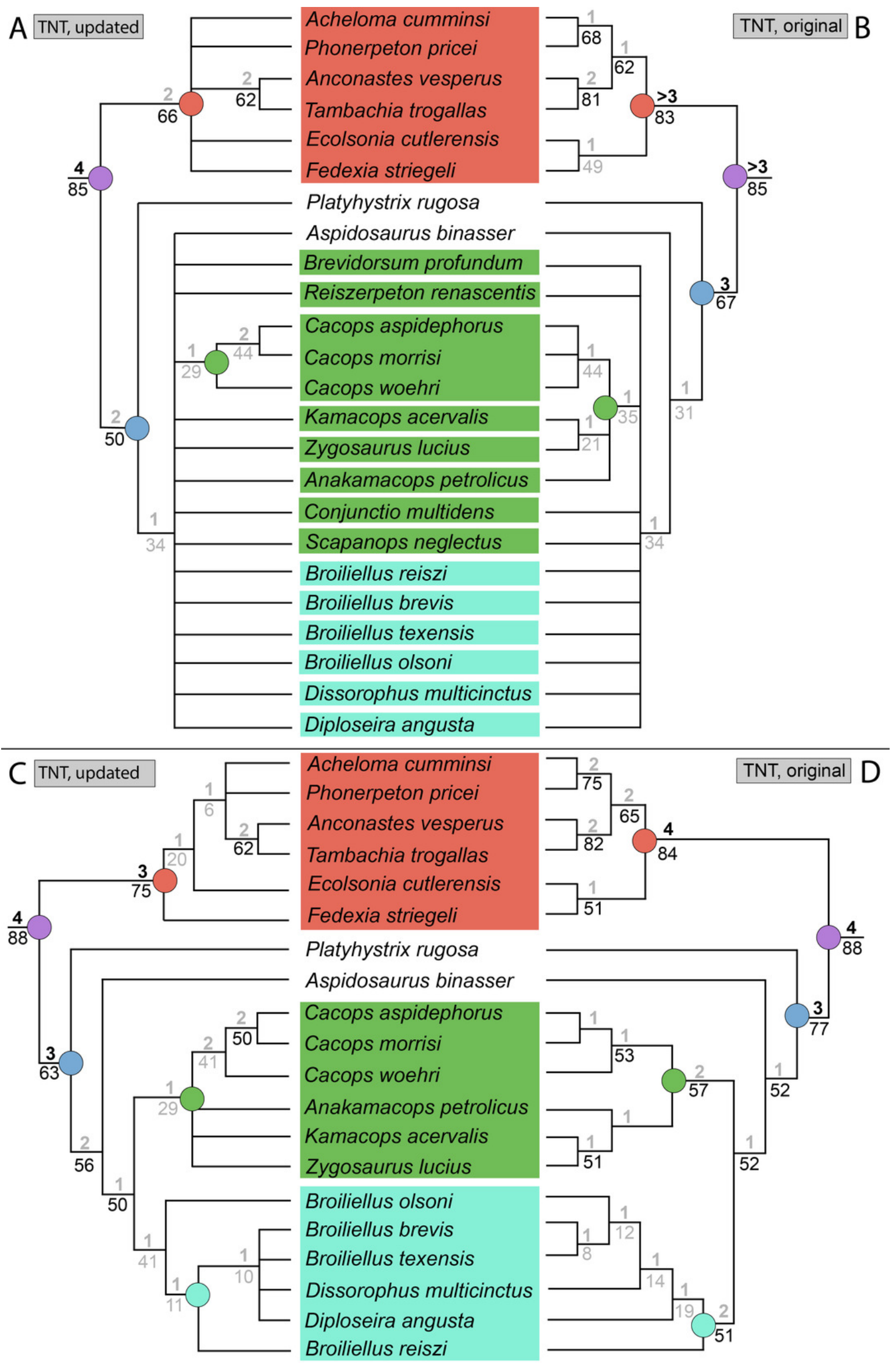




\section{Figure 21}

Morphological and phylogenetic concepts of Cacops.

(A-C) reconstruction of the skulls of the three species of Cacops; (D-K) pruned topologies from previous studies with the most exclusive clade that includes all sampled species of Cacops (shaded in green). (A) Cacops aspidephorus (from Anderson, Scott \& Reisz, 2020); (B) Cacops morrisi (modified from Reisz, Schoch \& Anderson, 2009); (C) Cacops woehri (new); (D) strict consensus of Fröbisch \& Reisz (2012); (E) 50\%-majority-rule consensus of Schoch (2012); (F) strict consensus of Schoch \& Sues (2013); (G) strict consensus (left) and $50 \%$ majority-rule consensus (right) of Maddin et al. (2013); (H) strict consensus (left) and $50 \%$ majority-rule consensus (right) of Holmes, Berman \& Anderson (2013); (I) strict consensus of Liu (2018); (J) strict consensus with wildcard dissorophids included (left) and excluded (right) of Dilkes (2020); (K) strict consensus of Gee et al. (2021). The two identical topologies figured for Holmes, Berman \& Anderson represent their two analyses (with and without scoring changes for the "Rio Arriba Taxon"). The topology of Cacopinae is unchanged in their 50\%-majority rule consensus trees. Cool colors represent skull roof elements; warm colors represent palatal elements. Scale bars equal to $1 \mathrm{~cm}$ for parts $\mathrm{A}-\mathrm{C}$. 

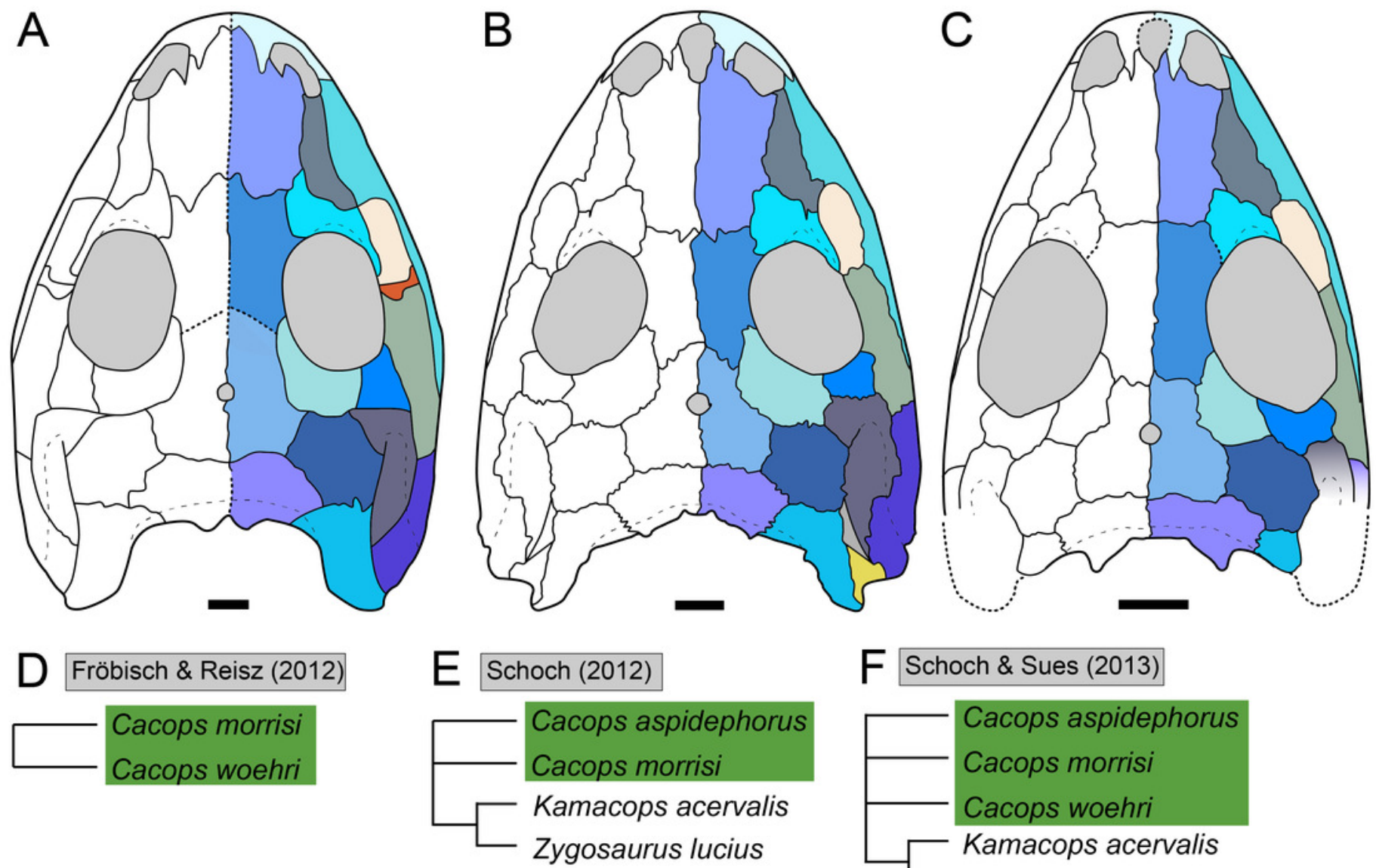

F Schoch \& Sues (2013)

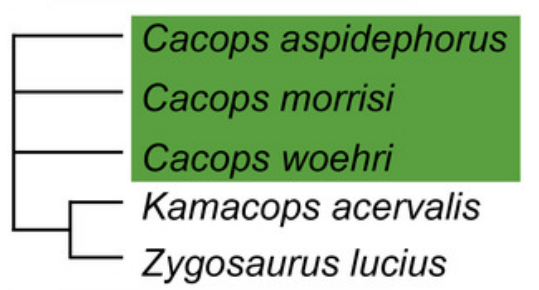

G Maddin et al. (2013)

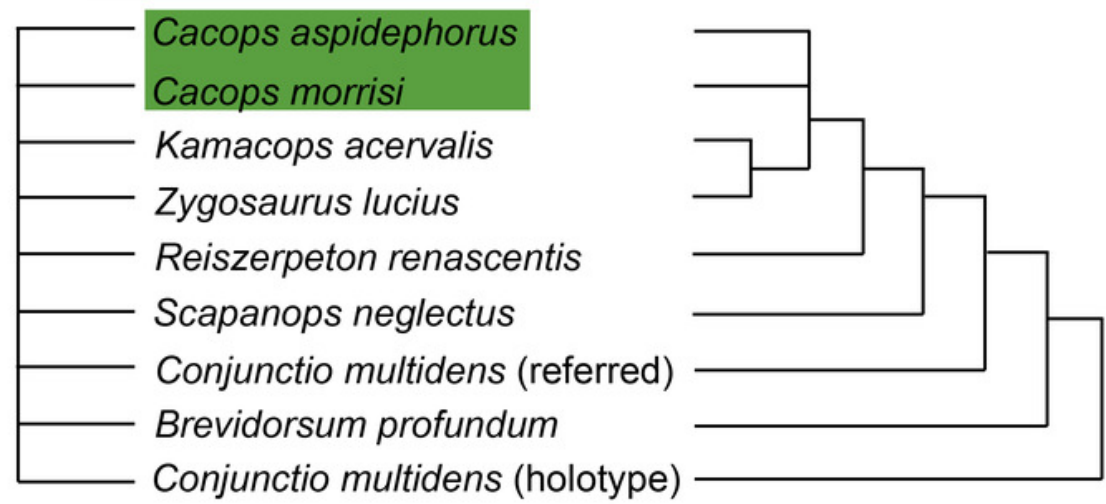

$\mathrm{H}$ Holmes et al. (2013)
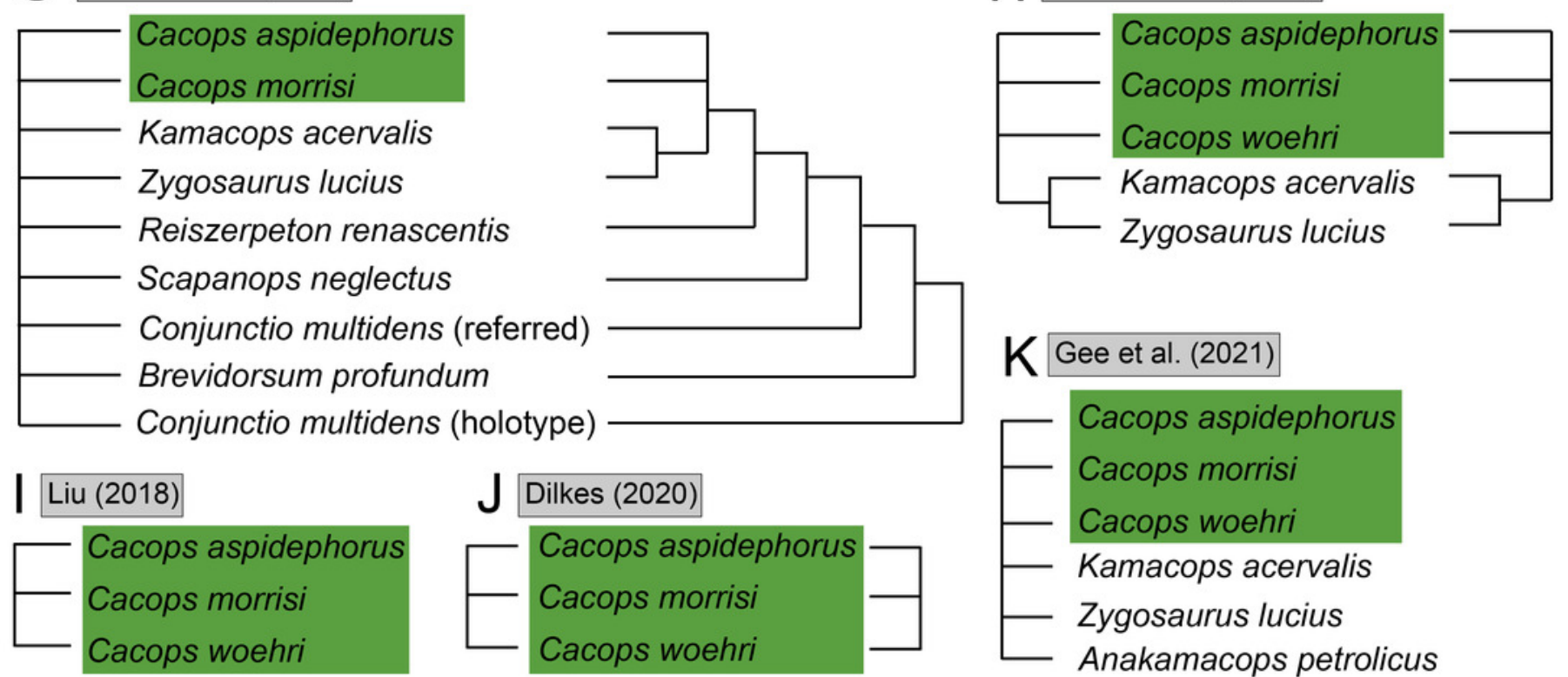

K Gee et al. (2021)

- Cacops aspidephorus

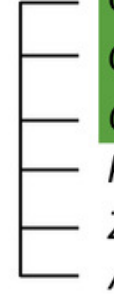

Cacops morrisi

Cacops woehri

Kamacops acervalis

Zygosaurus lucius

Anakamacops petrolicus 


\section{Figure 22}

Morphological and phylogenetic concepts of Broiliellus and Dissorophus.

(A-H) pruned topologies from previous studies with the most exclusive clade that includes all sampled species of Broiliellus and Dissorophus; (I-M) reconstruction of the skulls of Broiliellus and Dissorophus with known sutures. (A) 50\% majority-rule consensus tree of Schoch (2012);

(B) strict consensus tree of Schoch \& Sues (2013); (C) strict consensus (left) and 50\% majority-rule consensus (right) of Maddin et al. (2013); (D) strict consensus (left) and 50\% majority-rule consensus (right) of Holmes, Berman \& Anderson (2013) with modified scorings for the "Rio Arriba Taxon" from Schoch (2012); (E) the same, but without modified scorings; (F) strict consensus of Liu (2018); (G) strict consensus with wildcard dissorophids included (left) and excluded (right) of Dilkes (2020); (H) strict consensus of Gee et al. (2021); (I) Dissorophus multicinctus (from Schoch, 2012); (J) Broiliellus texensis (from Schoch, 2012); (K) B. brevis (from Schoch, 2012); (L) B. olsoni (from Schoch, 2012); (M) B. reiszi (from Holmes, Berman \& Anderson, 2013). Cool colors represent skull roof elements; warm colors represent palatal elements. Scale bars equal to $1 \mathrm{~cm}$ for parts I-M. 
A Schoch (2012)

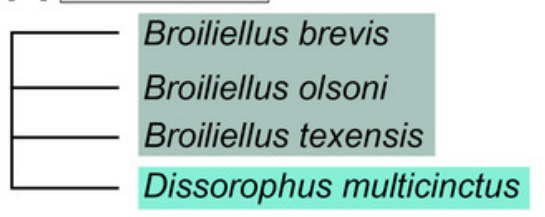

Dolmes et al. (2013)

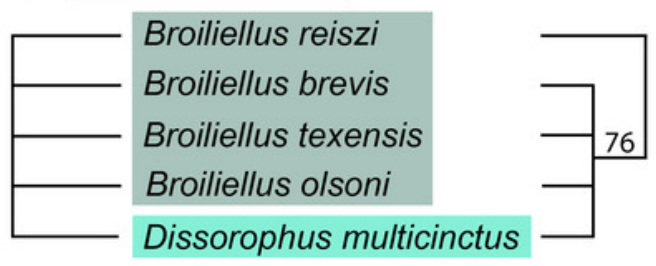

F Liu (2018)

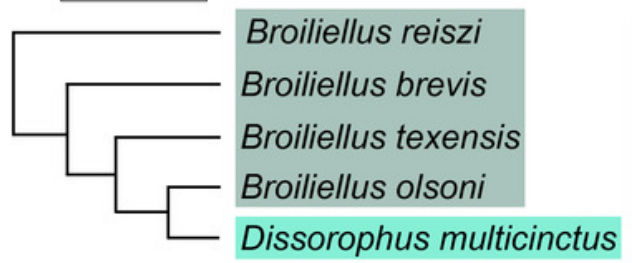

H Gee et al. (2021)

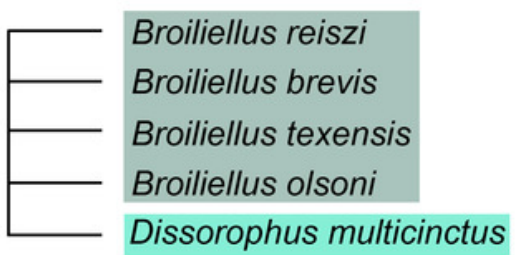

$\mathrm{J}$

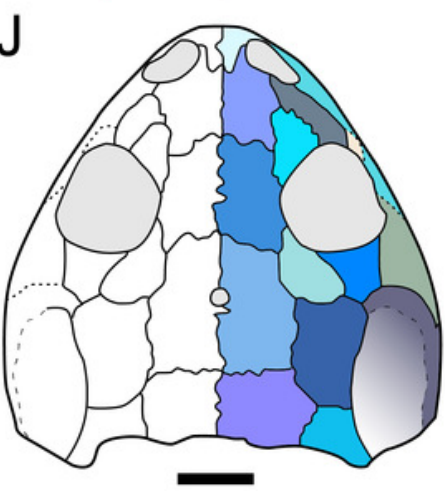

B Schoch \& Sues (2013)

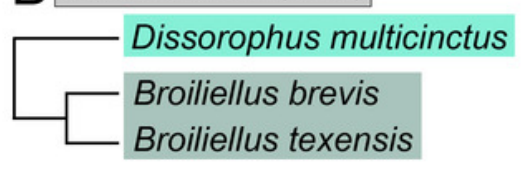

E Holmes et al. (2013)

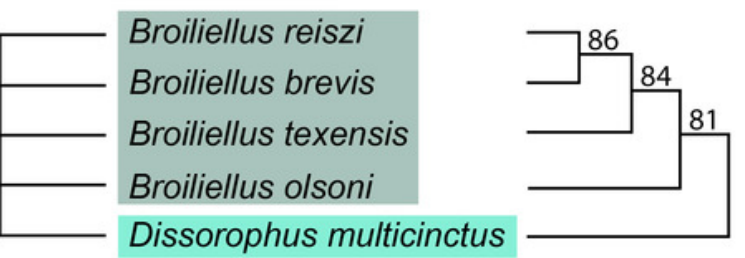

G Dilkes (2020)
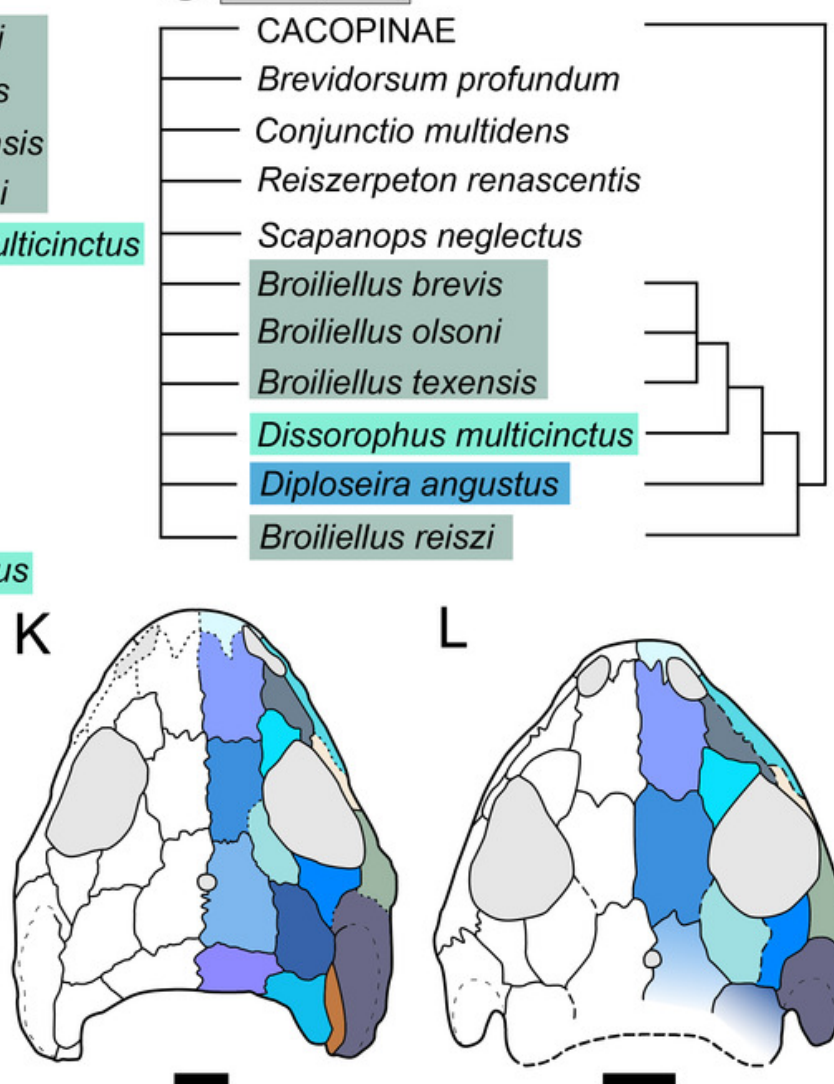

L

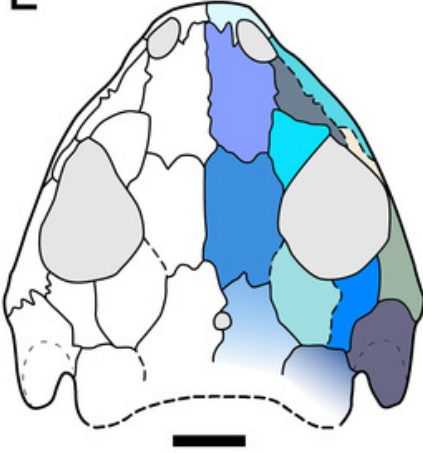

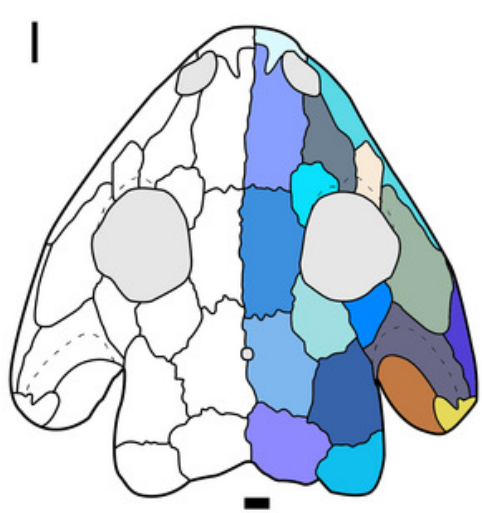

M

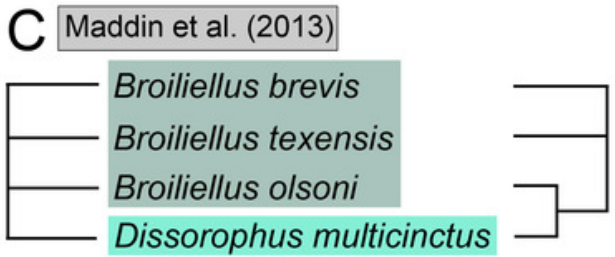




\section{Figure 23}

Photographs of neural spines in the collections of the American Museum of Natural History resembling those attributed to Aspidosaurus binasser.

(A) AMNH FARB 23406 (identified as ?Aspidosaurus, collected from the north fork of the Little Wichita River, TX in 1880); (B) AMNH FARB 23407 (identified as ?Aspidosaurus, collected from unknown locality in the Wichita Basin of TX in 1878); (C) AMNH FARB 23408 in part (identified as Aspidosaurus, collected from unknown locality in the Wichita Basin of TX in 1878; only the piece clearly representing an ornamented spine is shown); (D) AMNH FARB 23409 (identified as Aspidosaurus sp., collected from unknown locality in the Wichita Basin of TX in 1878); (E) AMNH FARB 23410 (identified as Aspidosaurus, collected from Shell Point, Archer Co., TX; Nocona Formation in 1878); (F) AMNH FARB 23411 (not identified, collected from Wichita Co., TX in 1878); (G) AMNH FARB 23412 (identified as Aspidosaurus sp., collected from unknown locality in the Wichita Basin of TX). Identifications are based on associated collections cards; the person(s) who identified them or the date of identification is not indicated for any specimen. Scale bars equal to $1 \mathrm{~cm}$. 

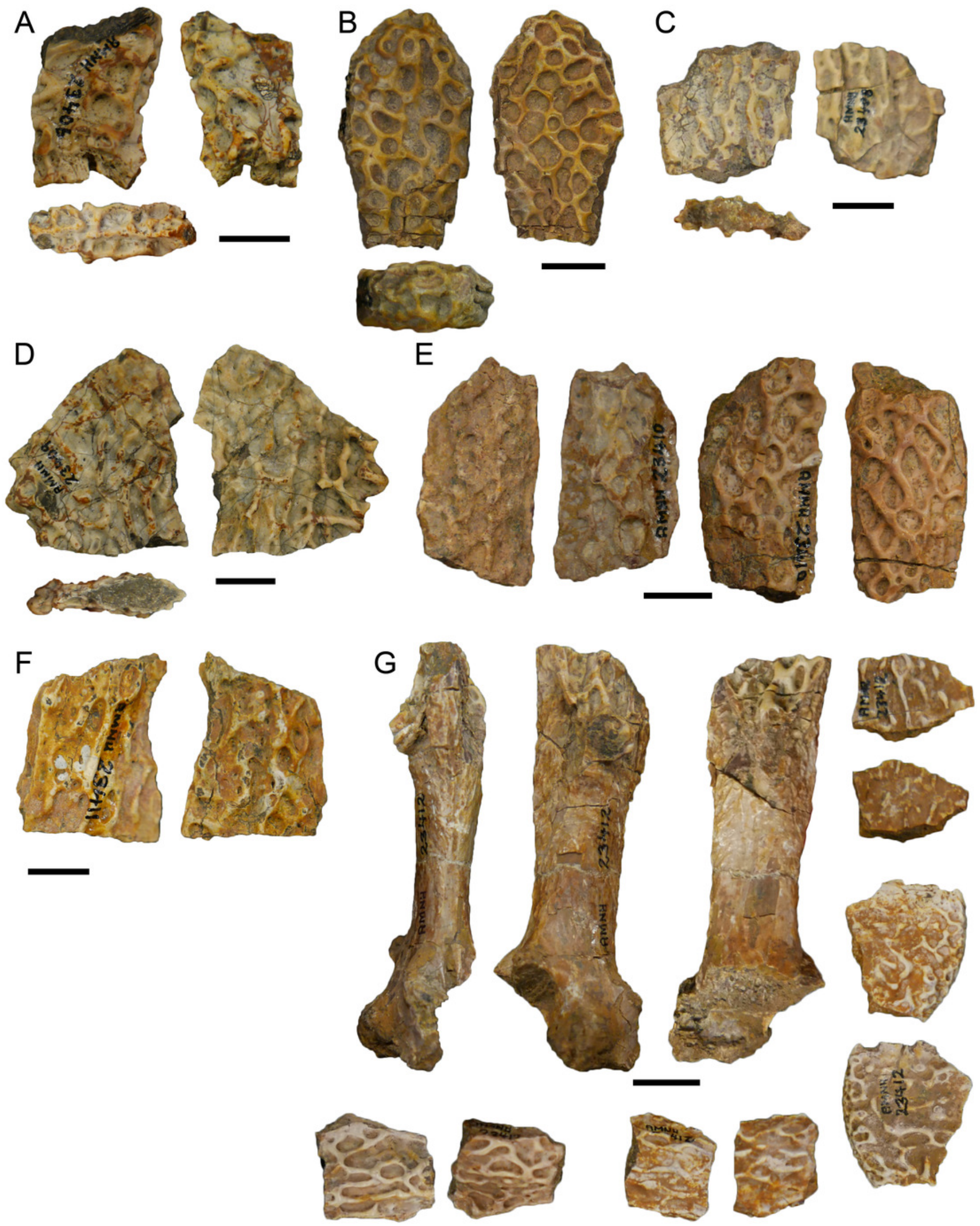


\section{Figure 24}

Photographs of the holotype of "Aspidosaurus apicalis" (AMNH FARB 4785).

(A) presumed osteoderm in dorsal and ventral views; (B) the same in lateral view and in either anterior or posterior view (siding is indeterminate); (C) presumed osteoderm in dorsal and ventral profiles; (D) the same in either anterior or posterior view; (E) osteoderm fused to the tip of the neural spine in anterior and posterior views (siding is indeterminate); (F) the same in dorsal view. Scale bars equal to $1 \mathrm{~cm}$. 

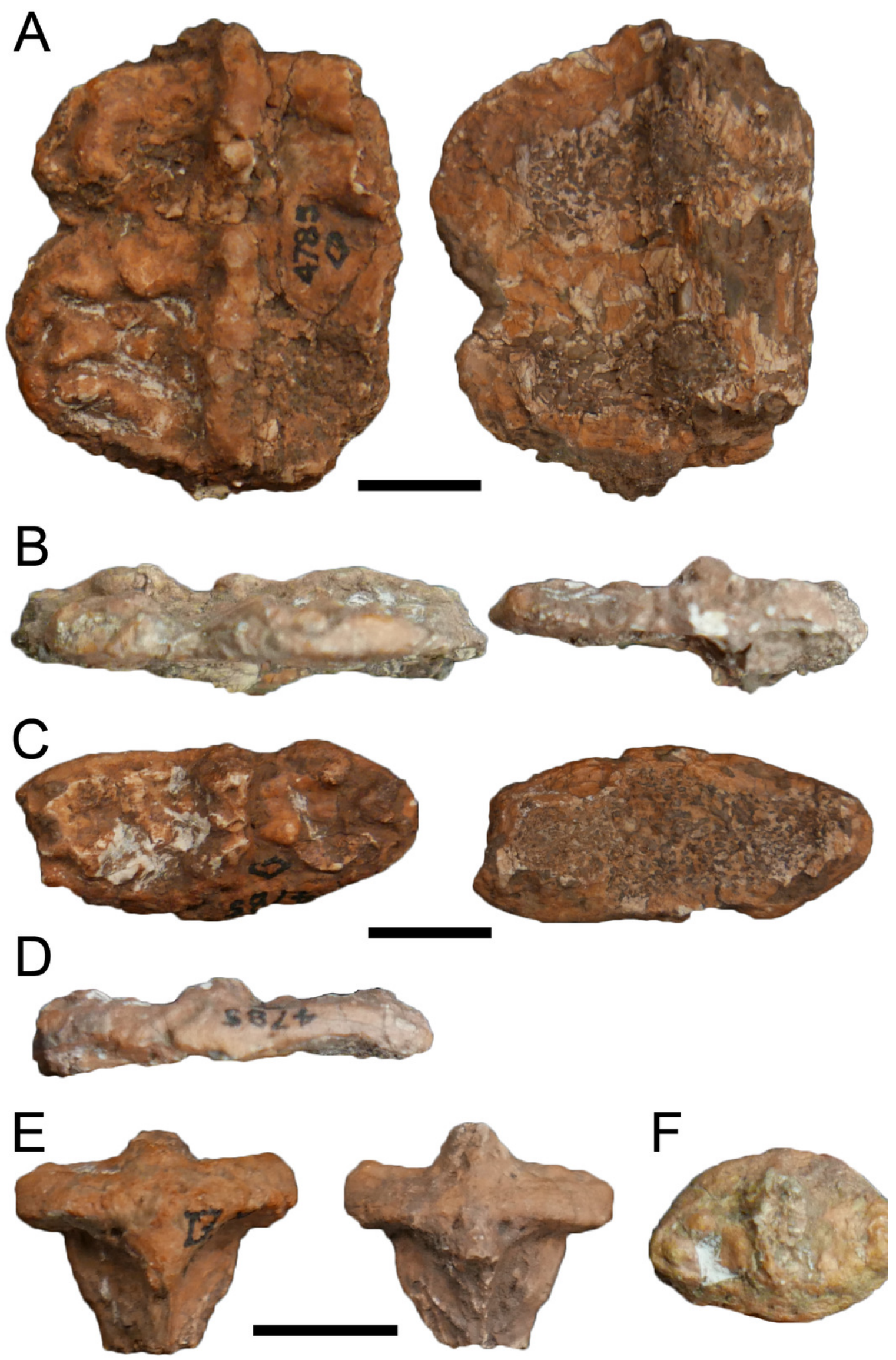


\section{Figure 25}

Photographs of postcranial material of Platyhystrix rugosus (AMNH FARB 11544).

(A) isolated neural spines associated with this individual of $P$. rugosus; (B) neural arches found in association with the other material figured here; $(\mathbf{C})$ sacral ribs associated with this individual (see Berman, Reisz \& Fracasso, 1981); (D) material catalogued under the same number but questionably associated with this taxon; the large fragment on the right may represent a synapsid scapula. Berman, Reisz \& Fracasso (1981) conjectured that these postcrania of $P$. rugosus belonged to the skull that is catalogued as AMNH FARB 11545; the skull was not available at the time of my visit to assess the purported fit between one neural spine and a fragment on AMNH FARB 11545. Scale bars equal to $1 \mathrm{~cm}$. 


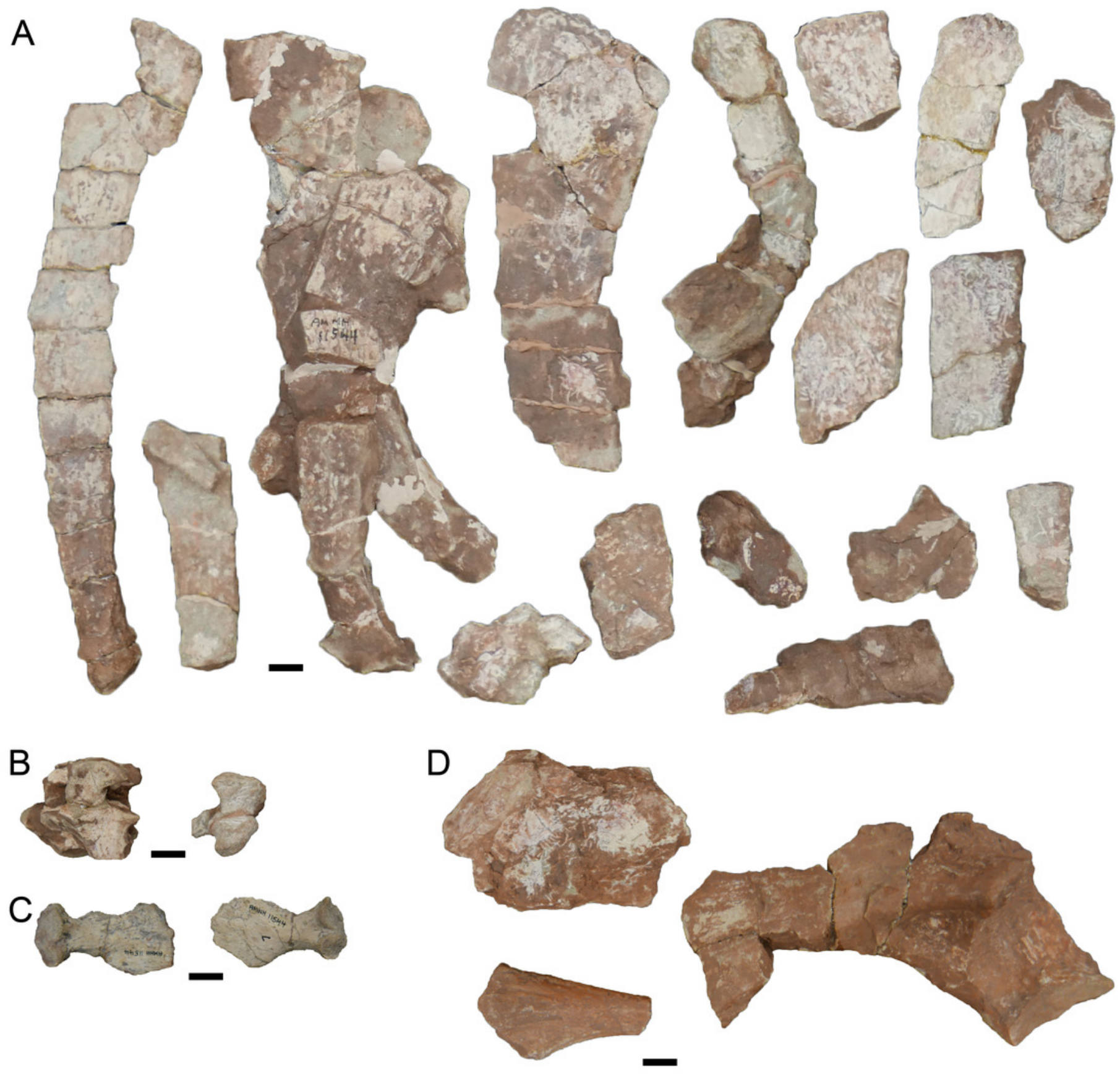


Figure 26

Comparative plot of known skull lengths and size ranges of olsoniforms.

Refer to Appendix 9 and Supplemental Table 3 for dataset and methods used to collect measurement data.

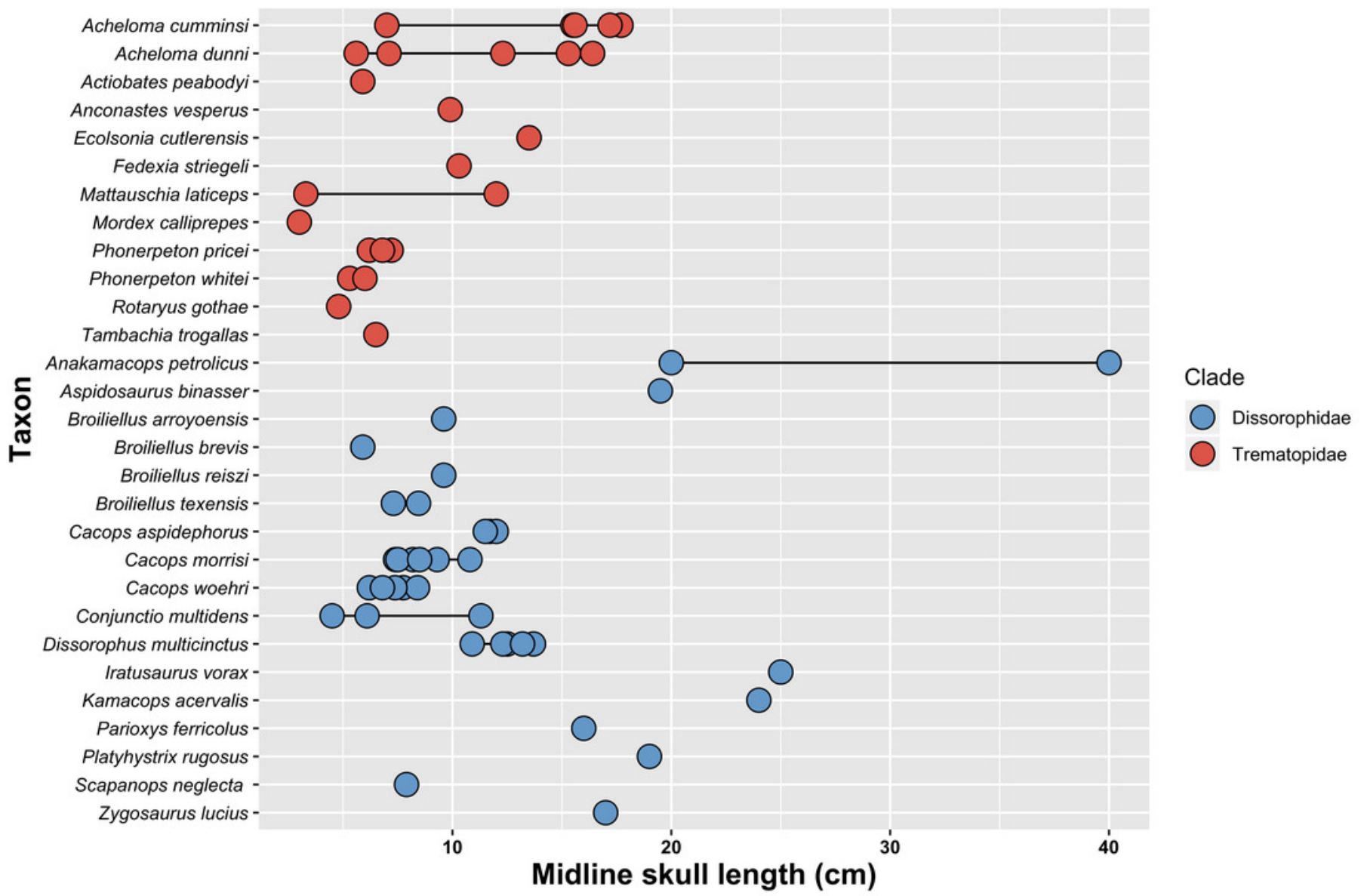




\section{Table $\mathbf{1}$ (on next page)}

Summary of newly added olsoniform taxa.

Completeness refers to percent of characters that could be scored; note that this includes cells scored as inapplicable (-), even though most programs treat these as missing data (?). 
1 Table 1. Summary of newly added olsoniform taxa. Completeness refers to percent of 2 characters that could be scored; note that this includes cells scored as inapplicable (-), even 3 though most programs and algorithms treat these as missing data (?).

4

\begin{tabular}{|c|c|c|c|c|}
\hline Taxon & Time & Location & References & Completeness \\
\hline Anakamacops petrolicus & Middle Permian & China (Gansu) & Li \& Cheng (1999); Liu (2018) & $68(62.3 \%)$ \\
\hline Aspidosaurus binasser & Early Permian & USA (TX) & Berman \& Lucas (2003) & $55(50.4 \%)$ \\
\hline Aspidosaurus chiton & Early Permian & USA (TX) & Broili (1904) & $22(20.1 \%)$ \\
\hline Aspidosaurus novomexicanus & Late Carboniferous & USA (NM) & Williston (1911); Carroll (1964a) & $23(21.1 \%)$ \\
\hline Brevidorsum profundum & Early Permian & USA (TX) & Carroll (1964a) & $30(27.5 \%)$ \\
\hline Broiliellus arroyoensis & Early Permian & USA (TX) & DeMar (1967) & $25(22.9 \%)$ \\
\hline Broiliellus brevis & Early Permian & USA (TX) & Carroll (1964a) & $79(72.4 \%)$ \\
\hline 'Broiliellus' hektotopos & Early Permian & USA $(\mathrm{OH})$ & Berman \& Berman (1975) & $40(36.6 \%)$ \\
\hline Broiliellus olsoni & Early Permian & USA (TX) & DeMar (1967); Bolt (1974b) & $37(33.9 \%)$ \\
\hline Broiliellus reiszi & Early Permian & USA (NM) & Holmes, Berman \& Anderson (2013) & $88(80.7 \%)$ \\
\hline Broiliellus texensis & Early Permian & USA (TX) & DeMar (1966); Bolt (1974b) & $61(55.9 \%)$ \\
\hline Cacops aspidephorus & Early Permian & USA (TX) & $\begin{array}{l}\text { Williston (1910); Anderson (2005); } \\
\text { Dilkes \& Brown (2007); Dilkes } \\
\text { (2009); Anderson, Scott \& Reisz } \\
\text { (2020) }\end{array}$ & $103(94.5 \%)$ \\
\hline Cacops morrisi & Early Permian & USA (OK) & $\begin{array}{l}\text { Reisz, Anderson \& Schoch (2009); } \\
\text { Gee \& Reisz (2018a); Gee, Bevitt \& } \\
\text { Reisz (2019) }\end{array}$ & $98(89.9 \%)$ \\
\hline Cacops woehri & Early Permian & USA (OK) & $\begin{array}{l}\text { Fröbisch \& Reisz (2012); Fröbisch, } \\
\text { Brar \& Reisz (2015); ; Gee, Bevitt \& } \\
\text { Reisz (2019) }\end{array}$ & $72(66.0 \%)$ \\
\hline Conjunctio multidens & Early Permian & $\begin{array}{l}\text { USA (CO, } \\
\mathrm{NM})\end{array}$ & $\begin{array}{l}\text { Case \& Williston (1913); Carroll } \\
\text { (1964a); Schoch \& Sues (2013); Gee } \\
\text { et al. (2021) }\end{array}$ & $59(54.1 \%)$ \\
\hline Diploseira angusta & Early Permian & USA (TX) & Dilkes $(2020)$ & $50(45.8 \%)$ \\
\hline Dissorophus multicinctus & Early Permian & USA (TX) & $\begin{array}{l}\text { DeMar (1968); Milner (2003); Dilkes } \\
\text { (2020) }\end{array}$ & $101(92.6 \%)$ \\
\hline Iratusaurus vorax & Middle Permian & $\begin{array}{l}\text { Russia } \\
\text { (Bashkortostan) }\end{array}$ & Gubin $(1980)$ & $12(11.0 \%)$ \\
\hline Kamacops acervalis & Middle Permian & $\begin{array}{l}\text { Russia (Perm } \\
\text { Krai) }\end{array}$ & Gubin (1980); Schoch (1999) & $\begin{array}{l}31(28.4 \%) \\
51(46.7 \%)\end{array}$ \\
\hline Nooxobeia gracilis & Middle Permian & $\mathrm{USA}(\mathrm{OK})$ & Gee, Scott \& Reisz (2018) & $19(17.4 \%)$ \\
\hline Palodromeus bairdi & Late Carboniferous & USA $(\mathrm{OH})$ & Schoch, Henrici \& Hook (2020) & $70(62.5 \%)$ \\
\hline Parioxys bolli & Early Permian & USA (TX) & Carroll (1964b) & $11(10.0 \%)$ \\
\hline Platyhystrix rugosa & Early Permian & $\begin{array}{l}\text { USA }(\mathrm{CO}, \\
\mathrm{NM})\end{array}$ & Berman, Reisz \& Fracasso (1981) & $67(61.4 \%)$ \\
\hline Reiszerpton renascentis & Early Permian & USA (TX) & Maddin et al. (2013) & $56(51.3 \%)$ \\
\hline Scapanops neglectus & Early Permian & USA (TX) & $\begin{array}{l}\text { Carroll (1964a); Schoch \& Sues } \\
\text { (2013) }\end{array}$ & $57(52.2 \%)$ \\
\hline Zygosaurus lucius & Early Permian & $\begin{array}{l}\text { Russia } \\
\text { (Bashkortostan) }\end{array}$ & Eichwald (1848); Efremov (1937) & $19(17.4 \%)$ \\
\hline
\end{tabular}




\section{Table 2 (on next page)}

Summary of the permutations performed in this study, indicating software, search type, and general characterization of the analysis with respect to taxon and character sampling.

Note that the heuristic search in TNT is termed 'traditional search,' and the branch-andbound search is termed 'implicit enumeration.' 
1 Table 2. Summary of the analyses performed in this study, indicating software, search type, 2 and general characterization of the analysis with respect to taxon and character sampling. 3 Note that the heuristic search in TNT is termed 'traditional search,' and the branch-and-bound 4 search is termed 'implicit enumeration.'

5

\begin{tabular}{|c|c|c|c|c|}
\hline Analysis & Software & Search & Taxon sample & Character matrix \\
\hline $1 \mathrm{~A}$ & TNT & Heuristic & This study & This study \\
\hline $1 \mathrm{~B}$ & TNT & Heuristic & This study & This study \\
\hline 2 & TNT & Heuristic & This study & This study \\
\hline 3 & TNT & Heuristic & This study & This study \\
\hline 4 & TNT & Heuristic & This study & This study \\
\hline 5 & PAUP* & Both & Dilkes (2020) & This study \\
\hline 6 & TNT & $\begin{array}{l}\text { Branch-and- } \\
\text { bound }\end{array}$ & Gee $(2020 b)$ & This study \\
\hline 7 & PAUP* & $\begin{array}{l}\text { Branch-and- } \\
\text { bound }\end{array}$ & Dilkes (2020) & Dilkes (2020), with scoring changes \\
\hline 8 & PAUP* & $\begin{array}{l}\text { Branch-and- } \\
\text { bound }\end{array}$ & Gee (2020b) & This study \\
\hline $9 \mathrm{~A}$ & TNT & $\begin{array}{l}\text { Branch-and- } \\
\text { bound }\end{array}$ & Dilkes (2020) & Dilkes (2020), original scores \\
\hline $9 B$ & TNT & $\begin{array}{l}\text { Branch-and- } \\
\text { bound }\end{array}$ & Dilkes (2020) & Dilkes (2020), with scoring changes \\
\hline
\end{tabular}

6 


\section{Table 3 (on next page)}

Comparison of reported support metrics for focal nodes from dissorophid-focused analyses.

All nodes are from strict consensus trees except for Schoch (2012). Abbreviations refer to publications: S12, Schoch (2012); MFEM13, Maddin et al. (2013); L18, Liu (2018); D20, Dilkes (2020). 'A' and 'W' refer to the taxon samples employed by Dilkes: all taxa (A) and without wildcards (W). The same sublettering is used for this study (Analysis 7). An en-dash indicates that a node was not recovered, and 'NR' means that the value was not reported. Because the composition of Cacopinae and Dissorophinae sometimes includes certain wildcard taxa (e.g., Conjunctio multidens) or do not include longstanding nominal members, these nodes are restricted in this specific comparison to the same stable constituent taxa in this table. Cacopinae is comprised of Cacops + Anakamacops + Kamacops + Zygosaurus; and Dissorophinae is comprised of Broiliellus + Diploseira + Dissorophus. Bremer decay indices are listed before the forward slash, and bootstrap values are listed before the forward slash. 
1 Table 3. Comparison of reported support metrics for focal nodes from dissorophid-focused 2 analyses.

3 All nodes are from strict consensus trees except for Schoch (2012). Abbreviations refer to 4 publications: S12, Schoch (2012); MFEM13, Maddin et al. (2013); L18, Liu (2018); D20, Dilkes 5 (2020). 'A' and 'W' refer to the taxon samples employed by Dilkes: all taxa (A) and without 6 wildcards (W). The same sublettering is used for this study (Analysis 7). An en-dash indicates 7 that a node was not recovered, and 'NR' means that the value was not reported. Because the 8 composition of Cacopinae and Dissorophinae sometimes includes certain wildcard taxa (e.g.,

9 Conjunctio multidens) or do not include longstanding nominal members, these nodes are

10 restricted in this specific comparison to the same stable constituent taxa in this table. Cacopinae

11 is comprised of Cacops + Anakamacops + Kamacops + Zygosaurus; and Dissorophinae is

12 comprised of Broiliellus + Diploseira + Dissorophus. Bremer decay indices are listed before the

13 forward slash, and bootstrap values are listed before the forward slash.

\begin{tabular}{lccccccc}
\hline Clade & S12 & MFEM13 & L18 & D20 (A) & this study (A) & D20 (W) & this study (W) \\
\hline Olsoniformes & $3 / 100$ & $\mathrm{NR} / 91$ & $\mathrm{NR}$ & $>3 / 90$ & $>3 / 75$ & $4 / 94$ & $4 / 77$ \\
Trematopidae & $2 / 77$ & $\mathrm{NR} / 84$ & $\mathrm{NR}$ & $>3 / 98$ & $2 / 61$ & $4 / 95$ & $3 / 63$ \\
Dissorophidae & $3 / 93$ & $\mathrm{NR} / 82$ & $3 / \mathrm{NR}$ & $3 / 86$ & $2 / 53$ & $3 / 90$ & $3 / 58$ \\
Cacopinae & $3 / 98$ & - & $3 / \mathrm{NR}$ & $1 / 54$ & - & $2 / 70$ & $1 / 39$ \\
Cacops & - & - & $1 / \mathrm{NR}$ & $1 / 71$ & $1 / 41$ & $1 / 73$ & $2 / 46$ \\
Dissorophinae & $1 / 76$ & $\mathrm{NR} / 72$ & $3 / \mathrm{NR}$ & - & - & $1 / 71$ & $1 / 50$ \\
Post-Platyhystrix & $1 / 60$ & $\mathrm{NR} / 69$ & $1 / \mathrm{NR}$ & $1 / 51$ & $1 / 32$ & $1 / 71$ & $2 / 53$ \\
Post-Aspidosaurus & $1 /<50$ & $\mathrm{NR}$ & - & $1 / 45$ & - & $2 / 72$ & $1 / 52$ \\
\hline
\end{tabular}




\section{Table 4 (on next page)}

Comparison of reported support metrics for focal nodes from trematopid-focused analyses.

All nodes are from strict consensus trees. Abbreviations refer to publications: B10, Berman et al. (2010); B11, Berman et al. (2011); PR11, Polley \& Reisz (2011); G20, Gee (2020b). Nodal support of Gee (2020b) refers to the analysis of that study that sampled all twelve trematopids at the species-level (figure 6 therein). This study's nodal support is derived from Analyses 6 and 8 (Figs. 14B, 17). An en-dash indicates that a node was not recovered, and 'NR' means that the value was not reported. Note that Trematopidae in Analyses 6 and 8 of this study only includes Acheloma cumminsi (the specifier for the clade) and Phonerpeton pricei. Bremer decay indices are listed before the forward slash, and bootstrap values are listed before the forward slash. 
1 Table 4. Comparison of reported support metrics for focal nodes from trematopid-focused 2 analyses.

3 All nodes are from strict consensus trees. Abbreviations refer to publications: B10, Berman et al. 4 (2010); B11, Berman et al. (2011); PR11, Polley \& Reisz (2011); G20, Gee (2020b). Nodal 5 support of Gee (2020b) refers to the analysis of that study that sampled all twelve trematopids at 6 the species-level (figure 6 therein). This study's nodal support is derived from Analyses 6 and 8

7 (Figs. 14B, 17). An en-dash indicates that a node was not recovered, and 'NR' means that the 8 value was not reported. Note that Trematopidae in Analyses 6 and 8 of this study only includes 9 Acheloma cumminsi (the specifier for the clade) and Phonerpeton pricei. Bremer decay indices

10 are listed before the forward slash, and bootstrap values are listed before the forward slash.

\begin{tabular}{lcccccc}
\hline Clade & \multirow{2}{*}{ B10 } & B11 & PR11 & G20 & $\begin{array}{c}\text { this study } \\
\text { (TNT) }\end{array}$ & $\begin{array}{c}\text { this study } \\
\text { (PAUP*) }\end{array}$ \\
\hline Olsoniformes & $2 / \mathrm{NR}$ & $2 / \mathrm{NR}$ & $2 / 66$ & $\mathrm{NR} / 55$ & $3 / 32$ & $3 / 58$ \\
Dissorophidae & $2 / \mathrm{NR}$ & $1 / \mathrm{NR}$ & $\mathrm{NR}$ & $\mathrm{NR} / 97$ & $>5 / 81$ & $>5 / 93$ \\
Trematopidae & $3 / \mathrm{NR}$ & $5 / \mathrm{NR}$ & $5 / 82$ & $\mathrm{NR}$ & $3 / 57$ & $3 / 78$ \\
Acheloma + Phonerpeton & $4 / \mathrm{NR}$ & $7 / \mathrm{NR}$ & - & $\mathrm{NR} / 92$ & $3 / 57$ & $3 / 78$ \\
Anconastes + Tambachia & $1 / \mathrm{NR}$ & $1 / \mathrm{NR}$ & $6 / 77$ & - & $1 / 21$ & $1 / 42$ \\
Ecolsonia as trematopid? & $\mathrm{No}$ & $\mathrm{No}$ & $\mathrm{Yes}$ & $\mathrm{Yes}$ & $\mathrm{No}$ & No \\
\hline
\end{tabular}

11 


\section{Table 5 (on next page)}

Comparison of absolute and GC frequencies for nodes recovered in Analysis 9A (taxon sample without wildcards; Fig. 19D). 
1 Table 5. Comparison of absolute and GC frequencies for nodes recovered in Analysis 9A (taxon 2 sample without wildcards; Fig. 19D).

\begin{tabular}{lccc}
\hline Node & Absolute & GC & Change \\
\hline Olsoniformes & 88 & 87 & $-1 \%$ \\
Trematopidae & 84 & 84 & - \\
Acheloma + Phonerpeton & 75 & 71 & $-4 \%$ \\
Anconastes + Tambachia & 82 & 81 & $-1 \%$ \\
Acheloma + Phonerpeton + & 62 & 60 & $-2 \%$ \\
Anconastes + Tambachia & 51 & 48 & $-3 \%$ \\
Ecolsonia + Fedexia & 77 & 77 & - \\
Dissorophidae & 52 & 51 & $-1 \%$ \\
Post-Platyhystrix dissorophids & 52 & 51 & $-1 \%$ \\
Post-Aspidosaurus dissorophids & 57 & 54 & $-3 \%$ \\
Cacopinae & 53 & 53 & - \\
Cacops & 51 & 47 & $-4 \%$ \\
Dissorophinae & & & \\
\hline
\end{tabular}

3 